\title{
The role of platelet phospholipids in prothrombin and factor $X$ activation
}

Citation for published version (APA):

van Rijn, J. L. M. L. (1984). The role of platelet phospholipids in prothrombin and factor $X$ activation.

[Doctoral Thesis, Maastricht University]. Rijksuniversiteit Limburg. https://doi.org/10.26481/dis.19840913jr

Document status and date:

Published: 01/01/1984

DOI:

10.26481/dis.19840913jr

Document Version:

Publisher's PDF, also known as Version of record

\section{Please check the document version of this publication:}

- A submitted manuscript is the version of the article upon submission and before peer-review. There can be important differences between the submitted version and the official published version of record.

People interested in the research are advised to contact the author for the final version of the publication, or visit the DOI to the publisher's website.

- The final author version and the galley proof are versions of the publication after peer review.

- The final published version features the final layout of the paper including the volume, issue and page numbers.

Link to publication

\footnotetext{
General rights rights.

- You may freely distribute the URL identifying the publication in the public portal. please follow below link for the End User Agreement:

www.umlib.nl/taverne-license

Take down policy

If you believe that this document breaches copyright please contact us at:

repository@maastrichtuniversity.nl

providing details and we will investigate your claim.
}

Copyright and moral rights for the publications made accessible in the public portal are retained by the authors and/or other copyright owners and it is a condition of accessing publications that users recognise and abide by the legal requirements associated with these

- Users may download and print one copy of any publication from the public portal for the purpose of private study or research.

- You may not further distribute the material or use it for any profit-making activity or commercial gain

If the publication is distributed under the terms of Article $25 \mathrm{fa}$ of the Dutch Copyright Act, indicated by the "Taverne" license above, 
THE ROLE OF PLATELET PHOSPHOLIPIDS IN PROTHROMBIN AND FACTOR X ACTIVATION

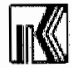

krips repro meppel 


\title{
THE ROLE OF PLATELET PHOSPHOLIPIDS IN PROTHROMBIN AND FACTOR X ACTIVATION
}

\author{
PROEFSCHRIFT \\ ter verkrijging van de graad van \\ Doctor in de Geneeskunde aan de \\ Rijksuniversiteit Limburg te Mastricht, \\ op gezag van de Rector Magnificus \\ Prof. Dr. H. C. Hemker, \\ volgens het besluit van het College van Dekanen \\ in het openbaar te verdedigen \\ in de Aula van de Universiteit \\ op donderdag 13 september 1984 \\ des namiddags te 16.00 uur
}

door

Johannes Leonardus Maria Laurentius van Rijn geboren te Haarlem 
Promotor Prof.Dr. R.F.A. Zual

Copromotor Dr. J. Rosing

Referenten Prof.Dr. H. Chap

Prof.Dr. J.J. SIXma

Prof.Dr. F. ten Hoor

Dit onderzok werd ultgevoerd op de afdellng Blachemie van de Rijksundversiteit Limburg in samenwerkfig met: Jan Rosing Gerbrand van Dieljen, Rob Zwaal, Coen Hemker, Edouard Bevers, Paul Comfurlusi en José Govers-Rlemslag. De flmanciële gteun werd verleend door de stichting voor Medlsch Wetenschappe11jk Onderzoek (FUNGO-ZWO).

Het proefschrift werd getypt door Marlet Molenaar. 
Aan mifin ouders

Voor Eveline en Calijn 


THE EXPOSURE OF PHOSPHATIDYLSERINE AT THE OUTER SURFACE OF PLATELETS.

based on:

Bevers, E.M., Comfurlus, P., van Rija, J.L.M.L.,

Hemker, H.C., and Zwaal, R.F.A. (1982)

Eur.J.B1ochem. 122, 429-436.

THE ROLE OF ACTIVATED HUMAN PLATELETS IN PROTHROMBIN AND FACTOR X ACTIVATION.

based on:

Hemker, H.C., van Rijn, J.L.M.L., Rosing, J., van

Diefjen, G., Bevers, E.M., and Zwaal, R.F.A. (1983)

Blood Cel1s 9, 303-317.

van Rifn, J.L.M.L., Rosing, J., van Dleljen, G., Bevers, E.M., Zwal, R.F.A., and Hemker, H.C. (1983) Arzne1m.-Forsch./Drug Res. 33, $1365-1369$.

Rosing, J., van Rfjn, J.L.M.L., Bevers, E.M., van Dieljen, G., Confurtus, P., and Zwaal, R.F.A. Submitted for publication. IN FACTOR X ACTIVATION INDUCED BY IONOPHORE A23187. based on:

van R1jn, J.L.M.L., Rosing, J., and van DLel Jen, G. (1983) Eur. I. Blochem. 133, 1-10. 
ASSEMBLY OF THE TNTRINSIC PACTOR X ACTIVATING COMPLEX; IMTERACTIONS BETHEEN FACTOR IXa, FACTOR VIIIa, AND PHOSPHOLIPID.

baged on:

van Dleljen, G., van Rijn, J.L.M.L., Govers-Rienslag, J.W.P., Hemker, H.C., and Rosing, J.

subnitted for publication.

Chapter WI

KINETIC STUDIES OF PROTHROMBTN ACTIVATION; THE EFFECT OF FACTOR Va AND PHOSPHOLIPIDS ON THE FORMATION OF THE ENZME-SUBSTRATE COMPLEX.

based on:

van $\mathbb{R} 1 j n$, J.L.M.L., Govers-Riemslag, J.W.P., Zwaal, R.F.A., and Rosing, J.

Blochemistry, in press.

van Rijn, J.L.M.L., Zwaal, R.F.A., Hemker, H.C.,

Rosing, J.

Haemostas1s, accepted for publication.

Chapter VII Conclustons and summary

Conclusles en samenvatting 


\section{ABBREVTATIONS}

DEAE

EDTA

Hepes

Me. $2^{\mathrm{Si}}$

PA

$\mathrm{PC}$

PG

PS

phospholipase $\mathrm{A}_{2}$ $\mathrm{p}-\mathrm{NPGB}$

$\mathrm{QAE}$

RVV-X

$\mathrm{SP}$

STI

$\mathrm{S} 2238$

$\$ 2337$

Tr1s die thy lam 1 noethy 1

ethylenediamine tetraacetic mcid

4-(2-hydroxyethyl)-1-piperazineethanesulfonic acid

dimethylsulfoxide

1, 2-dioleoy1-sn-g1ycero-3-phos phate

1, 2-dioleoyl-sn-glycero-3-phos phocholine

1,2-dioleoy1-sn-glycero-3-phos phoglycerol

1, 2-dioleoy1-sn-glycero-3-phos phoserine

phosphatide 2-acylhydrolase

p-nitrophenyl-p'-guanidinobenzoate hydrochloride

quaternary aminoethyl.

purifled factor $X$ activator from Russell's viper venom sul phopropyl

soybean trypisin inhibitor

H. D . pheny 1 al any $1-L-p 1$ pecolyl-L-arglnine-p-nitroanildde hydrachloride

N-benzoy1-L-isoleucy 1-L-glutamy 1-(p1per 1dy 1$)-g 1$ ycy $1-L-$ arginy 1-p-nitroanilide hydrochloride tris (hydroxymethyl)-aminomethane 

INTRODUCTION

Blood platelets from mamalian specles are biconvex disks with a diameter of 2-3 $\mu$ m and are formed in the bone marrow by fragmentation of megakaryocytes. The platelet count in peripheral blood is about $250,000 / \mu 1$ and the life-span of human platelets is usually 7-10 days. Blood platelets participate in a number of physlological processes. In vitro and in vivo studies have demonstrated that platelets play an important role in a variety of events such as hemostasis, thrombosis, atherosclerosis, inflamation, phagocytosis, wound healing and transplant rejection.

Platelets are involved in the process of hemostasis which is lnitiated by vascular injury. When, as a result of vascular damage, the collagen in the subendothelial layer of the vessel wall is exposed to the blood, platelets instantaneously adhere to the exposed collagen flbres ( $f i g .1$ ). The adhering platelets become activated to produce and release components which stimulate the aggregation of platelets from the blood stream with the adhered ones, thereby building up a fragile platelet plug (primary hemostatic plug). This platelet mass is consolidated by strands of fibrin, the ultimate product of the reactions of the coagulation cascade. In the end the flbrocellular mass, in which also other blood cells are trapped, retracts into the wound. As Indicated in figure 1 , platelets are not only involved in the formation of a primary hemostatic plug, but are also able to promote the activation of several clotting factors. Clotting factor activation is inltiated by varcular damage and leads to the formation of thrombin that catalyses fibrin formation and activates platelets. Activated platelets form a procoagulant surface, at which clotting factor activation is facilitated.

Platelet functions in primary hemostatic plug formation. Apart from adheston to the subendothelium of the vessel wall, all platelet functions required to form a primary plug are performed only after excessive changes in platelet shape and ultrastructure. The morphology of platelets, as viewed through the electron microscope, has advanced the understanding of their function in hemostasis (1). Being a fragment of the megakaryocyte"s cytoplasm, the platelet has no nucleus. Endoplasmic reticulum and Golgl apparatus are seen only occasionally. The platelet membrane is rich in glycoproteins, which become 


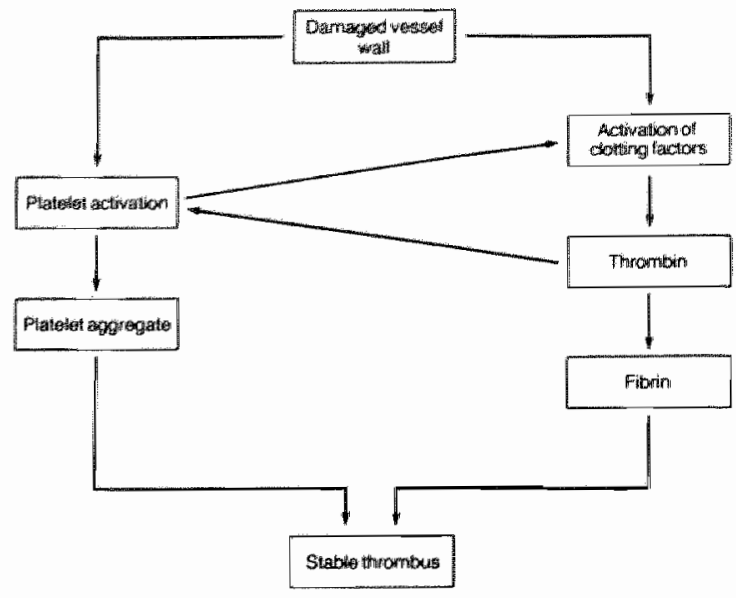

Fig.1. The role of platelets in the formation of a stable thrombus. (Taken from reference 50)

visible at stainting as a fuzzy surface coat, called glycacalyx. These glycoproteins have been found to function as receptors for platelet stimuli and are Involved in platelet aggregation and the adhesion of platelets to factor VIIIwon W1lebrand factor on vessel wall subendothellum $(2-5)$. Subjacent to the plasma membrane, a clrcumferential bundle of long microtubules supports the platelets asymmetric form (fig. 2). Many indentations of the plasma membrane penetrate deep in the platelet's Interior and form the so-called surface connected- or open canalicular system. This system facilitates the interaction of the platelet membrane with intracellular organelles and with plasma-borne substances. Not connected with the open canalicular system is another system of narrow, membrane-limfted tubules. This so-called dense tubular system has been shown to be the site where intracellular calcium, essential for platelet activatiom, 1s sequestered (6). In the platelet, at least two types of storage granules can be shown by electronmleroscopy; alpha granules and (electron) dense bodies, each surrounded by a membrane. Among the substances which are tored In the dense bodles are serotonin, calcium, ATP, ADP and pyrophosphate. Subcellular fractionation studies revealed that the alpha granule population Is heterogeneous and consists of a 1 ysosomal and a nonlysosomal fraction (7). Alphe granules of the nonlysosomal class contain a number of proteins several of which are involved in coagulation such as platelet factor 4 ( a heparinneutralizing proteln), factor $W$, factor WIII related antigen, fibronectin and flbrtnogen.

Activation of platelets. Platelets can be stimulated by a variety of compounds including collagen, thrombin, ADP, epinephrine, immune camplexes, serotonin, 


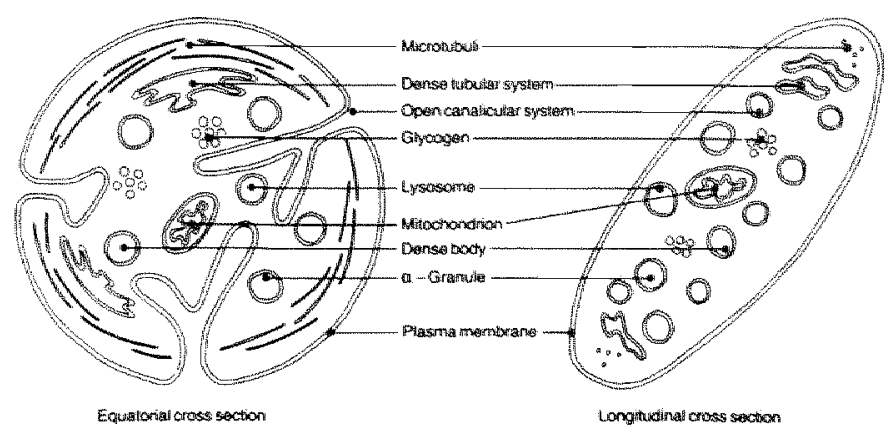

Enqualistial cross section
Fig. 2 Schematic view of the blood platelet. (Taken from reference 50)

arachidonic acid and prostanolds. For several of these stimulating agents specific receptors were found to be localized in the platelet menbrane ( 8 ). With almost all platelet stinuli the first response observed after triggerling is a rapid shape change of the platelet, consisting of a rounding up of the central body of the cell and an extruston of thin pseudopodia (9). Shape change is accompanied by an internal centralization of the storage granules which become enclosed by a ring of microtubules (10). The timing of this movement precedes or colncides with secretion of granular contents into the open canalicular system occurring after fusion of the granular membranes with the plasma membrane. Release of nonlysosomal alpha-granule proteins is induced by all of the agents that evoke dense body release. Small differences between dense body and alpha-granule release were found in the time course of release after the addition of the stimulus and in the required stimulus concentration (11). As compared with the discharge of the other granular contents, the release of Iysosomal proteins 15 delayed and less complete (12). Less information is avallable about the function of secreted compounds. Serotonin helps in the arrest of bleeding by its vasoconstricting property. In vitro, ADp and serotonin are able to stimulate platelets, which in vivo may contribute to the accumulation of platelets in the prlwary hemostatic plug. Although both are present in the plasma, the secreted factor $V$ and flbrinogen may be requlred. for the local process of coagulation. Fibrinogen 1s essentlal for platelet aggregation to occur (13). Aggregation requires extracellular $\mathrm{Ca}^{2+}$ and is dependent on the shear flow of the medium in which the platelets are present. Aggregation is not necessarily a prerequiste for the release reaction and vice versa. ADP and eplnephrine at low concentrations induce primary aggregation without release, whereas platelets which are not subject to shear stress do not aggregate but release normally (14). Moreover platelets from patients 
Wth Glanzmann" thromboghenta fall to aggregate but do release in response teo etidulation $(3)$.

Intracellular responges upon platelet activation. Upon stimulation of platelet endogenous phospholipases are activated, resulting lin the release of arachidonic acid from platelet phosphollpids. Part of the arachidonic acid is converted into 12-hydroxyelcosatetraenolc actd by the platelet enzyme arachidonate lipoxygnase, an enzymatic pathway which is reported to be essential for both the platelet aggregation and the release of serotonin (15). Another pathway is the conversion of arachldonic acid by platelet cyclooxygenase into the endoperoxides prostaglandin $\mathrm{G}_{2}$ and prostaglandin $\mathrm{H}_{2}$ " "These endoperoxides are further transformed to thromboxane $A_{2}$, which is a powerful initiator of platelet aggregation (16). The relative importance of thromboxane $A_{2}$ in the sequence of selfperpetuating platelet aggregation is not yet established, athough it is known that cyclooxygenase plays a central role in the activation of platelets. Platelets which are treated with aspirin show a depressed release and aggregation reaction due to inhibition of cyclooxygenase (17). The action of cyclooxygenase is controlled by the awallability of free arachidonate. Although arachidonic acid is one of the most abundant fatty acids in the platelet, almost all of it is esterified to the glycerol backbone of phospholdpids in the Inner leaflet of the plasma membrane. The release of arachldonlc acid from phospholipids occurs elther by the direct action of phospholipase $A_{2}$ liberating the free acld or by the sequential action of the phosphatidylinositol specific phospholipase $C$ and diglyceride 11pase (18-20). Both phospholipase $\mathrm{A}_{2}$ and phospholipase $C$ require $\mathrm{Ca}^{2+}$ for their enzymatic activity, which led to the suggestion that the phospholipases are activated by the 1ncreased cytosolic $\mathrm{Ca}^{2+}$ concentration, which is found after platelet stimulation $(21,22)$. Aso for other platelet responses which occur upon stinulation, an Increased cytosolic $\mathrm{Ca}^{2+}$ concentration is a prerequisite. Calcium 1 s Involved in the phosphorylation of proteins and increased contractile metivity. Studies with the calctun lonophore A23187 suggest that both pseudopod formation and granule centralization results from a flux of intracellular calclun from the dense tubular system into the cytoplasm (23). Also prostaglandin $G_{2}$ and thromboxane $A_{2}$ are able to release calcium from this subcellular fraction, whlch led to the hypothesls that thromboxane $A_{2}$ triggers the platelet activation mechanism by acting as an ionophore (24).

Procoagulant activity. Apart from their function in primary plug formation, blood platelets are involved in several reactions of the caagulation cascade. Stimulated platelets form a so-called procoagulant surface at which the later- 
action between clotting factors is promoted and consequently the rate of clotting factor activation is increased. Platelets are reported to particlpate in four speciflc coagulation reactions:

1. Contact product-forming activity of ADP-stimulated platelets, which resides in the platelet surface and concerns the binding and subsequent activation of factor XII (25).

2. Collagen induced coagulant activity of platelets, which bind factor XI to high affindty binding sites at their surface, thereby promoting the activation of factor XI in the presence of kallikrein (26-28).

3. Procoagulant activity of collagen-stlmulated platelets in the intrinstc factor Xa formation $1 . e$. the activation of factor $X$ by activated factor IX, factor VIII and $\mathrm{Ca}^{2+}(29)$.

4. Procoagulant activity of platelets in the activation of prothrombln by activated factor $X$, factor $V$ and $\mathrm{Ca}^{2+}$, often referred to as platelet factor 3 (29-31).

Whether phospholipids can account for the procoagulant activity of the plate lets in prothrombin- and factor $X$ activation, or that this activity arises from platelet proteins is a long-standing mater of debate. Although phospholipids highly promote both the factor $X$ - and prothrombin activation (29), isolated platelet plasma membranes were found to be more procoagulant in a clotting assay (32). This was interpretied to mean that platelet factor 3 represents the activity of platelet membrane lipoproteln rather than membrane phospholipids alone (33). Miletich et a1. (34-36) have demonstrated binding of human factor $\mathrm{Xa}$ to a receptor on isolated platelets, which was later 1dentified as factor Va (37). Factor Va binds with high affinity to an equal number of binding sites on the surface of non-stimulated- and thrombin-stimulated platelets, which indicates that the release reaction $1 \mathrm{~s}$ not a prerequistte for factor $X a$, factor Va binding $(38,39)$. Factor Xa bound to factor $V a$ on the platelet surface, catalyzes the activation of prothrombin efflclently, comparable with the activation of prothrombin in the presence of phospholipld bilayers $(35,40,41)$. To exhiblt procoagulant activity, membranes wust contaln negatively charged phospholipids $(42-45)$, whlch in the resting platelet are almost exclusively located in the platelet interfor (46). The question artses whether negatively charged phospholipids are of importance in the reactions on the platelet surface. To answer this question more instght is required about the mechanism by whlch phospholipids act in the activation of prothrombin and factor $\mathrm{X}$. 


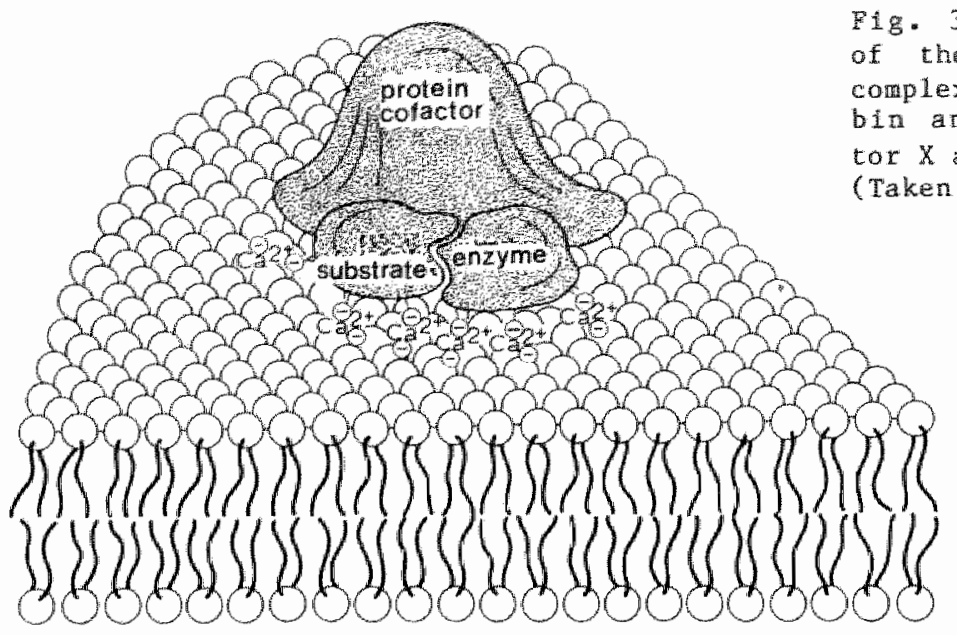

Activation of prothrombin and factor X. Prothrombin- and intrinsic factor $X$ activation have many features in common (for a review see ref. 47). Both the substrates (prothrombin and factor $X$ ) and the enzynes (factor Xa and factor IXa) are vitamin $K$ dependent proteins that contain $Y$-carboxyglutamic acid residues, which bind via $\mathrm{Ca}^{2+}$-bridges to negatively charged phospholipid surfaces. Both the enzymes are serine proteases and the substrates are zymogens of seriae proteases. The protein cofactors (factor Va and factor viIla) have no enzymatic activity and have a high affinity for negatively charged phospholipid surfaces, although they lack $r$-carboxyglutamic acld residues. Eigure 3 shows a representation of the active enzymatic complex consisting of enzyme, substrate and protein cofactor bound at a phospholipid bllayer. Bovine factor $x$ is a zymogen which exists as a two chain disulfide-linked glycoproteln. The Hight chali of the molecule contalns the $r$-carboxyglutamic acids, and remains covalently linked with the proteln after activation of factor $X$ into 1 to protease fort called factor Xa. The heavy chain, when cleaved by factor 1 Xa at position Arg $\mathrm{Al}^{-\mathrm{IL}_{52}}$, contains the active site for proteolytic actulty of the factor Xa molecule. The conversion of the glycoprotefn prothrombin into its activated form thrombin requires two reaction steps. First, factor Xa cleaves off an activation peptide (fragment 1.2) by splitting an arglnine-threonine bond leaving prethrombin 2. Prethrombin 2, which lost its $r$-carboxyglutamic aclds and has no protease actuity, is further converted Into thrombin after cleaving an arginine-isoleucine bond by factor Xa. In the absence of accessory components, $i$.e. phospholipid and protein cofactors, prothrombin and factor $X$ activation are very inefficient processes. 
Kinetic studies revealed that without accessory components the vmax is less than one turnover per min and that the values of the km for prothrombin and factor $X$ axe considerably higher than their plasma concentrations of $2 \mu M$ and $0.2 \mu \mathrm{M}$ respectiwely $(41,48)$. The presence of phospholipld plus Ca ${ }^{2+}$ causes, in both couplexes, a drastic drop in the kn to values far below the factor $x$ and prothrombin concentration in plasma, wh1le the protein cofactors strongly increase the Vmax $(41,48)$. The increase of the Vmax of prothrombin activation by factor $\mathrm{Va}$ is ascribed, for a great deal, to alterations in the catalytic pathway leading from the enzyme-substrate complex to the ultimate product (41). Although it is generally accepted that phospholipid bilayers act as surfaces that promote the assembly of enzyme-cofactor-substrate complexes, the mechanism by which they decrease the $\mathrm{km}$ is still matter of discussion (49).

The present investigation. This thesis describes studies on the procoagulant properties of platelets and phospholipids present in platelet membranes. In particular, the role of platelets and phospholipids in prothrombin- and factor X activation was investigated, using systems with highly purifled coagulation factors and chromogenic substrates to measure rates of thrombin and factor Xa formation. Chapter II presents a study on the changes in phospholipid composition In the outer leaflet of the plasma membrane of platelets after stimulation. This was done in order to find a relationship between platelet act1vity in prothrombin activition and the presence of procoagulant (net negative$1 \mathrm{y}$ charged) phospholipids in the outer monolayer of the platelet membrane.

In a more extended investigation, presented in chapter III, we employed reaction systems for prothrombin- and intrinsic factor $X$ activation, which were made suitable for the detection of procoagulant phospholipids in membranes. With these reaction systems the appearance of platelet-procosgulant activity was followed after stimulating the platelets whth collagen plus thrombln. The same reaction systems were also applied to platelets whlch were gtimulated by the calcium-1onophore A23187. The appearence of platelet procoagulant activity was compared with the dose dependent induction of platelet aggregation, release of ATP and release of factor $V$. The results of this study are presented In chapter IV. The study described $\mathbb{1 n}$ chapter $V$ concerns the role of factor VIII in the assembly of the complex for intrinsic factor $X$ activation on bilayers which are composed of phospholipids present in platelets. Parameters of binding of factor IXa to these bilayers were inferred from kinetlc measurements in the absence and presence of factor VIILa. Chapter VI describes the relationship of the kinetic parameters of prothrombin activation with the 
amount of acldic phospolipids in membrane bllayers. Special attention is given to the role of factor $V a$ in the assembly of enzymatic complexes on merbianes wth minute amounts of acidic phospholipids. Evidence is presented for a wad about the mode of action by which phospholiplds decrease the kon for prothrombin.

\section{REFERENCES}

1. White, J.G. (1979) Am.J. C11n. Pathol. 71, 363-378.

2. Ganguly, P., Gould, N.L. and Sldhu, P. (1979) Blochim. Blophys. Acta 586, $574-583$.

3. Phillps, D.R. and Agin, P.P. (1977). J. Clin. Invest. 60, 535-545.

4. Jenkins, C.S.P., Philips, D.R., Clemetson, K.J., Meyer, D.* Larrleu,M.J. and Lïscher, E.F. (1976). J. Clin Invest. 57, 112-124.

5. Bolhuis, P.A., Sakariassen, K.S., Sander, H.J., Bouma, B.N. and Sixma, J.J. (1981) J. Lab. C11n. Med. 97, 568-576.

6. Käser-Glanzmann, R. Jakabova, M., George, J.N., and Lüscher, E.F. (1978) Blochitr. Blophys. Acta 512, 1-12.

7. Broekman, M.J., Handin, R.I., and Cohen, P. (1975) Brit.J. Maematol. 31, $51-63$.

8. Mills, D.C.B., and Macfarlane, D.E. (1976) in : Plateletg in Blology and Pathology (G.L. Gordon, ed), p.p. 159-201, Elsevier-North Holland, Amsterdam and New York.

9. White, J.G. (1968) Blood 31, 604-615.

10. White, J.G., and Gerrard, J.M. (1978), in : Platelets a Multidisciplinary Approach (G. de Gatano and S. Garattini, eds) pp. 17-34, Raven Press, New York.

11. Kaplan, K.L., Broekman, M.J., Chernoff, A., Lesznik, G.R., and Dril1ings, M. (1979) Blood 53, 604-618.

12. Holmsen, H. and Day, H.J. (1970). J. Lab. Clin. Med. 75, 840-852.

13. Tollefsen, D.M. and Majerus, P.W. (1975) J. Clin. Invest 55, 1259-1268.

14. Mustard, J.F. and Packham, M.A. (1970) Pharmacol. Rev. 22, 97-187.

15. Duthi1, C.E., Haddeman, E., Jonvenaz, G.H., Ten Hoor, F. and Nugteren, D.H. (1979) Lilplds $14,241-246$.

16. Hamberg, M., Svensson, J., Samuelsson, B. (1975). Proc. Nat1. Acad. Sci. 72, 2994-2998.

17. Roth, G.J. and Majerus, P.W. (1975) J. C11n Invest. 56, 624-632.

18. Mauco, G., Chap, H.J., Simon, M.F. and Douste-Blazy, L. (1978) Biochimte $60,653-661$.

19. Rittenhouse-Simons, S. (1979) J. C1in. Invest. 63, 580-587.

20. Bell, R.L., Kennerly, D.A., Stanford, N* and Majerus, P.W. (1979).Proc. Nat1. Acad.Sc1. U.S.A. 76, 3238-3241.

21. B11lah, M.M. and Lapetina, E.G. (1982) J. Blol. Chen. 257, 11856-11859.

22. Felnstein, M.B. (1980) Blochem. Blophys. Res. Commun. 83, 593-595.

23. Gerrard, J.M., White, J.G. and Rao, G.H.R. (1974) Am. J. Pathol. 77, 151-166.

24. Gerrard, J.M., Butler, A.M., Peterson, D.A. and Whte, J.G. (1978) Prost. Med. 1, 387-396.

25. Walsh, P.N. (1972) Brit. J. Haenatol. 22, 237-254.

26. Walsh, P.N. (1972) Brit. J. Haematol. 22, 393-405. 
27. Wa1sh, P.N. and Griffin, J.H. (1981) Blood 57, 106-118.

28. Greengard, J.S., Walsh, P.N. and Griffin, J.H. (1981) Blood 58, 194 a.

29. Walsh, P.N. (1978) Brit.J. Haematol. 40, 311-331.

30. Joist, J.H., Dolezel, G., Lloyd, J.V., Raelene, L. (1974) J. Lab. C1in. Med. $84,474-482$.

31. van Zutphen, H. Bevers, E.M., Hemker, H.C. and Zwaal, R.F.A. (1980) Brit. J. Haematol. $45,121-131$.

32. Marcus, A.J., Zucker-Franklin, D., Safier, L.B. and U1 mann, H.L. (1966) J. Clin. Invest. $45,14-28$.

33. Marcus, A.J. (1978) J. Lipld Res. 19, 793-826.

34. Miletich, J.P., Jackson, C.M. and Majerus, P.W. (1977). Proc. Natl. Acad. Sci. U.S.A. 74, 4033-4036.

35. Miletich, J.P., Jackson, C.M. and Majerus, P.W. (1978) J* B101. Chem. 253, $6908-6916$.

36. Miletich, J.P., Majerus, D.W. and Majerus, P.W. (1978) J. Clin Invest. 62, $824-831$.

37. Dahlbäck, b. Stenflo, J. (1978) Blochemistry 17, 4938-4945.

38. Tracy, P.B., Nesheim, M.E., Mann, K.G. (1981) J. B1ol. Chem. 256, 743-751.

39. Kane, W.H., Lindhout, M.J., Jackson, C.M., Majerus, P.W. (1980) J. Bioll. Chem. 255, $1170-1174$.

40. Dahlbäck, B., Stenflo, J. (1980) Eur. J. Blochem. 104, 549-557.

41. Rosing, J. Tans, G., Govers-Rlemslag, J.W.P., Zwaal, R.F.A. and Hemker, H.C. (1980) J. B1ol. Chem. 255, 274-283.

42. Daemen, F.J.M., van Arkel, C., Hart, H.C., van der Drift, C. and van Deenen, L.L.M. (1965) Thromb. Diath. Haemorrh. 13, 194-217.

43. Bangham, A.D. (1961) Nature 192, 1197-1198.

44. Hemker, H.C., (1975) in : Handbook of Hemophilla (Brinkhous, K.M. and Hernker H.C., eds.) pp. 31-48. Experta Medica, Amsterdam.

45. Zwal, R.F.A. (1978) Biochim. Blophys. Acta 515, 163-205.

46. Chap, H.J., Zwaal, R.F.A. and van Deenen, L.L.M. (1977) Blochim. Blophys. Acta $467,146-164$.

47. Jackson, C.M. and Nemerson, Y (1980) Ann. Rev. Blochem. 49, 765-811.

48. van Dieyen, G., Tans, G. Rosing, J., Hemker, H.C. (1981) J. Biol. Chen. $256,3433-3442$.

49. Pusey, M.L. and Nelsestuen, G.L. (1983) Blochem. Blophys. Commun, 114, 526-532.

50. Bevers, E.M. (1983) in : Atherogenesis and Thrombosis 5. (G. Hornstra and R.F.A. Zwaal eds), Boehringer Ingelheim International. 



\title{
GENERATION OF PROTHROMBIN-CONVERTING ACTIVITY AND THE EXPOSURE OF PHOSPHATIDYLSERINE AT THE OUTER SURFACE OF PLATELETS.
}

\author{
SUMMARY
}

In the present paper we compare prothrombin-converting activities of platelets non-activated, or activated by collagen, thrombin or collagen plus thrombin in the absence and presence of added factor Va. In all experiments described, the rate of thrombin formation for platelets activated by the combined action of collagen and thrombin is greater than that of platelets stimulated by collagen or thrombin alone. The presence of added factor Va enhanced the rate of thrombin formation in all cases, but the higher activity observed with platelets stimulated by collagen plus thrombin remalns. When platelets are activated by collagen plus thrombin in the presence of factor Xa and prothrombin, a lag period of approximately $10 \mathrm{~min}$ is observed before the rate of thrombin formation reaches a steady state. Addition of an excessi of factor Va in this experiment reduces the lag time to $3 \mathrm{~min}$. This lag period $1 \mathrm{~s}$ interpreted as the time required to generate extra binding sites for the prothrombinase complex at the platelet surface. These extra sites explain the difference in thrombin formation rate between these platelets and platelets activated by either collagen or thrombin only.

The exposure of phospholipids at the platelet outer surface was studied with phospholipases after varlous activations of the platelets. It is demonstrated that activation by collagen plus thrombin is accompanled by increased susceptibility of platelet phosholipids towards phospholipase $A_{2}$. Among these degradable phosphollpids are $25 \%$ of the phosphatidylserine and $30 \%$ of the phosphatidylethanolamine. On the other hand, little or no phosphatidylserine is exposed at the membrane exterior of thrombin-treated or control platelets. We propose that the exposure of phosphatidylserine at the outer surface of platelets activated with thrombin plus collagen 1 s essental for the rate enhancement of thrombin formation observed under these conditions. The possibllity of a transbllayer mowement of phosphollpids in the platelet membrane as a result of the activation process will be discussed.

\section{INTRODUCTION}

One of the major functions of platelets in the process of hemostasis 1 s to provide a catalytic surface for the formation of the intrinsic factor-X-actiwating complex and the prothrombinase complex (for a review, see (1)). Nesheim et a1. (2) have shown that there is no appreclable difference in catalytic efficiency of the prothrombinase complex when phospholipid vestcles plus factor Va are substituted for activated platelets. Rosing et al. (3) showed 
that the role of phospholipids in the prothrombinase complex is to decrease the Kom for prothromin below $1 \mathrm{ts}$ plasma concentration, whereas factor va strongly Increases the Vmax of the reaction $(2,3)$. Recently similar results were found for the role of phosphollpids in the intrinsic factor -X-activating complex (4).

It has been demongtrated that the cytoplasmlic surfaces of both erythrocytes and platelets, as well as 1lposomes prepared from phosphollpids present In the Inner leaflet of the plasma membrane of these cells, possess a strong procoagulant activity (5). In contrast, resting platelets and intact erythrocytes, exposing only the outer membrane surface, do not reduce the clotting time in a one-stage prothrombinase assay. Moreover, liposomes prepared from phospholfplds present in the outer leaflet of these membranes are also inactive. The difference in clot-promoting activity between inner and outer surface of these blood cells can be explained by the asymetric distribution of phospholiplds over the membrane bllayer. The vitamin-K-dependent coagulation factors $X a$ and II require the presence of negatively charged phospholipids for the calcium-mediated blinding via their $\gamma$-carboxyglutamic acid residues $(6-10)$. The phospholipid orientation in erythrocyte and platelet plasma membranes has been established using phospholipases (11-17) and chemical labels (18-21) and appears to be rather similar for both types of membranes. In both membranes, the negatively charged phospholipids, phosphatidylserine and phosphatidylInositol, are almost exclustuely located in the Inner leaflet, which provides an explanation for the procoagulant activity of the inner surface of both membranes.

In contrast to erythrocytes platelets have the unique property of undergoing morphologlcal and functional changes following addition of ADP, collagen, thrombin and several other agents, resulting in shape change, aggregation and release of their granule contents. Th1s may be accompanled by exposure of a procoagulant 11 pld surface. It has been suggested, however, that the procoagulant behaviour of platelets, activated by thrombin is due to the release and activation of factor $V$, whlch then forms the receptor for factor Xa on the platelet surface $(22-25)$. In fact, addition of factor Va to unstimulated platelets results in the same number of factor Xa molecules bound as observed for platelets activated by thrombin (26). Furthermore, a patient has been desctibed whose platelets show decreased binding of factor $\mathrm{Xa}$, although the platelet factor $\mathrm{Va}$ content and phospholipid composition seemed to be normal, suggesting the involvement of a membrane protein in the factor-Va-factar-Xa receptor on the platelet outer surface $(27,28)$. Also, it has been shown that 
IgM paraprotein from a patient with macroglobulinemia reacts with negatively charged phospholipids and inhibits ca-dependent binding of radiolabeled factor $X$ and II to phospholipid vesicles but not to platelets (29). These observations cast some doubt on whether or not phospholipids are involved in the formation of the prothrombinase complex at the platelet surface. The purpose of the expertments described in this paper was to study the exposure of phospholipids at the platelet outer surface after various activation procedures in order to attempt to correlate alterations in platelet prothrombin-converting activity with reorientations in the platelet membrane phospholipids. The data presented here have implications for the participation of negatively charged platelet phospholipids in prothrombinase activity occurring at the platelet surface.

\section{EXPERIMENTAL PROCEDURES.}

Materials. $\quad\left[{ }^{14} \mathrm{C}\right]$ Serotonin creatinine sulfate $(58 \mathrm{Cl} / \mathrm{mol})$ was obtained from Amersham Corp. From Sigma Chemical Co. (St. Louls) were purchased: fat-free human serum albumin, nicotinamide adenine dinucleotide, reduced form (NADH), Naja naja venom, bee venom (Apis mellifera) and Russell's viper venom. Adenosine diphosphate (ADP) was from Boehringer, Mannheim. Collagen was from Hormon Chemie, München. $\$ 2238$ was purchased from AB Kab1 Diagnostica (Stackholm, Sweden).

Protein preparations. Factor-X-activator from Russell's viper venom was purifled as described by Schiffmam et al. (30) and was free of phospholipase activity. Bovine prothrombin was prepared according to the method of owen et al (31). Prothrombin concentrations were calculated from the absorbance at 280 nm, using $A_{280}^{1 \%}=15.5(31)$, and 72000 for the molecular welght of prothrombin (31). Bovine factor $X$ was prepared from factor $x_{2}$ using factor-X-activator according to the method of Fujikawa et al. (32). Factor Xa concentrations were calculated after active-site titration according to Snith (33). Factor $V$ was 1sollated as described by Esmon (34) with minor modifications (umpublished results of $\mathrm{L} \mathbb{1}$ ndhout et $\mathrm{al}$.$) . Factor \mathrm{V}(0.3 \mathrm{mg} / \mathrm{ml})$ was activated with thrombin and the specific activity of the activated preparation was 500 undto/mg, measured according to Kappeler (35). One unit is defined as the amount of factor $V$ present in $1 \mathrm{ml}$ normal bowlne plasma. The concentration of factor $V$ was calculated assuming a molecular weight of 330 000 for factor $V$ ( 36 ). Thrombin was purified from prothrombin after activation wh factor $\mathrm{Xa}$ as described by Rosing et al. (3). The thrombin concentration was determined by 
active- 1 te thration according to Chase and shaw (37). Phosphollpase $\mathbb{A}_{2}$ from U. na ja venom and bee venom, as well as sphingomyelinase $C$ from staphylococcus aureus were purifled as described elsewhere (15).

Igolation of platelets. Fresh blood was drawn from healthy male volunteers who had not taken any medlcation for at least a meek. Acld citrate dextrose was used as an anticoagulant. Platelet-rich plasma, obtalned after centrifugation at $120 \mathrm{xg}$ for $10 \mathrm{~min}$, was incubated with $1 \mu \mathrm{Cl} /\left[^{1 / 4} \mathrm{C}\right] \mathrm{sec}$ totonin/100 m plasma for $20 \mathrm{~min}$ at room temperature resulting $1 \mathrm{n} 95 \%$ uptake. Platelets were 1solated by centrifugation (1400 $\mathrm{xg}, 15 \mathrm{~min}$ ) and the pellet was gently resuspended in a calcium-free Hepes buffer pH 6.2, containing $137 \mathrm{mM} \mathrm{NaCl}, 2.68 \mathrm{mM}$ $\mathrm{KCl}, 10 \mathrm{mM}$ Hepes, $1.7 \mathrm{mM} \mathrm{MgCl}, 25 \mathrm{mM} \mathrm{glucose}$ and $0.5 \mathrm{mg}$ fat-free human serum album $1 \mathrm{n} / \mathrm{ml}$. Cells were washed twice and finally resuspended in the same buffer at pH 7.4. Cell counts were carried out using a Coulter Counter. A11 platelet handling was done at room temperature.

Measurement of serotonin release and leakage of lactate dehydrogenase. Release of $\left[{ }^{14} \mathrm{C}\right]$ serotonin was determined in the platelet supernatant after centrifugation at $7000 \mathrm{xg}$ for $2 \mathrm{~min}$ in an Eppendorf microfuge. Leakage of platelet lactate dehydrogenase was determined according to the method of Wroblewsk1 and 1a Due (38). Total lactate dehydrogenase content of the platelets was measured after complete lysis, which could be obtalned either by sonication, or by freeze-thawing or by addition of $0.1 \%$ Triton X-100. All three methods resulted in the same total lactate dehydrogenase activity.

Measurement of platelet prothrombin-converting activity by a chromogenic substrate assay. Washed platelet suspensions $(0.5 \mathrm{~m} \mathbb{1}$ ) with a platelet concentration of $5 \times 10^{6} \cdot \mathrm{ml}^{-1}$ were activated in the presence of $15 \mu 10.1 \mathrm{M} \mathrm{CaCl}_{2}$ by $10 \mu 1$ collagen $(0.5 \mathrm{mg} / \mathrm{ml})$ and/or $10 \mu \mathrm{l}$ thrombin $(0.1 \mu \mathrm{M})(\mathrm{final}$ concentrations durling the platelet activation are $10 \mu \mathrm{g} / \mathrm{ml}$ collagen and 2 nM thromb1n). Elght minutes after platelet activation was started, $25 \mu 1$ factor Xa ( 20 $\mathrm{nM})$, and $\mathrm{In}$ some experiments $25 \mu \mathrm{I}$ factor $\mathrm{Va}(40 \mathrm{nM})$, were added to the incubation mixture. Two minutes later, $430 \mu 1$ of a buffer of $\mathrm{pH} 7.9$ contalning 50 $\mathrm{mM}$ Tr1s, $120 \mathrm{mM} \mathrm{NaCl}, 3 \mathrm{mM} \mathrm{CaCl}, 0.5 \mathrm{mg}$ human serum albumin/ml and $2.6 \mu \mathrm{M}$ prothrombin were added to start the formation of thrombin. The final incubation mixture then consisted of $2.5 \times 10^{6}$ platelets/mi, $3 \mathrm{mM} \mathrm{CaCl}_{2}, 0.5 \mathrm{nM}$ factor $X a, 1.0 \mathrm{nM}$ factor Va (1f added) and $1.1 \mu \mathrm{M}$ prothrombln. The activation of platelets as well as the thrombin formation were carried out at $37^{\circ} \mathrm{C}$ under continuous stirring with a siliconized stirrer in plastic tubes. After various tine Intervals, samples of 25-100 $\mu 1$ are taken from the incubation mixture and added to $2 \mathrm{ml}$ buffer containing $50 \mathrm{mM} T \mathrm{Tr} 1 \mathrm{~s}, 120 \mathrm{mM} \mathrm{NaCl}, 2 \mathrm{mM} \mathrm{EDTA}, \mathrm{pH} 7.5$ and 
$0.249 \mathrm{mM} \mathrm{S} 2238$. From the absorbance change at $405 \mathrm{~nm}$ the amount of thrombin formed was calculated from a calibration curve made with known amounts of active-site-titrated thrombin. In some experiments thrombin formation was measured immediately after the addition of platelet activator. In these cases, factor Xa (and factor Va) was added 2 min prior to the simultaneous addition of activator(s) and prothrombin. We did not use platelet suspenslons at a physiological concentration of $10^{8} \cdot \mathrm{m}^{-1}$ because too high rates of thrombln formation in these suspensions gave rise to deviations from linearity in thrombin formation as a function of time.

Phospholipase treatment of the platelets. $20 \mathrm{ml}$ of activated platelet suspensions $\left(5 \times 10^{8} \cdot \mathrm{ml}^{-1}\right)$ or appropriate controls were incubated with a mixture of phospholipase $A_{2}$ from bee venom (35 IU) and $\mathrm{N}$. naja (48 IU) in the presence of $10 \mathrm{mM} \mathrm{CaCl}, 2 \mathrm{mM}$ o-phenantroline and $1 \mu \mathrm{g}$ indomethactn/m. After $60 \mathrm{~min}$, samples were taken to determine the amount of lysis. Phospholipase activity was inhibited by addition of $2 \mathrm{~m} 10.2 \mathrm{M}$ EDTA. The incubation mixture was centrifuged at $30000 \mathrm{xg}$ for $30 \mathrm{~min}$ and the resuspended platelet pellet was extracted according to the method of Bligh and Dyer (39). Phospholipid analysis was carried out as described before (12). In order to detect phospholipid degradation in intact platelets only, corrections were made for phosphollpid breakdown in the population of lysed cells.

\section{RESULTS}

Rate of thrombin formation in the absence of exogenous factor va. The effect of activated and non-activated platelets on the conversion of prothrombin to thrombin by factor Xa was measured and the results are shown In Fig. 1. Initia1 rates of thrombin formation after activation of the platelets for $10 \mathrm{~min}$ with varlous stimulators are given in Table 1 . In the absence of exogenous factor Va, the initial rate of thrombin formation found for unstimulated platelets is nil. However, as shown $1 \mathrm{n}$ FIg. $\mathbb{A}$, thrombin $\mathbb{1}$, formed after a period of approx. $10 \mathrm{~min}$. After this lag period, a steady-state rate of thrombin formation of $2 \mathrm{nMmin}^{-1}$ is reached, belng the equivalent of approx. 0.2 units.m $1^{-1} \cdot \mathrm{min}^{-1}$ (assuming that $1 \mathrm{mg}$ thrombin corresponds to 2500 units) for $3 \times 10^{6}$ platelets/ml. This is in agreement with the observations by Dahlbäck et al. (25) and Miletich et al. (24) who found 2 units.m $1^{-1} \cdot \mathrm{min}^{-1}$ and 5 units.m. $1^{-1}, \mathrm{~min}^{-1}$ respectively, for $10^{8}$ platelets/ml. The 1nttial veloctty of prothrombin activation catalyzed by platelete that have been stimulated by thrombin amounts to $2 \mathrm{nM} . \mathrm{min}^{-1}$ and this rate of thrombin formation remains 


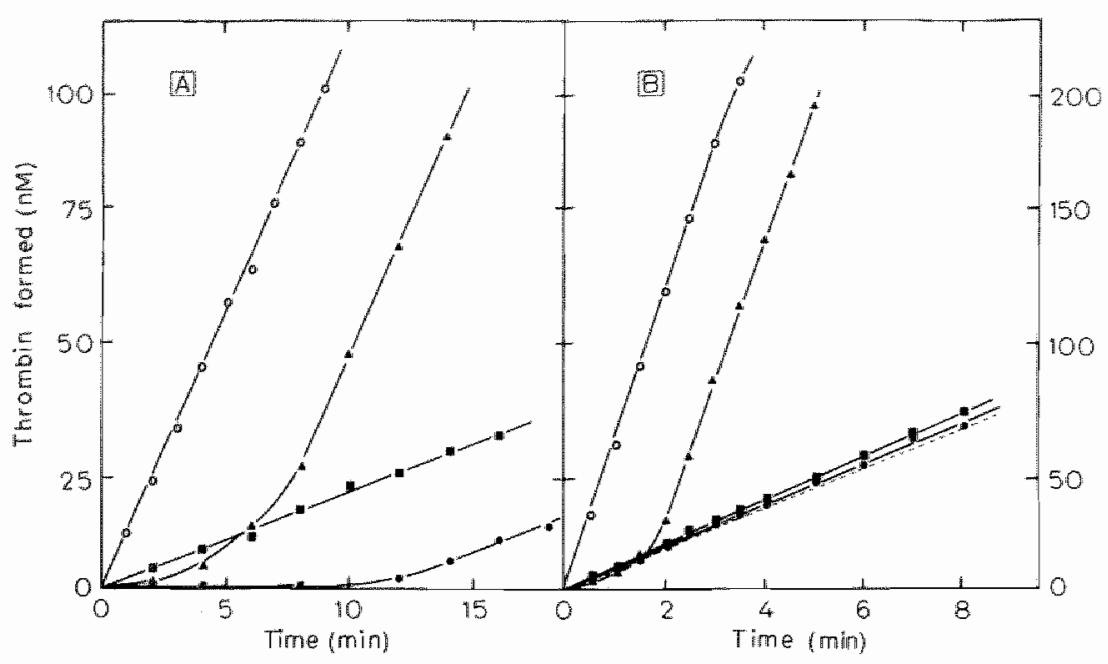

Fig. 1. Platelet prothrombin-converting activity in the absence and presence of exogenous factor Va. Platelet actlvators were added $10 \mathrm{~min}$ prior to the Initiation of the reaction by addition of prothrombin. Factors $X a$ (and $V a$ ) were added $2 \mathrm{~min}$ before the reaction was started. (A) Thrombin formation in the absence of exogenous factor $\mathrm{Va}$. (B) Thrombin formation in the presence of exogenous factor Va. Platelets were activated by: collagen plus thrombin (O), collagen $(\boldsymbol{\Lambda})$ and thrombin $(\boldsymbol{D})$. Control platelets are represented by the closed circles (O). The dashed line in B represents thrombin formation on $1 \% 1 y s e d$ platelets. Concentrations of coagulation factors and platelets are given in Experimental Procedures.

constant with time. When platelets are activated by a mixture of collagen and thrombin, the (Initial) rate of thrombin formation is increased to $11 \mathrm{nM}$ thrombin formed per min. This emanced rate of thrombin formation could not be observed when piatelets were activated by other stimulators such as ADP, adrenaline, kaolin or comblnations of these stimulators (not shown). Activation of platelets by collagen results in an initial rate of thrombin formation of zero but after a lag perlod of several minutes thrombin is formed at a gteady-atate rate equal to that of platelets treated with collagen plus thrombin. An explanation for this obgervation will be given later in this section. Rate of thrombin formation in the presence of exogenous factor Va. In the experiments described above, the rate of thrombin formation is at least partially deternined by the release and activation of factor $V$ present in the plateLet granules. In order to see whether addltion of exogenous factor Va influences the rate of prothrombin conversion we repeated the same experiments in the presence of added factor $\mathrm{Va}$. The results of these experiments are shown in 
Table 1. Rate of thrombin formation on activated human platelets in the presence and absence of exogenous factor Va. The values given in the table are initial velocities. The data are obtained from the experiments desm cribed in Fig. $1 \mathrm{~A}$ and $\mathrm{B}$. Experimental detalls are given in the legend of F1g. 1 and in Experimental Procedures.

\section{Platelet \\ Initial rate of thrombin formation activator}

without exogenous Va

with exogenous Wa

$\begin{array}{lcc} & n M, m^{-1} & n \cdot m^{-1} \\ \text { None } & 0 & 8 \\ \text { Collagen } & 0 & 7 \\ \text { Thrombin } & 2 & 9 \\ \text { Collagen + thrombin } & 11 & 7 \\ 1 \% \text { Lysed platelets } & 0 & \end{array}$

Fig. 1B. Addition of factor Va, factor Xa and prothrombin to unstimulated platelets initiates thrombin formation at a rate of $8 \mathrm{nM} \cdot \mathrm{min}^{-1}$. In contrast to the experiment in the absence of factor Va, no lag time is observed. An alinost equal rate of thrombin formation of $9 \mathrm{nM} \cdot \mathrm{min}^{-1}$ is found after activation of the platelets with thrombin for $10 \mathrm{~min}$. However, with platelets activated by the combined action of collagen and thrombin, the rate of thrombin formation is increased to $61 \mathrm{nM} \cdot \mathrm{min}^{-1}$. The effect of collagen alone 18 similar to that of collagen plus thrombin with the exception that a lag period of 2 min is observed before steady-state velocity is reached. An explanation for this phenomenon with collagen-activated platelets will be given below. The conclusion from this set of experiments is that platelets activated by a combination of collagen and thrombin form a more suftable catalytic surface for the prothrombinase complex than platelets treated only with thrombin. The difference In the rate of thrombin formation cannot be explained by a difference th extent of platelet secretion. No differences in $\left.\mathbb{1}^{\mathbb{1 4}} \mathrm{C}\right]$ serotonin release are observed between platelets stimulated wh thrombin or the combined action of collagen and thrombin. A possible explanation could be a difference in platelet lysis due to a different activation of the cells. The Inner leaflet of the platelet plasma membrane which will be exposed as a result of lyais of the cells has a much higher procoagulant activity compared to the outer leaflet of intact platelets $(1,40)$. Therefore measured the amount of lactate dehydrogenase, a cytoplasmic enzyme which is 11berated upon cell 1ysis. Approximately 
1\% of this enzyme actuity 1 present in the supernatant of platelets stimulated by both thrombin and collagen plus thrombin. The rate of thrombin formation using prepatation of $1 \%$ lysed platelets, obtained by a $1: 100$ dilution of a completely lysed platelet preparation, is found to be $7 \mathrm{nM}^{\mathrm{m}} \mathrm{n}^{-1}$ in the presence of exogenous factor Va (see Table 1). In the absence of exogenous factor Va no measurable amounts of thrombin can be detected. In as far as leakage of $1 \%$ lactate dehydrogenase really reflects $1 \%$ cell damage this cannot explain the rate of thrombin formation with a platelet suspenston activated by a combination of collagen and thrombin. The raximal rate of thrombin formation found for platelets stimulated th collagen alone equals that of platelets stimulated by the combined action of collagen and thrombin, both in the absence and in the presence of exogenous factor Va. However, when thrombin formation 1 meastred by incubating collagen-activated platelets with factor Xa, factor Va and prothrombin, the thrombin formed may react with the platelets producing a situation which reflects platelet activation by the combined action of collagen and thrombin. This may also explain why steady-state veloclty of thrombin formation with collagen-activated platelets is observed after a lag time. Moreover, platelets activated for 10 min with collagen and subsequently $5 \mathrm{~min}$ with thrombin exhibit the same prothrombin-converting activity as with the simultaneous addition of collagen and thrombin (data not shown). Generation of prothrombin-converting activity in platelets activated by collagen plus thrombin. Platelets stimulated by the comblned action of collagen and thrombin exhibit a higher prothrombin-converting activity than thrombln-activated or non-activated platelets. This indicates that platelet activation by collagen plus thrombin generates a large number of additional blnding ltes for the prothrombinase complex, the more so as highex rates of thrombin formation are also apparent in the presence of exogenous factor Va. In order to measure the generation of these sites, platelets were activated by collagen plus thrombin in the presence of factor $\mathrm{Xa}$ and prothrombin and with or whthout exogenous factor Va. The amount of exogenous factor Va was chosien such that maxtmal rate of thrombin formation was observed, in order to avold any effect of the factor $\mathrm{Va}$ released by the platelets. At different time intervals after platelet activation the reaction was stopped by EDTA and the amount of thrombin formed was measured as described in Experimental Procedures. The results are shown in Fig.2. In the absence of exogenous factor Va, 1t takes about $10 \mathrm{~min}$ before steady-state velocity of thrombin formation is reached. In the presence of exogenous factor Va, however, this lag period is reduced to approx. $3 \mathrm{~min}$. No lag time is apparent when the same experiment is 


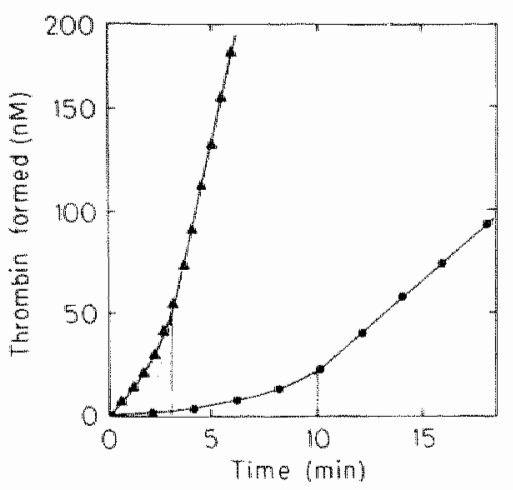

Fig. 2. Effect of exogenous factor Va on the lag time observed in platelets activated by collagen plus thrombin. Platelets were activated by collagen (10 $\mu \mathrm{g} / \mathrm{ml}$ ) plus thrombin (2 nM) immediately followed by addition of prothrombith. Factor Xa (and factor $\mathrm{Va}$ ) were added $2 \mathrm{~min}$ prior to the addition of collagen, thrombin and prothrombin. Experimental condtions are given in Experimental Procedures.

Circles represent platelets in the absence of exogenous factor Va; triangles in the presence of $2 \mathrm{nM}$ exogenous factor Va.

carried out with lysed platelets, or when platelets are activated first for 10 min before addition of the clotting factors (compare also FLg.1). This Indicates that the lag period is not caused by the binding rate of the components of prothrombinase to the platelets. It is suggested that formation of additional binding sites by platelets activated by collagen plus thrombin is completed in about $3 \mathrm{~min}$, whereas maximal release and activation of factor $V$ from the plateles takes approx. 10 min. A similar time perlod for the release of factor Va by thrambin-treated platelets has also been observed by Kane et al. (26). Our data also indicate that the amount of factor Va coming from the platelets is not suffictent to saturate all the binding sites that are generated upon platelet activation by the comblned action of collagen and thrombin.

Localisation of prothrombin converting activity of platelets. In order to establish whether the prothrombin-converting activity of activated platelets remains associated with the platelets or is released as a separate entity 1 nto the supernatant, platelet suspenstons activated by collagen plus thrombin are centrifuged for $5 \mathrm{~min}$ at $7000 \mathrm{xg}$. More than $85 \%$ of the activity is found in the platelet pellet. Moreover, when activated platelet suspensions are flltered through $0.45-\mu \mathrm{m}$ millipore filters, no activity whatsoever is observed in the flltrate. It is concluded that the prothrombin-converting activity bitli forms an integral part of the platelet surface after stimulation.

Phospholipase treatment of platelets. Because it is known from model experiments with phospholipid vesicles that negatively charged phospholiplds, and In particular phosphatidylserine molecules, are required to obtain a sultable surface for the prothrombinase complex, it was of interest to determine the exposure of the phospholipids at the outer surface of platelets after different activation procedures. In analogy to the work on erythrocytes $(11,12$, 
15) and previous studles on platelets $(16,17)$ we used phospholipases as a tool to establish the phospholipid localization in the platelet membrane before and after activation. Because of thelr size, phospholipases are unable to permeate the membrane and therefore their action 1 restricted to the lipids present in the outer monolayer of the membrane $(1)$. An essential reguirement for evaluation of the results is that membrane integrity is maintalned during phospholipase treatment. This was obtalned by addition of $2 \mathrm{mM}$-phenantroline to the actuated platelets prior to the addition of phospholipases. This reduced cell lysis caused by phospholipase action to less than 10\%, an amount for which rellable corrections can be made. Action of phospholipase $\mathrm{A}_{2}$ results in the liberation of free arachidonlc acti which is rapidly converted by the platelet cyclo-oxygenase into thromboxane $A_{2}$, which is a potent platelet activator (41). In order to prevent any effect of this compound both in control platelet and activated platelets, indomethacin was added prior to the addition of phospholipase. The data of these experiments are summarized in Table 2. Activation by collagen, thrombin or the combination of these stimulators did not result in a change in total phosphollpld composition of the platelets. Previous observations by several workers (42-45) demonstrated translent changes in phospholipid composition (in particular phosphatidylinositol and phosphatidic acld) during the first minutes of platelet activation, but the composition $1 \mathrm{~s}$ normalized within $15 \mathrm{~min}$. Therefore, in the experiment to determine the exposure of phosphollplds, phospholipases were added 15 min after the activation procedure.

Phospholipids from intact unstimulated platelets are hardly susceptible to a mixture of phospholipase $A_{2}$ from bee venom and $\mathbb{N}$.nafa. A mixture of these two phospholipases was used to eliminate differences In substrate specificity. Not more than $2.2 \%$ of the total phosphollpid can be degraded in these platelets under non-lytic condltions. This is in agreement with the finding of Chap et a1. (16) who explained this fallure of phospholipld hydrolysts by the tight packing of the Ifplds in the membrane. A slight Increase in total phospholipld hydrolysis is observed when thrombln-activated platelets were subjected to both phosphollpases. Approx. $6 \%$ of the total phosphollpid can be hydrolysed consisting malnly of phosphatidylcholine and phosphatidylethanolamine (Table 2). Whether phosphatidylserine or phosphatidylinositol are also hydrolysed is not clear since standard deviations are large. Changes in the ortentation of phospholiplds in the membrane of thrombin-treated platelets have been reported by schtck et al. (21) using the non-penetrating probe trinttrobenzenesulfontc acld. They found an increased exposure of phosphatidylethanolamine but not of 
Table 2. Non-1ytic degradation of platelet phospholipids by simultaneous action of phospholipases $\mathbb{A}_{2}$ fron $\mathbf{N}$. naja and bee venoms . Platelets were activated for 15 min followed by addition of phospholipases. Final concentration for thrombin was $2 \mathrm{nM}$ and for collagen $10 \mu \mathrm{g} / \mathrm{m} 1$. Experimental details are given in Experimental Procedures. Phospholipld composition ls expressed as percentage of total lipid phosphorus \pm S.D. Hydrolysis is expressed as the percentage degradation $\pm S . D$. of the corresponding phospholipid classes. The number in parentheses refer to the number of experiments from which these data were calculated. Data for phospholipld composition and phospholipid hydrolysis of platelets treated with collagen only, are similar to those for untreated platelets. Sphingonyelin is not hydrolysed because it is not a proper substrate for phosphollpase $A_{2}$.

\section{Phospholipid composition $(\%)$}

Phosphollpld

$$
\text { untreated }
$$

$9.8+1.3$

Phosphatidylserine

Phosphatidylinositol

Sphingomyelin

Phos phat idy lcholine

Phosphatidyle thanolamine
$4.2 \pm 1.2$

$19.1 \mp 1.2$

$36.9 \pm 2.1$

$27.6 \pm 1.8$

$(n=\overline{1} 2)$ activated by

throrabin

$10.2 \pm 0.2$
$3.3 \pm 0.2$
$19.1 \pm 0.3$
$37.7 \pm 0.5$
$28.0 \pm 0.5$
$(n=8)$

activated by collagen + thromblin

$10.2+0.3$

$2.7+0.4$

$19.8 \mp 0.2$

$37.9 \mp 0.8$

$27.5 \mp 1.0$

$(n=8)$

Hydrolysis (\%)

Phospholipid

untreated

activated by

activated by

thrombin

collagen + thrombln

Phosphat Idylserine

Phosphatidylinositol

Sphingomyellin

Phosphatidylcholine

Phos phatidy lethanoland ne

Total phospholipld

$\begin{array}{ll}0.4 \pm 0.3 & 4.4 \pm 5.0 \\ 0 & 1.2 \pm 2.0 \\ 0 & 0\end{array}$

$4.0+1.6$

$1.2 \pm 1.3$

$9.8+3.3$

$8.8 \pm 2.5$

$5.8 \pm 2.1$

$\left(\mathrm{n}^{\mathrm{xax}} 10\right)$
$24.6 \pm 1.4$
$4.6 \pm 5.1$
0

$25.0+3.5$

$30.0 \pm 2.5$

$20.4 \pm 2.1$

$(n=11)$

phosphatidylserine at the platelet outer surface which is in agreement wlth our observations. In contrast, when platelets activated by collagen plus thrombin are treated with phospholipase $A_{2}$, a maximum of about $20 \%$ of the total platelet phospholipids can be degraded without signiflcant lysis of the cells. This increased susceptibility of platelet phospholiplds indicates that changes in membrane stucture have occurred as a result of the activation process. Micro-environmental changes in human platelet membranes during act 1 vation by thrombin have also been reported by Nathan et a1.(46) using a fluorescent probe. The hydrolysed fraction of phospholiplds cons1sts of $24.6 \%$ of 
the phoshatidylaterine, $25 \%$ of the phosphatidylcholine and $30 \%$ of the phosphatidylethrolamine content of the platelets. When unstimulated platelets were subjected to a comblned action of aphingomyelinase $c$ from staphylococcus aureus and phosphollpase $A_{2}$ from Naja naja a degradation of approx. $25 \%$ of the total phosphollpld was observed but less than $6 \%$ of the phosphatidylserine molecules were degraded (datal not shown), confirming the findings of chap et 1. (16). However, using the same enzyme mixture on activated platelets which underwent the release reaction, results were obtained which were poorly reproduclble and difficult to interpret because of an increased lysis of the platelets (more than $25 \%$ of the total lactate dehydrogenase activity is found in the supernatant at the end of this phospholipase treatment). The experiments wth phospholipases indicate that during activation by collagen and thrombin micro-environmental alterations occur in the lipid bilayer membrane which are accompanfed by an increased exposure of phosphatidylserine at the platelet outer surface. This phenomenon may be responstble for the increased prothrombin-converting activity of these platelets, since an increase of exposed phosphatidylserine would create more binding sites for the components of the prothrombinase complex.

\section{DISCUSSION}

It has been established recently that factor Va serves as the binding site for factor xa at the platelet surface $(2,22-28)$. Platelet procoagulant activity which appears after thrombin activation was explained by the release and activation of factor $V$ from the platelet granules, thereby providing the receptor for factor Xa. Our observations on the prothrombin-converting activity of thrombin-treated and control platelets support this concept. In the absence of exogenous factor Va, non-activated platelets show the same steady state rate of thrombin formation after 10 aln as thrombin-treated platelets, which can be explained by the fact that control platelets become activated by trace amounts of thrombin formed during the lag period, resulting 1 n release and activation of factor W. Moreover, addition of exogenous factor Va to thrombin-stimulated or control platelets results in an equal rate of thrombin formation for both preparations. This is in full agrement wth the results of Kane et al. (26) who demonstrated that the binding sltes for factor Va-factor Xa are present on the surface of unstimulated platelets. Since addition of an excess of factor $V a$ to thrombin-stimulated platelets results in a five-fold enhancement of the rate of thrombin formation, the amount of factor va re- 
leased from the platelets is apparently not sufflclent to saturate all the binding sites. This seems to be in contrast to the observations by Mletich et a1. (27) who showed that normal platelets release at least flve tittes nore factor Va activity than is required for maximal binding of factor Xa. We have no explanation for this discrepancy although it should be mentloned that these investigators have measured binding of factor $\mathrm{Xa}$, whereas we have measured the rate of thrombin formation which is also determined by the binding of the substrate prothrombin. Although factor Va has been suggested to form the receptor for factor Xa on the platelet surface (26) as well as on phospho1ipid vesicles (2), the nature of the factor Xa-factor Va binding sites on platelets is still obscure. It is generally known that the activation of prothrombin on phospholipid vesicles requires the presence of negatively charged phospholipids. Recently, Bloom et al. (47) found that the number of factor Va molecules bound per phosphollpid vesicle Increases with increasing mole fraction of phoshatidylserine. Moreover the binding constant of factor Xa for negatively charged phospholipids in the presence of factor Va 1s the same as that observed for factor Xa binding to thrombin-activated platelets (2). Whether or not small amounts of phosphatidylserine are involved in factor Va-factor Xa binding sites at the surface of thrombin-stimulated and control platelets remains uncertain. The present results with phospholipase $A_{2}$ treatment on non-actiwated platelets show too little phospholipid hydrolysis to exclude the possibility that a minor fraction of the phosphatidylserine 18 present at the membrane exterior. Perret et al. (17) found $9( \pm 12) \%$ hydrolysis of the phosphatidylserine in the plasma membrane after treatment of intact platelets with a mixture of phosphollpase $A_{2}$ and sphingomyelinase. We observed $4.4( \pm 5) \%$ breakdown of the phosphatidylserine when thrombin-activated platelets were treated with phospholipase $A_{2}$. No detectable phosphat1dylserine can, however, be labelled by treatment with trinterobenzenesulfonic acid of elther control or thrombin-treated platelets (21). Kane et al. (26) do not exclude the possibility that indeed some specialized phosphollpid structures are required for the binding sites. However, the finding of a patient deficlent in these binding sites suggests that some protein component might be involved as well, also since no abnormalities in these patients' platelet phospholipid composition have been found $(27,28)$. Since it has been observed in different laboratories $(5,16,17,21)$ that considerable anounts of phosphatidylgerine are present on the cytoplasmic surface of the platelet plasma membrane, it w11 be clear that lysed platelets provide an excellent surface for the formation of the prothrombinase complex. This indeed appears to be the case as shown by the 
fact that completely lysed platelets exhibit a much higher prothrombin-conuerting activity than intact platelets. Therefore, it is lmportant to know whether platelet activation is accompanted by lysis of the cells. Some leakage of lactate dehydrogenase, often considered as a marker for platelet lysis, is observed during platelet activation which is in agreement with the findings of Jolst et al. (48). This may indicate actual cell damage, but may also reflect leakage of lactate dehydrogenase as a result of the fuston process caustng the platelet release reaction. Transient leakage of enclosed components during fuston of phosphollpld vesicles has been denonstrated by wilschut et a1. (49). In as far as liberation of lactate dehydrogenase would 1 ndeed represent cell membrane damage, we cannot exclude the posslbility that a minute amount of broken cells, whlch may be present in the platelet population, participates in the prothrombia-converting activity of platelets. Activation of platelets by a mixture of collagen and thrombin results in a much higher prothrombin-converting activity compared to platelets which are activated by thrombin or collagen alone. When thrombin formation is measured immediately after platelet activation by collagen plus thrombin in the presence of an excess of exogenous factor Va a minimal lag time of $3 \mathrm{~min} 1 \mathrm{~s}$ observed before thrombin formation reaches a steady-state rate. This lag perlod can be interpreted as the time required to generate the extra sites for the prothrombinase complex In addition to those already present with non-activated or thrombin-activated platelets. In the latter two cases, no lag time in thrombin formation was observed (unpublished observation), suggesting that a limited number of binding sites are already present at the platelet outer surface. Data from phospholipase treatment of platelets activated with collagen plus thrombin reveal that approximate1y $25 \%$ of the phosphatidylsexine has become exposed at the platelet outer surface. In analogy to the observation with negatively charged phospho11pid vestcles, Increased exposure of phosphatidylserine may create additional binding sites for the components of the prothromblnase complex, resulting in a higher rate of thrombin formation when platelets are activated by a mixture of collagen and thrombin. It is tempting to speculate that during activation by the combined action of collagen plus thrombin, phospholipids (and in particular phosphatidylsertne) are transferred from the inner to the outer monolayer of the platelet membrane. Such a transbllayer movement of phospholipids, also referred to as 'fllp-flop' was demonstrated to be an extremely slow process In 1ipid vesicles, composed of phosphatidylchollne only (50). More recently, however, evidence has become avallable for the existence of rapid flip-flop of phospholipid molecules both in artificial and natural membranes (for a review 
see (51)). Different mechanisms have been proposed to explatn the transbilayer movement of phospholipids. One possibility concerns the formation of intrabilayer inverted lipid micelles as shown by cullis and de kruiffe (51-52). These structures, the formation of which is affected by $\mathrm{Ca}^{2+}$, are suggested to play a role in endocytosis and exocytosis and may therefore also occur during the platelet release reaction. It should be emphasized, however, that no significant amounts of phosphatidylserine are exposed as a result of platelet activation by thrombin alone, although extensive secretion of granular components occurs. Alternative mechanisms for flip-flop have been proposed some of wich include the involvement of membrane proteins (53). Whether one or more of the platelet membrane proteins are able to induce transbilayer movement of phospholipids, after platelet stimulation by the combined action of collagen and thrombin, is part of our current research. An alternative explanation for the exposure of phosphatidylserine is that these negatively charged phospholipids are already present in considerable quantitles, but shielded by proteins in such a way that they are netther avallable for phospholipases nor for coagulation factors. From the present data it is difflcult to refute this possibility. However, in unstimulated platelets approx. 50\% of the pllasma membrane phospholipids can be hydrolyzed ithout cell lysis by the combined action of phospholipase $A_{2}$ and sphingomyelinase, but no signiflcant degradation of phosphatidylserine or phosphatidylinositol occurs. Assuming and equal distribution of phosphollpids aver both halves of the membrane 1 t may be concluded that the negatively charged phospholipids of the platelet plasma membrane are predominantly confined to the cytoplasmic surface of unstimulated platelets. Also, with erythrocytes it has been established by a variety of methods that phosphatidylserine is localized only at the membrane interior. Therefore, we favour the possiblitty that rapld transbilayer movement of phospholipids occurs when platelets are activated by a combination of collagen and thrombin.

In conclusion, platelets can contribute two components to the prothrombinase complex: factor Va and binding sites for the components of the prothrombinase complex. The way in which factor $V$ becomes avallable 1s clear from the 1iterature $(22,24,54,55)$. It appears as a result of the release reaction and small amounts of thrombin can convert $1 t$ to factor Va. Once factor Va 1 is formed it can create a few hundred binding sites for factor Xa on the platelet surface and appreciable thrambin formation can occur (24). Whether or not minor amounts of phosphatidylserine particlpate in the platelet receptor for factor-Va-factor-Xa is not clear at present. However, when collagen Ls also 
present, additlonal binding stees for the components of the prothrombinase complex appear, due to an increased exposure of phosphatidylserine at the platelet outer surface. As a result 4 creased amounts of facror-Va-factor-Xa as well a prothrombin can bind to the platelet surface leading to enhanced thrombln formation. Th1s may represent an 1 mportant physiological mechanism in hemostasis, particularly when the vessel wall is ruptured and collagen becomes exposed to circulating platelets.

\section{REFERENCES}

1. Zwaal, R.F.A. (1978) Blochim.Blophys.Acta 515, 163-205

2. Neshetm, M.E., Taswe11, J.B. Mann, K.G. (1979) J.Blol.Chem. 254, 10952-10962.

3. Rosing, J., Tans, G., Govers-Riemslag, J.W.P., Zwaal, R.F.A. \& Hemker, H.C. (1980) J.B1o1. Chem. 255, 274-283.

4. van Dieljen, G., Tans, G*, Rosing, J. Henker, H.C. (1981) J.Biol.Chem. $256,3433-3442$.

5. Zwaal, R.F.A., Comfurius, P. \& van Deenen, L.L.M. (1977) Nature (Lond.) $268,358-360$.

6. Papahadjopoulos, D.P., Houg1e, C. Hanahan, D.J. (1962) Proc.Soc.Exp. Blol.Med. $111,412-416$.

7. Papahadjopoulos, D.P. Hananan, D.J. (1964) Blochim.Biophys.Acta 90, 436-439.

8. Barton, P.G. \& Hanahan, D.J. (1969) Biochtm. Biophys.Acta 187, 319-327.

9. Bull, R.K., Jansons, S. Barton, P.G. (1972) J.Blol.Chem. 247, $2747-2754$.

10. Gitel, S.N., Owen, W.G., Esmon, C.T. \& Jackson, C.M. (1973) Proc.Nat1. Acad. Sc1. USA, 70, 1344-1348.

11. Zwaal, R.F.A., Roelofsen, B. \& Colley, C.M. (1973) Biachim.Blophys.Acta 300 , 159-182.

12. Verkley, A.J., Zwaal, R.F.A., Roelofsen, B., Comfurius, P., Kastelijn, D. \& van Deenen, L.L.M. (1973) Bloch1m.Blophys.Acta, 233, 178-193.

13. Gul, S. Smith, A.D. (1974) B10chim.Biophys.Acta, 367, 271-281.

14. Kahlenberg, A., Walker, C. Rohrlich, R. (1974) Can.J.Blochem. 52, 803-806.

15. Zwal, R.F.A., Roelofsen, B., Comfurtus, P. wan Deenen, L.L.M. (1975) Bloch1. Blophys. Acta 406, 83-96.

16. Chap, H.J. Zwaa1, R.F.A. \& van Deenen, L.L.M. (1977) Blochim.Biophys. Acta $467,146-164$.

17. Perret, B., Chap, H.J. \& Douste-Blazy, L. (1979) Blochim.B1ophys.Acta, $556,434-446$.

18. Bretscher, M.S. (1972) Nat. New Blol. 236, 11-12.

19. Whiteley, N.M. Berg, H.C. (1974) J.Mol.B1ol. 87, 541-561.

20. Gordesk1, S.E., Marinett1, G.V. \& Love, R. (1975) J.Membr.Blol. 20, $111-132$.

21. Schick, P.K., Kurlca, K.B. Chacko, G.K. (1976) J.C11n.Invest. 57, 1221-1226.

22. M1let1ch, J.P., Jackson, C.M. \& Majerus, P.W. (1977) Proc.Nat1.Acad. Sc1. USA, 74, 4033-4036.

23. Miletich, J.P. \& Majerus, P.W. (1978) J.Cl1n.Invest. 62, 824-831. 
24. Miletich, J.P. Jackson, C.M. Majerus, P.W. (1978) J.B101.Cher. 253, 6908-6916.

25. Dahlbäck, B. \& Stenflo, J. (1980) Eur.J.Blochem. 107, 331-335.

26. Kane, W.H., Lindhout, M.J., Jackson, C.M. \& Majerus, P.H. (1980) J.Blo1. Chem. $255,1170-1174$.

27. Miletich, J.P., Kane, W.H., Hofmann, S.L., Stanford, N. \& Majerus, P.W. (1979) Blood, 45, 1015-1022.

28. Weiss, H.J., Vicic, W.J., Lages, B.A. \& Rogers, J. (1979) Aim.J.Med. 67, 206-213.

29. Thlagarajan, P., Shapiro, S.S. \& De Marco, L. (1980) J.Glin.Invest. 66, 397.

30. Schiffman, S., Theodor, I. \& Rapaport, S.I. (1969) Blochenistry, 8, $1397-1405$.

31. Owen, W.G., Esmon, C.T. \& Jackson, C.M. (1974) J.Biol. Chen. 249, 594-605.

32. Fujikawa, K., Legaz, M.E. \& Davie, E.W. (1972) Blochemistry, 11 , 4892-4899.

33. Smith, R.I. (1973) J.Biol.Chem. 248, $2418-2423$.

34. Esmon, C.T. (1979) J.Btol. Chem. 254, 964-973.

35. Kappeler, R. (1955) Z.K1 in.Med. 153, 103-113.

36. Nesheim, M.E., Myrmel, K.H., Hibbard, L. \& Mann, K.G. (1979) J.BAol.Chem. $254,508-517$.

37. Chase, T., Jr. \& Shaw, E. (1969) Blachemistry, 8, 2212-2224.

38. Wroblewski, F. La Due, J.S. (1955) Proc.Soc.Exp.Biol.Med.90, $210-215$.

39. Bligh, E.G. \& Dyer, H.J. (1959). Can.J.Blochem.Physiol, 37, 911-917.

40. Zwaal, R.F.A., Rosing, J., Tans, G., Bevers, E.M. \& Henker, H.C. (1980) in The Regulation of Coagulation (Mann, K.G. \& Taylor, F.B. eds.) p. 95, Elsevier, North Holland.

41. Samuelson, B., Granström, E., Green, K., Hamberg, M. \& Hammarström, S. (1975) Annu.Rev. Blochem. 44, 669-695.

42. Bel1, R.L., Kennerly, D.A., Stanford, N. \& Majerus, P.W. (1979) Proc. Nat1. Acad.Sci. USA, 76, 3238-3241.

43. Rittenhouse-Simmons, S. (1979) J.C11n. Invest. 63, 580-587.

44. Mauco, G., Chap, H., Simon, M.F. \& Douste-Blazy, L. (1978) Blochimle (Paris) 60, 653-661.

45. Lloyd, J.V. \& Mustard, J.F. (1974) Br.J.Haenato1. 26, 243-253.

46. Nathan, I., Fleisher, G., LIwne, A., Dvilansky, A. \& Parola, A.H. (1979) J.Biol. Chem. 254, 9822-9828.

47. Bloom, J.W., Nesheim, M.E. \& Mann, K.G. (1979) Biochemistry, 18, $4419-4425$.

48. Joist, J.H., Dolleze1, G., Lloyd, J.V., Kinlough-Rathbone, R.L. \& Mustard, J.F. (1974) J.Lab.Clin.Med. 84, 474-482.

49. Wilschut, J. \& Papahad jopoulos, D. (1979) Nature (Lond) $281,690-692$.

50. Kornberg, R.D* McConnel, H.M. (1971) Proc.Nat1.Acad.Sc1. USA, 68, 2564-2568.

51. Cullis, P.R. \& de Krulffe, B. (1979) Blochim.Btophys.Acta 559, 399-420.

52. Cullis, P.R. \& de Krulfff, B. (1978) Blochim.Blophys.Acta 507, 207-218.

53. van Zoelen, E.J.J., de Krulfff \& van Deenen, L.L.M. (1978) BLochim. Blophys. Acta, 508, 97-108.

54. Dsterud, B., Rapaport, S.I. \& Lavine, K.K. (1977) Blood, 49, 819-834.

55. Dahlbäck, B.\& Stenflo, J. (1978) Blochemlstry, 17, 4938-4945. 
THE ROLE OF ACTIVATED HUMAN PLATELETS IN PROTHROMBIN AND FACTOR X ACTIVALTON

\author{
SUMMARY
}

The role of activated human platelets in intrinsic factor $X$ activation was compared with their effect in prothrombin activation. Compared with unstimulated platelets, platelets triggered by the comblned action of collagen plus thrombin showed a lo-fold activity increase in prothrombin activation, and a 20-fold rate enhancement in factor $X$ activation. Treatment of collagen plus thrombin stimulated platelets with $\mathrm{N}$.naja phosphollpase $\mathrm{A}_{2}$ almost completely abolished their activity in prothrombin and factor $X$ activation. Since no significant cell lysis occurs during phosphollpase treatment, this indicates that platelet phospholipids, exposed at the membrane exterior, play an essential role in the interaction of platelets with the proteins of the prom thrombin and factor $X$ activating complexes.

The time course of generation of the procoagulant platelet surface was different when the amount of coagulation factors present in the assay systems was varied. At suboptimal concentrations of coagulation factors maximum platelet activity was reached after a shorter time perlod than at saturating concentrations. When neasured at suboptimal anounts of coagulation factors the platelet activity in prothrombin and factor $X$ activation is also more sensitive to phospholipase treatment. Experiments with synthetic phospholipld mixtures show that prothrombin and factor $X$ activation are optimal at low mole $\%$ phosphatidylserine when high concentrations of factor Va and factor VIIIa are employed. The optimal mole \% phosphatidylserine increases when the concentrations of non-enzymatic proteln cofactors is lowered. These findings are discussed in relation to a model in which phosphatidylserine, exposed at the outer surface of activated platelets plays an essential role in prothrombin and factor $X$ activation. It is proposed that this phosphatidylserine 1 s not homogeneously distributed in the platelet outer membrane, but that areas with different phosphatidylser $\mathbb{1}$ ne density particlpate in coagulation factor activation.

\title{
INTRODUCTION
}

The interaction between blood platelets and coagulation factors is essential for haemostatic plug formation. Activated platelets promote the catalysis of two sequential reactions of the blood coagulation cascade: the activation of factor $X$ into factor $X a$ by a complex of factor IXa, factor VIIIa and ca ${ }^{2+}$ and the conversion of prothrombin 1 nto thrombin by a complex of factor Xa, Factor $\mathrm{Va}$ and $\mathrm{Ca}^{2+}(1,2)$.

Detalled information is avallable on the interactions of protelns of the 
prothromblnase complex wh the platelet membrane. Unstimulated bovine and human platelets reversibly bind factor va with high affinty $(3,4)$. Platelet bound factor Va, elther derived from added factor Va or released from platelet upon actuation with thrombin, is required for high affinity factor Xa blading (5-8). Kinetic experiments suggest that the platelet bound factor Xa-factor Va complex particlpates in prothrombin activation.

The nature of the components that comprise the binding site for factor va and factor $X a$ on the platelet membrane 18 not yet defined. Simlarities between the effects of platelets and negatively charged synthetic phospholipid vealcies in prothrombin activation led to the assumption that negatively charged phospholiplds might also be involved in the assembly of the prothrombinase complex at the platelet membrane. Negatively charged (procoagulant) phospholipids are, however virtually absent from the outer surface of unstimulated platelets. They are almost exclusively lacated at the inner surface of the platelet plasma membrane and in intracellular membranes (9-12). This explains why intact unstimulated platelets show little procoagulant activity compared with lysed platelets. However, when platelets are stimulated by the combined action of collagen and thrombin, about $25 \%$ of the platelet phosphatidylserine molecules become exposed at the platelet outer surface, presumably by a mechanfsm Involving transb1layer movement of phosphatidylserine $(13,14)$. This process is accompanied by an increase of activity of platelets in prothrombin activation.

Since negatively charged phospholipids have simllar effects in factor $X$ and prothrombin activation $(15,16)$, it could be anticipated that the appearance of phosphatidylserine at the platelet outer surface would stimulate both activit1es. In the present study we compared the effect of platelets, stimulated with vartous activators, in prothrombin and factor $X$ activation. We report here that those platelet activators that increase the activity of platelets in prothrombin activation also increase the capacity of platelets to enhance Intrinsic factor $X$ actlvation. The data support the concept that the exposure of phosphatidylserine at the outer surface of platelets is essential to obtaln an optimal activity of platelets in prothrombin and factor X activation. 
Materials. S2238 H-D-Phenylanalyl-L-pipecoly1-L-arganine-p-nitcoanilide hydrochloride and $\$ 2337$ W-benzay1-L-isoleucyl-L-glutamy -( -plper1dy1)-glycyl-L-arginine-p-nitroanllide hydrochloride were purchased fron $A B$ Kabi Diagnostica, Stockholm, Sweden. p-NPGB (p-nitrophenyl-p'-guanidinobenzoate hydrochloride) was from Nutritional Blochemicals. DEAE-Sephadex A-50, QAE-Sephadex A-50 and Sephadex G-100 and G-200 were products of Pharmacia. Factor VIII defictent: plasma was from George King Blomedical, Overland, KS, USA. Echis carinatus, Russell's viper, soy bean trypsin inhibitor (STI) and fat-free human serum albumin were from Sigma. Naja naja venom was from Koch Light. Reaction tubes were $2 \mathrm{ml}$ plastic flatbottom tubes obtained from sterilin Ltd. Teddington Middlesex England. Teflon coated magnetic spinning bars, $7 \times 2$ m were purchased from Bel-Art Products USA. Phosphatidylinositol and sphingongelin were purchased from Koch Light. Phosphatidylcholine $(18: 1 \mathrm{cls} / 18: 1 \mathrm{cls}$ phosphatidylcholine) was from Sigma, USA. $\left[{ }^{14} \mathrm{C}\right]$ serotonln creatine sulfate (58 CA/mol) was obtalned from Amersham Corp. Lactate dehydrogenase reagents were from Boehringer Mannheim, Germany. All reagents used were of the highest grade comercially available.

Phospholipid and phospholipid vesicle preparations. Phosphatidylethanolamine and phosphatidylserine (both $18: 1_{\mathrm{cls}} / 18: 1_{\mathrm{cis}}$ ) were prepared from phosphatidylcholine by enzymatic synthesis by the method of Comfurius and Zwaal (17). Single bllayer vesicle solutions were prepared according to de Kruyff (18) as described earlier (16). Phospholipid concentrations were determined by phosphate analysis according to Böttcher et al. (19). Extraction of total phosphoIipid from platelets was done according to Reed et al. (20). Lipld analysis was carried out as described previously (13).

Proteins. Phospholipase $A_{2}$ was purified from Naja nafa venow according to Zwaal et a1. (21). One IU is defined as that amount of enzyme which degrades 1 $\mu$ Mol of egg phosphatidylcholine per min at $37^{\circ} \mathrm{C}$. In the purified phosphollpase $\mathrm{A}_{2}$, which had a specific activity of $700 \mathrm{IU} / \mathrm{mg}$, no proteolytic activity could be detected (21). The vitamin $K$ dependent factors prothrombln, factor $I X$ and factors $x_{1}$ and $x_{2}$ were purifled from bovine blood according to established procedures (22) as described prevlously $(15,16)$. The factor $X$ activator from Russell's viper venom was purified as described by Schiffmann et a1. (23). The puriflcations of thrombin, factor Xa, factor IXa and factor XIa (contact product) were described earlier $(15,16)$. Bovlne factor $V$ was purtfled according a method similar to that described by Kane et a1. (7) Which 1 s published in de- 
tall (24). Bactor VIIIC was purifled from bovine blood according to the method of Vehar and Davie (25) with slight modifications (26). Factor $V$ and factor VIII were activated with thrombin as described earlier (26). The speciflc clotting activities of the coagulation factors were: $6 \mathrm{U} / \mathrm{mg}$ (prothronbul), $30 \mathrm{U} / \mathrm{mg}$ (factor V), $100 \mathrm{~W} / \mathrm{mg}$ (factor X), 145 U/mg (Factor IX) and 324 U/mg (factor VII). One clotting unit is defined as the amount of coagulation factor present in 1 ml normal bovine plasma. Thrombin had a specific activity of 2360 NIH units/mg ( $1 \mathrm{nM}$ thrombin is 0.085 NIH units/ml). Factor $V$ was stored at $-70{ }^{\circ} \mathrm{C}$ in $50 \mathrm{mM}$ Tris, $175 \mathrm{mM} \mathrm{NaCl}$ and $10 \mathrm{mM} \mathrm{CaCl} 2$ (pH 7.9) and factor VIII in $10 \mathrm{mM}$ Mes (morpholl no ethanesulfonic acid), $175 \mathrm{mM}$ NaCl and 10 m M $\mathrm{CaCl}_{2}$ adjusted to $\mathrm{pH} 6.5$ wth $1 \mathrm{M}$ Trls. The other protein preparations were stored at $-70^{\circ} \mathrm{C}$ after dialysis agatnst $50 \mathrm{mM}$ Tris-HCl, $175 \mathrm{mM} \mathrm{NaCl}$ at pH 7.9. Before storage at $-70^{\circ} \mathrm{C}$, prothrombin and the factor $x_{1}, x_{2}$ and IX preparations were passed through a column of STI-agarose $(0.5 \times 10 \mathrm{~cm})$ to reduce the small amounts of factor $\mathrm{Xa}$ that might be present in these preparations. No thrombin or factor $\mathrm{Xa}$ could be detected in our protein preparations as determined with the chromogente substrates $\$ 2238$ and $\$ 2337$.

Protein concentrations. Thrombin, factor Xa and factor IXa concentrations were deternined by active site titration with p-NPGB (27-29). Prothrombin concentrations were determined after complete activation with Echls carinatus venom followed by active site titration with $\mathrm{p}-\mathrm{NPGB}$. Simflarly; factor $\mathrm{x}$ concentrations were obtained by active site titration after complete activation of factors $x_{1}$ or $x_{2}$ by $R V V-X$. Factor Va concentrations were determined by kinettc analysis (24). The molar concentration of factor VIIIa was determined by kinetic analysis similar to that employed for factor Va (30).

Isolation of platelets. Human platelets were tsolated by differential centrifugation as described earlier (26). Platelets were kept at room temperature in a calcium free buffer pH 6.7 contalning $136 \mathrm{mM} \mathrm{NaCl}, 2.68 \mathrm{mM} \mathrm{KCl}, 2 \mathrm{mM} \mathrm{MgCl}_{2}$, $10 \mathrm{mM}$ Hepes, $5 \mathrm{mM}$ glucose and $0.05 \%$ fatty acid free human serum albumin, condtions at which no loss of platelet activity was found for at least 15 hours. Platelet concentratlons were determined with a Coulter counter. Bovine platelets were Isolated according the same procedure.

Platelet stlmulation and determination of prothrombin and factor $x$ converting activity. Platelet activity $I n$ prothrombin and factor $X$ activation was measured in 2 mi flatbotton plastic tubes, in which the reaction mixtures were strred at $350 \mathrm{rev} / \mathrm{min}$ wth teflon stirring bars. To a reaction tube contalaing $292.5 \mu 1$ of a platelet suspension $13 \mu 1$ of $75 \mathrm{mM} \mathrm{CaCl}_{2}$ was added. The tube content was warmed and stirred for $5 \mathrm{~min}$ at $37^{\circ} \mathrm{C}$ and platelet activation 
was started by addition of a platelet stimulator resulting in a final volume of $325 \mu \mathrm{l}$ and a $\mathrm{CaCl}_{2}$ concentration of $3 \mathrm{mM}$. After a variable time period at $37^{\circ} \mathrm{C}$ and stirring, referred to as platelet activation time, the components for either prothrombin activation or for factor $X$ activation were added, to determine the effect of platelets on the rates of thrombin or factor Xa formation. Assay of platelet activity in prothrombin activation. Two minutes befora measuring the effect of platelets in prothrombin activation, $25 \mu 1$ factor Va and 25 factor Xa were added to the platelet suspenston to allow equ111bration with the platelets. Prothrombin activation was started by adding 125 H1 of a prewarmed mixture containing prothrombin in $50 \mathrm{mM}$ Tris-HCl, $175 \mathrm{mM}$ $\mathrm{NaCl}, 14.2 \mathrm{mM} \mathrm{CaCl}$, and $0.5 \mathrm{mg} / \mathrm{ml}$ human serum albumin at $\mathrm{pH} 7.9$. The final reaction mixture $(500 \mu 1)$ contalned: $20 \mathrm{mM}$ Tris, $6 \mathrm{mM}$ Hepes, $150 \mathrm{mM} \mathrm{NaCl}, 1.6$ mM KCl; $2.9 \mathrm{mM}$ glucose, $1.2 \mathrm{mM} \mathrm{MgCl}, 6 \mathrm{mM} \mathrm{CaCl}, 0.5 \mathrm{mg} / \mathrm{ml}$ human serum albumin at $\mathrm{pH} 7.9$ and amounts of platelets, factor Xa, factor indicated in the legends of the tables and figures. 15 and 30 seconds after Initiating prothrombin activation aliquots (usually 5 or 10 H) were taken from the reaction mixture and transferred to cuvettes to determine the amount of thrombin formed. The cuvettes (thermastated at $37^{\circ} \mathrm{C}$ ) contalined a buffer of $50 \mathrm{mM} \mathrm{Tris}-\mathrm{HCl}, 175 \mathrm{mM} \mathrm{NaCl}, 0.5 \mathrm{mg} / \mathrm{ml}$ ovalbumin and $20 \mathrm{mM}$ EDTA at pH 7.9 in such amounts that the final volume was $2 \mathrm{~m} 1 ; 335 \mu \mathrm{M}$ of the thrombin specific chromogenic substrate $\$ 2238$ was also present. Further activation of prothrombin is prevented by dilution and the presence of EDTA. The absorbance change recorded at 405 minus $500 \mathrm{~nm}$ on an Aminco 0 W2 spectrophotoneter (set in the dual wavelength mode) is a measure of the amount of thrombin present in the allquots. From a calibration curve made with known amounts of active site titrated thrombin, deternined under the same conditions as described above, the amount of thrombin present in the reaction mixture $1 \mathrm{~s}$ calculated. Under the conditions used, the formation of thrombin th the reaction mixtures was linear in time, and the rate of thrombin formation was calculated from the amount of thrombin present after 15 and 30 seconds.

Assay of platelet activity in factor $X$ activation. Forty five seconds before measuring the effect of platelets in factor $X$ activation 25 fl factor IXa and $33.4 \mu 1 \mathrm{CaCl}_{2}(60.6 \mathrm{mM})$ were added to the platelet suspension. Factor $X$ act $1-$ vation was started with $16.6 \mu 1$ factor $X_{2}$ and $100 \mu 1$ activated factor VIII. The final reaction mixture (500 pl) had the same composition as described above for prothrombin activation and contalned amounts of platelets, factor IXa, factor VIIIa and factor $X$ indicated in the legends of the tables and figures. 45 and 90 seconds after initiating factor $X$ activation allquots from 
the reaction nixcure were trangferred to cuvettea to deternine the amount of factor Xa formed. The experimental set up to measure factor Xa is essentially the ame as degribed for the measurement of thrombin formation, with the exception that the absorbance change at 405 minus $500 \mathrm{~nm}$ was measured using the factor Xa speciflc chromogenlc substrate $\$ 2337$ (final concentration $192 \mu M$ ). Factor Xa formation is linear in time after a lag period of about 15 seconds after starting the reaction. Therefore the interval between 45 and 90 seconds after Inttating factor $X$ activation was used to calculate the rate of factor Xa formation. Control experiments were carried out to check whether the concentration of factor $X_{a}$ is adequately measured in the presence of activated platelets or artificlal phospholipld vesicles. A known amount of factor Xa was added to artificlal phospholipid vestcles plus $\mathrm{Ca}^{2+}$ or to platelets that were subsequently activated with thrombin plus collagen. All added factor Xa is recovered in the chromogentc assay described above, which indicates that the binding of factor Xa to platelets and phosphollplds is either reversible (EDTA Is present in the assay system) or does not interfere with the chromogenic assay.

Stimulation of platelets by collagen. The collagen used in most of the experiments presented in this paper, was horse tendon collagen obtained from Hormon Chemle, Mitinchen, Germany. Also collagen prepared from bovine achilles tendon obtalned from Sigma and Merck, Germany as well as highly purifled (type I) collagen from calfskln (a gift from Prof. J. Caen) were employed in these studies. Collagens were added in the non-fibrillar form dissolved in acidic dilution buffer obtained from Hormon Chemie.

Platelet aggregation. Platelet aggregation studies were carried out in a lum-aggregometer from Chronolog Corporation. Platelets suspended in a Hepes buffer at pH 7.5 (see above) were brought in a cylindrical sillconlzed glass cuvette in a volume of $614 \mu 1$ and stirred with a teflon coated spinning bar. This cuvette was placed in the aggregometer thermostated at $37^{\circ} \mathrm{C}$ and $26 \mu 1$ of a $75 \mathrm{mM} \mathrm{CaCl}_{2}$ solution was added. The platelets were prewarmed for 5 intin and atirred. Then $10 \mu 1$ platelet stimulator was added and the aggregation pattern was recorded.

Measurement of serotonin release and leakage of lactate dehydrogenase. The conditions for platelet stimulation are the same as described by the determination of platelet prothrombin and factor $X$ converting activity. Release of $\left[{ }^{14} \mathrm{C}\right]$ serotonin was determined in the platelet supernatant after centrifugation at $7000 \mathrm{x} g$ for $2 \mathrm{~min}$. In an Eppendorf microfuge. Leakage of lactate dehydrogenase was measured as described earlier (13). 
Activity of stimulated platelets in prothrombin and factor $X$ activation. In a previous paper we have shown that activation of platelets with thrombin plus collagen resulted in the formation of a procoagulant surface highly active in prothrombin activation (13). It was proposed that the exposure of the negatively charged phospholipld phosphatidylsertne at the outer surface of the platelets, which accompanied the generation of the procoagulant surface, is essentlal for the observed increase of platelet activity in prothrombin activation. In order to compare the activity of platelets in prothrombin and intrinsic factor $X$ activation, assay systems were developed in which rates of thrombin and factor Xa formation were proportional with the amount of procoagulant phospholipid present. At high concentrations of coagulation factors this condition was satisfied. F1g.lA shows that with 15 nM factor Xa, $30 \mathrm{nM}$ factor Va and $4 \mu \mathrm{M}$ prothrombin present in a reaction mlxture, rates of prothrombin activation are proportional with the amount of procoagulant phospho11 pld when a platelet 1ysate, a platelet lipid extract or synthetic vestcles, containing 2.5 or 40 mole \% phosphatidylserine, are used as a phospholipld source. At phospholipld concentrations below $2.5 \mu \mathrm{M}$ rates of prothrombln activation are linear with the amount of phospholipid present. A further Increase of the concentration of coagulation factors had no effect on the rate of thrombin formation, which indicates that all avallable sites on the phospholipid surface partlcipate in prothrombin activation. For intrinsic factor $X$ activation saturation with coagulation factors and a linear relation between rates of factor Xa formation and the phospholipid concentration was obtained at $150 \mathrm{nM}$ factor IXa, $15 \mathrm{nM}$ factor VIIIa and $0.5 \mu \mathrm{M}$ factor X. Due to a 11mited supply of factor VIII It was not posslble to regularly use the saturating factor VIIa concentrations. We succeeded, however, in selecting coagulation factor concentrations at which rates of factor $X$ activation, though not saturated with respect to factor VIIIa, are st111 proportional with the amount of phospholipid present (FIg.1B).

Table I shows the effect of human platelets, stimulated with various platelet activators, in prothrombin and factor $X$ actluation. Human platelets $\left(5 \times 10^{6}\right.$ platelets $/ \mathrm{ml})$, stimulated for $15 \mathrm{~min}$ with optimal concentrations of different platelet activators, were used as a source of phospholipid in the assay systems described above. In this experiment factor $X$ activation is measured at saturating factor VIIIa concentration (15 nM). Release of serotonin and platelet aggregation was determined in a separate experiment. Platelets stimulated 

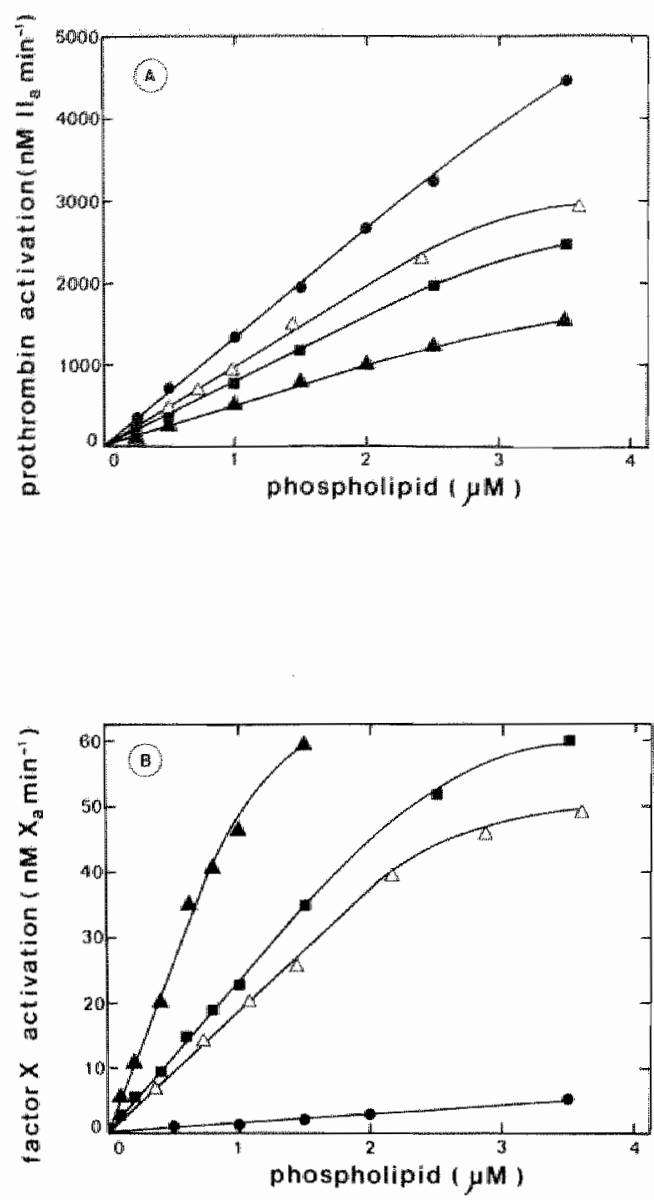

P1g. 1A,B. Effect of the concentration of procoagulant phospholipids on the rate of prothrombin (A) and factor $X$ activation ( $B)$.

The concentrations of phospholipid given are the final concentrations present in the assay systems for prothrombin and factor $X$ activation. (-) vestcles composed of (mole\%) $2.5 \%$ phosphatidylserine, $4 \%$ phosphatidylinositol, $47.5 \%$ phosphatidylchollne, $28 \%$ phosphatidylethanolamine, $18 \%$ sphingomyelin and cholesterol in a $1: 1$ molar ratio to total phospholipld; (A-A) vesicles composed of $40 \%$ phosphatidylserine, $4 \%$ phosphatidylinositol, $10 \%$ phosphatidylcholine, 28\% phosphatidylethanolamine, $18 \%$ sphingomyelin and cholesterol in a l:l molar ratio to total phospholipid; ( $\mathbf{0}-\mathbf{0})$ vestcles made from a total phosphollpid extract from platelets; $(\Delta-\Delta)$ sonlcated platelets. Prothrombin activation was measured at $4 \mu \mathrm{M}$ prothrambin, $15 \mathrm{nM}$ factor $X a$ and 30 nM factor $V a$ and factor $X$ activation at $0.5 \mu \mathrm{M}$ factor $\mathrm{X}, 50 \mathrm{nM}$ factor IXa and $0.1 \mathrm{nM}$ factor vifla. The total lipid extract from platelets had the following phosphoI1pid composition $11 \%$ phosphatidylserine, $4 \%$ phosphatidylinositol, $39 \%$ phosphatidylcholine, $28 \%$ phosphat 1 dylethanolamine, $\quad 18 \%$ sphingomyelin and cholesterol in a $1: 1$ molar ratio to phospholipid. Lipld extraction from platelets, 11pid analysis and the assay systems for prothrombin and factor $X$ activation are described in the experimental procedures.

by the combined action of $10 \mu \mathrm{g} / \mathrm{ml}$ collagen and $1.3 \mathrm{nM}$ thrombin exhibited a 10-fold activity increase $\mathbb{1 n}$ prothrombin activation and were 20 times more active in factor $X$ activation than unstimulated platelets. Platelets stimulated only with thrombin show little rise in activity, but platelet stimulation wth collagen alone resulted in activities that were approximately $30 \%$ of that observed with platelets stimulated by collagen plus thrombin. In a recent paper Bevers et al. (14) have shown that there is a 11mited exposure of phosphatidylserlne when platelets are stimulated with collagen alone. Although the standard deviation for the determination of the amount of phosphatidylserine exposed was relatively high, it is possible that it accounts for the procoa- 
Table I. Effect of platelets in prothrombin and intrinsic factor $x$ activation. A comparison with platelet aggregation and serotonin release.

Human platelets at a concentration of $5 \times 10^{6} / \mathrm{ml}$ were stimulated for $15 \mathrm{~m} / \mathrm{n}$ with $1.3 \mathrm{nM}$ thrombin and/or $10 \mu \mathrm{g} / \mathrm{m}$ collagen. In the experiment in which phospholipase was used platelet stimulation was followed by 15 min incubation with $3 \mathrm{IU} / \mathrm{ml}$ phospholipase $A_{2}$ (Naja naja). Platelet aggregation was measured in a separate experiment at $5 \times 10^{2}$ platelets/m1. Platelet aggregation, serotonin release and rates of prothrombin and factor $X$ activation were determined as described in the experimental procedures.

\begin{tabular}{|c|c|c|c|c|c|c|}
\hline \multirow[t]{2}{*}{ Platelet stimulator } & \multicolumn{2}{|c|}{$\begin{array}{l}\text { Prothrombin } \\
\text { actluation } \\
\text { (nM IIa/min) }\end{array}$} & \multicolumn{2}{|c|}{$\begin{array}{l}\text { Factor } X \\
\text { activation } \\
(\mathrm{nm} \mathrm{Xa} / \mathrm{min})\end{array}$} & Aggregation & $\begin{array}{l}\text { Serotonln } \\
\text { release }\end{array}$ \\
\hline & $\mathrm{Xa}^{\mathrm{a}}$ & $\mathrm{Xa}-\mathrm{Va}$ & $\mathrm{IXa}^{\mathrm{C}}$ & IXa-VIIIad & & \\
\hline None & 0 & 34.4 & $<0.1$ & 2.3 & - & $0 \%$ \\
\hline thrombin & 1.9 & 40.3 & $<0.1$ & 3.1 & + & $72 \%$ \\
\hline collagen & 7.9 & 98.7 & $<0.1$ & 18.6 & + & $60 \%$ \\
\hline $\begin{array}{l}\text { thrombintcollagen } \\
\text { thrombintcollagent }\end{array}$ & 24.5 & 351.5 & $<0.1$ & 47.3 & + & $74 \%$ \\
\hline phospholipase $A_{2}$ & 0.4 & 17.4 & $<0.1$ & 1.1 & n.d & $\mathrm{m} . \mathrm{d}$ \\
\hline
\end{tabular}

a. $0.5 \mathrm{nM}$ factor $X a$, no factor Va, $4 \mu \mathrm{M}$ prothrombin

b. $15 \mathrm{nM}$ factor $\mathrm{Xa}, 30 \mathrm{nM}$ factor $\mathrm{Va}, 4$ MM prothrombin

c. $150 \mathrm{nM}$ factor IXa, no factor VIIla, $0.5 \mu \mathrm{M}$ factor $\mathrm{X}$

d. $150 \mathrm{nM}$ factor IXa, $15 \mathrm{nM}$ factor VIIIa, $0.5 \mu \mathrm{M}$ factor $X$

gulant activity observed for collagen stimulated platelets. However, it can also not be ruled out that activities found with collagen stimulated platelets were in fact the result of a combined action of collagen and small amounts of thrombin present in the assay system. In the prothrombinase assay 2 nM thrombin is formed in less than 5 seconds, while thrombin is also present in the assay system in which factor $X$ activation 1 s measured because the factor VIIla preparation still contalned the small amounts of thrombin that were used for the activation of factor VIII. With other platelet activators (ADP, serotonin, epinephrine either alone or In combination) activities sinilar to unstimulated platelets were observed (data not shown). It is essentlal that platelets are stirred during the activation process. Non-stirred platelets incubated with thrombin plus collagen show no activity increase lit prothrombin and factor $X$ activation. It should be emphasized, that the prothrombin and factor $X$ converting activities mainly reside with the stimulated platelets since les than $10 \%$ of the activity remained in the supernatant after sedimenting the platelets by centrifugation at $7000 \mathrm{xg}$.

A possible explanation for the effect of collagen plus thrombin could be that platelets stimulated with this trigger are subject to increased cell 1ysis. 
This could explain the increaged prothrombin and factor $X$ converting activithes sincs lysed platelets are highly active in prothrombin and factor $X$ activation (see $\mathbf{F} 1 \mathrm{~g} \cdot \mathbb{1 A}, \mathrm{B}$ ). We used leakage of lactate dehydrogenase, a cytoplasmic platelet enzyme, as a marker for cell lysis during platelet activat1on. Approxlmately $1-2 \%$ of the total lactate dehydrogenase present leaks out of platelets that were stimulated wth thrombin or collagen plus thrombin. The rateg of prothrombin and factor $X$ activation for a preparation of $2 \%$ lysed plateleta, elther obtalned by 1:50 dilution of completely lysed platelets or by 11 mited sontcation that 11berated $2 \%$ of the lactate-dehydrogenase present in platelets (cf. ref. 26 ), were $58 \mathrm{nM}$ thrombin/min and $3.8 \mathrm{nM}$ factor Xa/min, respectively. Since this is far below the rates abserved with collagen plus thrombin stimulated platelets we conclude that the increased activity of these platelets is not due to cell lysis.

To atress the 1 mportance of the presence of added non-enzymatic cofactors factor Va and factor VIILa experiments are included fin table I tn which the activity of stimulated platelets in prothrombin and factor $X$ activation is measured in the absence of added factor Va or factor VIIIa. The presence of added factor VIIIa 18 essential to observe activity of collagen plus thrombin stimulated platelets in factor $X$ activation. This indicates that there is no release of factor VIII:C from stimulated platelets. The lack of activity of platelet lysates (up to $10^{7}$ lysed platelets/m1) in factor $X$ activation measured in the absence of factor VIIIa suggests that platelets do not contain detectable amounts of factor VIII:C. The actlvity of thrombin and collagen plus thrombin stimulated platelets in prothrombin activation measured in the absence of added factor $V a$ is presumably enhanced by factor $V$ liberated from the platelets during the release reaction. Also in the absence of added factor Va platelets stimulated with collagen plus thrombin had the highest activity in prothrombin activation.

To cest the proposal that the procoagulant surface af activated platelets has a "phosphollpid-1tke" nature, platelets were first stimulated with collagen

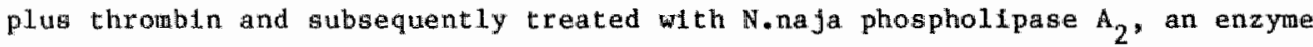
able to degrade phospholipid molecules exposed at the outer platelet surface $(13,31)$. Under these conditlons, both the prothrombin and factor $X$ converting activities were almost completely abolished and activitles were observed that were even below those of unstimulated platelets (Table I). The activity of unstimulated platelets is also drastically lowered upon treatment with phosphollpase $\mathrm{A}_{2}$ (cf.ref.31). The absence of leakage of lactate dehydrogenase from the platelets indicates that the platelet membrame remalns intact during 


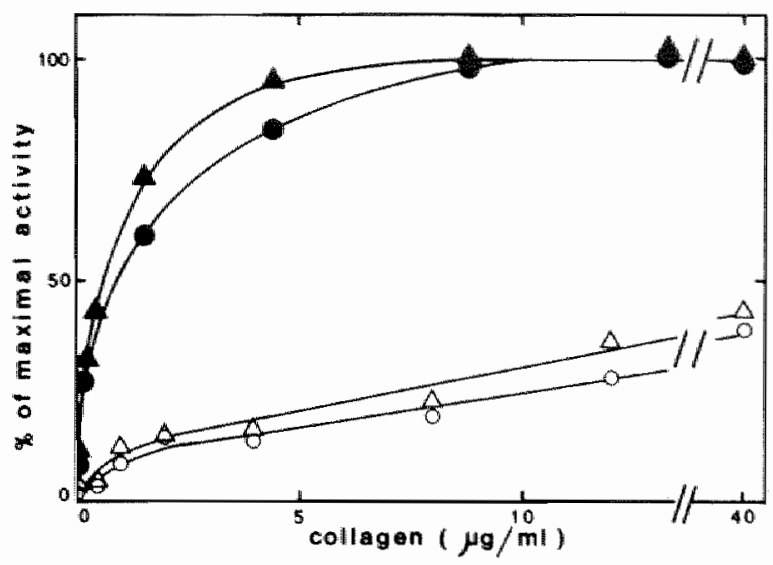

Fig.2. Stimulatory effect of varying amounts of collagen either in the absence or presence of thrombin on the actfvity of platelets in prothrombin and factor $X$ activation. Platelets $(0.9 \times 10 / \mathrm{ml})$ were stimulated for $10 \mathrm{~min}$ with $0-40$ $\mu \mathrm{g} / \mathrm{ml}$ collagen (open symbols) or $5 \mathrm{nM}$ thrombin plus $0-40 \mu \mathrm{m} / \mathrm{ml}$ collagen (closed symbols). Prothrombin $(\Delta-\Delta, \Delta-\Delta)$ and factor $X(0-0,0-0)$ activation were determined as described in the experimental procedures. The concentrations of coagulation factors present in the assay systems were: $4 \mu \mathrm{M}$ prothrombin, $15 \mathrm{nM}$ factor $\mathrm{Xa}$ and $30 \mathrm{nM}$ factor Va (prothrombin actlvation) or $0.5 \mu \mathrm{M}$ factor $\mathrm{X}, 50$ $\mathrm{nM}$ factor IXa and $0.1 \mathrm{nM}$ factor VIIIa (factor X activation). 100\% activity $\mathbb{i n}$ prothrombin activation was $670 \mathrm{nM} I I a / m i n$ and in factor $X$ activation $15.1 \mathrm{nM}$ $\mathrm{Xa} / \mathrm{min}$.

treatment with phospholipase $A_{2}$ * The experiment presented in Table I was also carried out with bovine platelets. The effects of thrombin, collagen and collagen plus thrombin on the prothrombin and factor $X$ converting activities of bovine platelets were the same as on human platelets.

Dependence of platelet activation on the concentration of thrombin, collagen and the source of collagen. The activity of platelets in prothrombln and factor $X$ activation was measured after stlmulation with varlable amounts of collagen either in the absence of thrombin or at constant thrombin concentration ( $5 \mathrm{mM}$ ). As shown in Fig.2 both activities rise parallel when the amount of collagen is increased and reach a maximum at a collagen concentration of $8 \mu \mathrm{g} / \mathrm{ml}$. The collagen used in this experiment was in the nonfibrll1ar form. When collagen was first allowed to form fibrtls at neutral pH and subsequently used for platelet stimulation the same activity in prothrombin and factor $X$ activation was found. The collagen was obtalned from horse tendon (Hormon Chemie). Collagens prepared from bovine achilles tendon (S1gma and Merck) and a highly purifled type I collagen from calfskin are equally active in generating platelet prothrombin and factor $X$ converting activities (data 


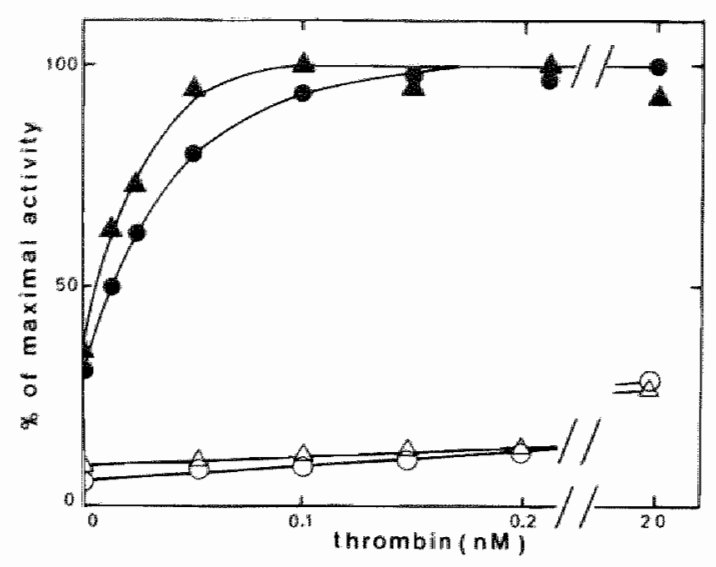

Fig.3. Stimulatory effect of varying thrombin concentrations on the activity of platelets in prothrombin and factor $X$ activation. Platelets $(0.9 \times 10 / \mathrm{m} 1)$ were stimulated for $10 \mathrm{~min}$ with varying concentrations of thrombin in the absence (open symbols) and presence of $4 \mu \mathrm{g} / \mathrm{ml}$ collagen (closed symbols). The concentration of thrombin given in this figure is nM present in the platelet activation mixture ( $1 \mathrm{nM}$ thrombin $1 \mathrm{~s}$ approx. 0.085 NIH units thrombin/mil). Prothrombin $(\Delta-\Delta, \Delta-\Delta)$ and factor $X(0-0,-0)$ activation were determined as described in the experimental procedures. The concentrations of coagulation factors in the assay systems were $4 \mu \mathrm{M}$ prothrombin, $15 \mathrm{nM}$ factor Xa, $30 \mathrm{nM}$ factor Va (prothrombla activation) or $0.5 \mu \mathrm{M}$ factor $\mathrm{X}$, $50 \mathrm{nM}$ factor IXa, 0.1 nM factor VIIIa (factor $X$ activation). 100\% activity in prothrombin activation was $600 \mathrm{nM} \mathrm{IIa/min} \mathrm{and} \mathrm{In} \mathrm{factor} X$ activation $16.6 \mathrm{nM} \mathrm{Xa/min.}$

not shown). The effect of variable thrombin concentrations is shown in Fig. 3 . In the presence of $4 \mu \mathrm{g} / \mathrm{m} 1$ collagen, $0.1 \mathrm{nM}$ thrombin 1 s already sufficient to evoke maximal platelet activity in prothrombin and factor $X$ activation. In the absence of collagen there is a siow rise of both activities when the amount of thrombin is increased. At high thrombin concentrations the platelet activity 1 s stil appreclably lower than that of platelets stimulated by the comblined action of thrombin plus collagen.

The concentrations of thrombin and collagen required to expose the procoagulant surface are simflar to those required to induce platelet aggregation and release. Table II summarizes the concentrations of thrombin or collagen that produce threshold, half-fraximal and maximal effect in platelet aggregation and release. The comblned effect of thrombin plus collagen on these platelet functions is synerglstic. Corblnation of concentrations of collagen and thrombin below the threshold concentrations for the individual components already produce half maximal platelet aggregation and release. 
Table II. Collagen and thrombin requirements for platelet aggregation and release. Plafelets were activated by thrombin and for collagen at a concentration of $5 \times 10^{7}$ platelets/m. and the platelet aggregation and release reaction was measured as described in the experimental procedures.

Aggregation/Release

threshold effect half-maximal effect maximal effect

\begin{tabular}{llll}
\hline thrombin & $0.5 \mathrm{nM}$ & $0.75 \mathrm{nM}$ & $1.2 \mathrm{nM}$ \\
collagen & $1.0 \mu \mathrm{g} / \mathrm{ml}$ & $3.3 \mathrm{\mu g} / \mathrm{ml}$ & $5.0 \mu \mathrm{g} / \mathrm{ml}$ \\
thrombin plus & & $0.4 \mathrm{nM} \mathrm{plus}$ & \\
collagen & & $0.5 \mathrm{\mu g} / \mathrm{ml}$ &
\end{tabular}

Time course of appearance of platelet activity in prothrombin and factor $X$ activation. The generation of a procoagulant surface was followed in time for platelets stimulated with thrombin or with collagen plus thrombin. Since the effect of collagen alone could not be singled out from the combined collagen and thrombin effect (see above), collagen stimulated platelets were not further considered. The activity of platelets in prothrombin activation was measured with different concentrations of factor $X a$ and factor Va present in the prothrombinase assay. The prothrombin activating mixtures contained platelets, $4 \mu \mathrm{M}$ prothrombin and $0.5 \mathrm{nM}$ factor $\mathrm{Xa}$, no added factor $\mathrm{Va}$ (F1g.4A), 0.5 $\mathrm{nM}$ factor $\mathrm{Xa}, \mathbb{1} \mathrm{nM}$ factor $\mathrm{Va}(\mathrm{F} 1 \mathrm{~g} .4 \mathrm{~B})$ or $15 \mathrm{nM}$ factor $\mathrm{Xa}, 30 \mathrm{nM}$ factor Va (Fig.4C). In all assay systems platelets became active upon stimulation with collagen plus thrombin. As expected, the highest activitles were found at saturating factor $X a$ and factor Va concentrations (Fig.4C). Unstimulated platelets exhibited the lawest prothrombin converting activity. Stimulation of platelets with thrombin alone resulted in a slow rise of prothrombin converting activity when added factor Va is present in the prothrombinase assay mixture (Fig. $4 \mathrm{~B}, \mathrm{C})$. When prothrombin activation 1.5 measured in the absence of added factor Va the situation is somewhat different (F1g.4A). Unstimulated platelets are completely inactive in prothrombin activation, presumably due to the virtual absence of both a procoagulant surface and factor Va. Thrombin stimulation of platelets gives rise to an appreciable activity of platelets in prothrombin activation when this is measured in the absence of added factor va and compared with the activity of unstimulated platelets. However, also in the absence of added factor va the highest activity was observed with platelets stimulated by thrombin plus collagen. We propose that in platelet experiments carried out in the presence of a saturating concentration factor va the rate of prothrombin activation 18 determined by the procoagulant surface already 

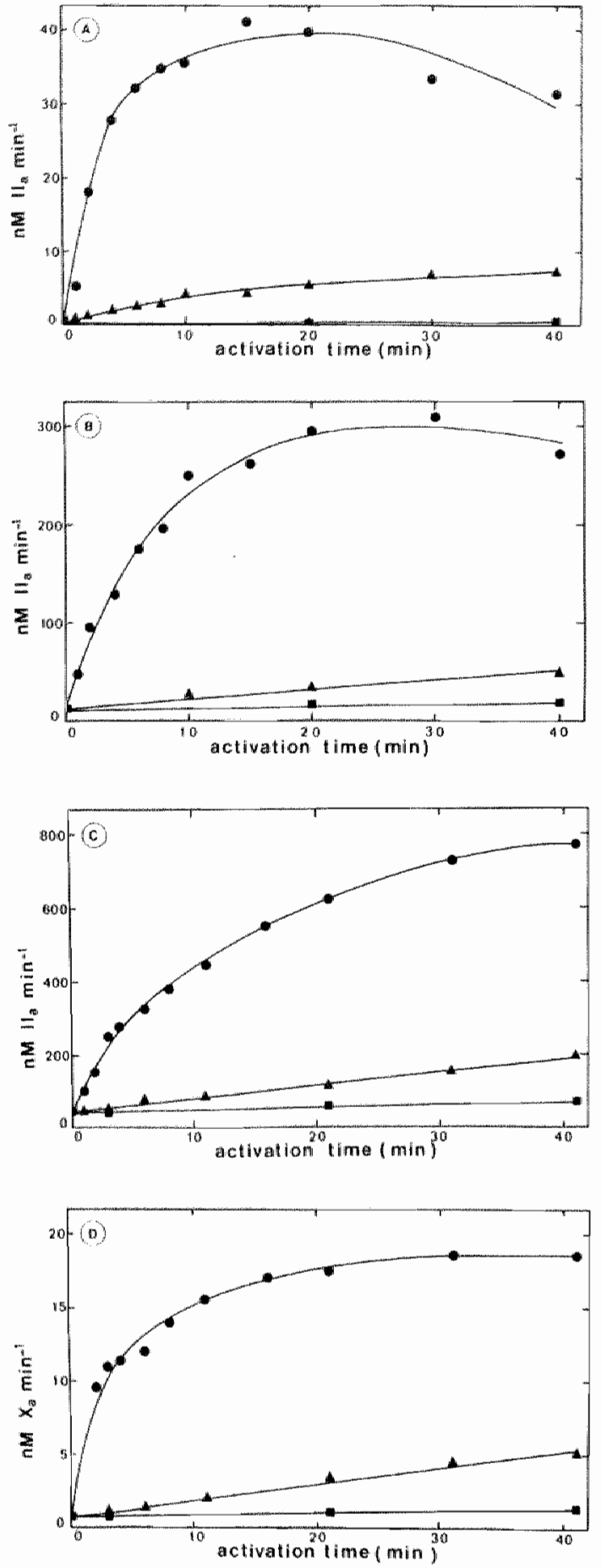

F1g.4A-D. Time course of appearance of platelet activity in prothrombin and factor $X$ activation. The platelet concentration during stimulation was $0.9 \times 10^{7} / \mathrm{ml}$. Platelets were not stimulated (a-D), stimulated with $1.3 \mathrm{nM}$ thrombin $(\boldsymbol{A}-\boldsymbol{\Delta})$ or stimulated with $1.3 \mathrm{mM}$ thrombin plus $10 \mu \mathrm{g} / \mathrm{ml}$ collagen (-) . At different time intervals after stimulation coagulation factors were added and prothrombin $(A, B, C)$ and factor $X$ (D) activation were measured as described in the experimental procedures. The amounts of coagulation factors present in the assay systems were:

(A) $4 \mu \mathrm{M}$ prothrombin. $0.5 \mathrm{nM}$ factor $\mathrm{Xa}$, no factor $\mathrm{Va}$,

(B) $4 \mu \mathrm{M}$ prothrombin, $0.5 \mathrm{nM}$ factor $x_{a}, 1.0 \mathrm{nM}$ factor $\mathrm{Va}$, (C) $4 \mu \mathrm{M}$ prothrombin, $15 \mathrm{nM}$ factor $\mathrm{Xa}, 30 \mathrm{nM}$ factor $\mathrm{Va}$ or (D) $0.5 \mu \mathrm{M}$ factor $\mathrm{X}, 50 \mu \mathrm{nM}$ factor IXa and $0.1 \mathrm{nM}$ factor VIIIa. 
present in case of unstimulated platelets or the procoagulant surface generated in case of platelets stlmulated with thrombin plus collagen In the absence of added factor Va both the presence or appearance of the procoagulant surface and the release of platelet factor Va is probed. We have no explanation for the origin of the procoagulant surface of unstluulated platelets. It is either present on platelets circulating in the blood or exposed upon platelet lysis or platelet activation during venepuncture of the blood or the isolation of the platelets.

one other feature of the time generation curves has to be mentioned here. The appearance of platelet prothrombin converting activity is apparently more rapid when prothrombinase activity is assayed in a system contaling low amounts of factor $\mathrm{Xa}$ and factor Va. Half maximal activities were obtalned after $2 \frac{1}{2} \mathrm{~min}(\mathrm{Fig} .4 \mathrm{~A}), 4 \mathrm{~min}(\mathrm{Fig} .4 \mathrm{~B})$ and $9 \mathrm{~min}(\mathrm{Fig} .4 \mathrm{C})$. Compared with prothrombin converting activity, factor $X$ converting activity appeared even more rapidly when platelets were stimulated by thrombin plus collagen (FIg*4D). Within two minutes after platelet activation half maximal factor $X$ converting activity was observed in an assay system, in which suboptimal factor VIII concentrations were used. Also in factor $X$ activation unstimulated platelets exhibit a constant and low activity and stimulation with thrombin alone results in a slow rise of platelet activity.

The effect of platelet concentration in prothrombin and factor $X$ activation is shown in Fig.5A,B. Collagen plus thrombin stimulated platelets show a linear increase of both activities with the platelet concentration, until rates of thrombin and factor Xa fortation were reached at which clotting factor act1vation in these assay systems is no longer linearly proportional with the amount of phospholipld present (cf. Fig. I). Thrombla stimulated and ungtimulated platelets also show a linear increase of factor $X$ activation when the platelet concentration 1 n the assay system $1 \mathrm{~s}$ increased. For the sllght deviam tion from ilnearity with thrombin stimulated platelets at high platelet concentrations we have no explanation.

Effect of phospholipase $A_{2}$ on the activity of stimulated platelets in prothrombin and factor $X$ activation. The results presented in Table $I$ show that the activity of platelets in prothrombin and factor $x$ activation could be completely abolished by treating the collagen plus thrombin gtimulated platelets with phosphollpase $\mathrm{A}_{2}$. The time course of disappearance of platelet prothrombin and factor $X$ converting activities was followed when platelets stimulated for $30 \mathrm{~min}$ with thrombin plus collagen were subsequently treated with a small amount of phospholipase $A_{2}(0.04 \mathrm{IU} / \mathrm{ml})$. After different time intervals 

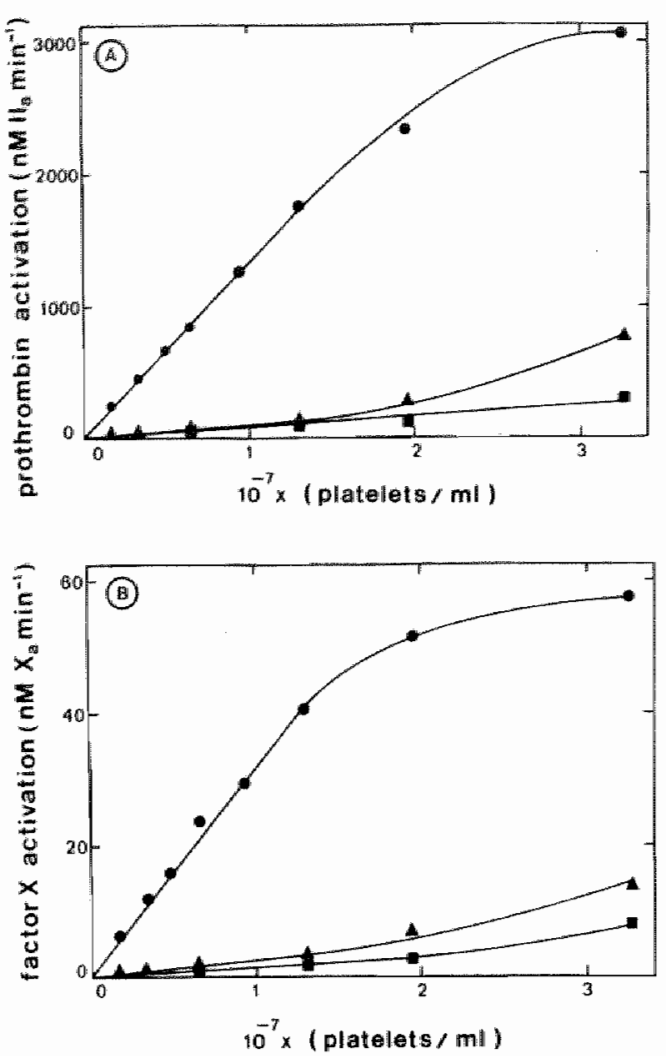

Fig. 5A, B. Effect of the concentration of stimulated platelets on the rates of prothrombin and factor $X$ activation.

Platelet stimulation and the assay systems for prothromin activation (A) and factor $X$ activation (B) are described in the experimental procedures. Platelets were not stimulated (-) , stimulated for $15 \mathrm{~min}$. with $1.3 \mathrm{nM}$ thrombin $(-\Delta)$ or stimulated for 15 min. with 1.3 nM thrombin plus $10 \mu \mathrm{g} / \mathrm{ml}$ collagen $(\boldsymbol{\omega}-\boldsymbol{\theta})$.

Prothrombin activation was measured at $4 \mu \mathrm{M}$ prothrombin, $15 \mathrm{nM}$ factor Xa, $30 \mathrm{nM}$ factor Va $(F i g \cdot 5 A)$. Factor $X$ activathon was measured at $0.5 \mu \mathrm{M}$ factor $X, 50 \mathrm{nM}$ factor IXa and $0.1 \mathrm{nM}$ factor VIIIa (FIg.5B). The amount of platelets indicated in the figure is that present in the final assay mixture.

of phospholipase treatment coagulation factors were added to measure the remalning activity of platelets in prothrombin and factor $X$ activation. Fig.6 shows that the prothrombinase activity of stimulated platelets is more sensitive to phosphollpase treatment when measured in the absence of factor Va than at suboptimal and saturating factor $X a$ and factor Va concentratlons. It seems that part of the prothrombinase activity measured at saturating factor $X a$ and factor Va is less senittive to phospholipase treatment. The prothrombinase activity measured at saturating factor $X a$ and factor Va could, however, be completely abollshed when the stimulated platelets were treated with higher amounts of phospholipase $A_{2}(21 \mathrm{U} / \mathrm{ml})$. F1g.6 also shows that the factor $\mathrm{X}$ converting activity of stimulated platelets measured at suboptimal factor VIIla is highly sensitive to treatment with low amounts of phospholipase $\mathbb{A}_{2}$. The results shown in Fig.6 cannot be due to a detrimental effect of phosphoIIpase $A_{2}$ on the coagulation factors since their activity was not affected by prolonged Incubation with phospholipase. This can actually also be concluded from the experiment itself. For each data point in the figure there is an 


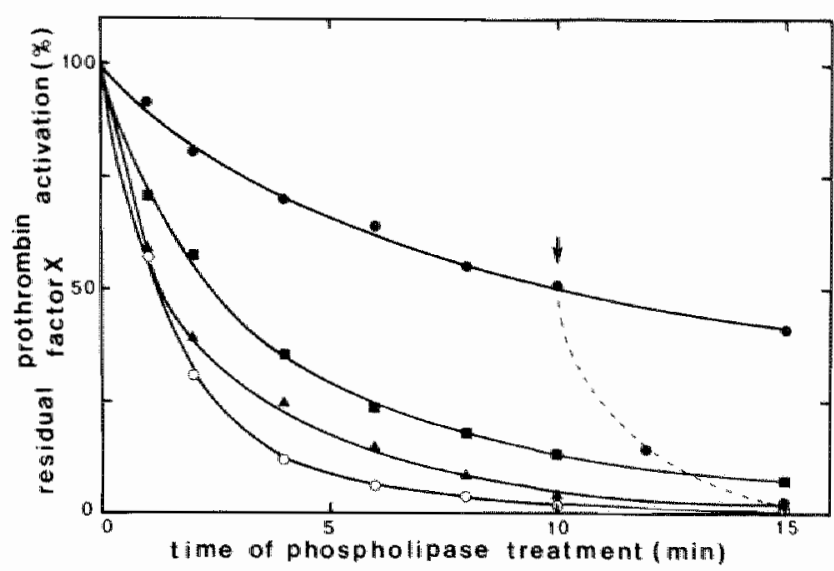

Fig.6. Effect of phosholipase $A_{2}$ on the actlvity of stimulated platelets in prothrombin and factor $X$ activation. Platelets $\left(0.9 \times 10^{7} / \mathrm{ml}\right)$ were stimulated for $30 \mathrm{~min}$ with $1.3 \mathrm{nM}$ thrombin plus $10 \mu \mathrm{g} / \mathrm{ml}$ collagen. Then phosphollpase $\mathrm{A}_{2}$ was added to a final concentration at $0.04 \mathrm{IU} / \mathrm{ml}$. After the time intervals indicated, the remaining activity of platelets $1 \mathrm{n}$ prothrombin and factor $X$ activation was measured as described in the experimental procedures.

Prothrombin activation was determined at: $4 \mu \mathrm{M}$ prothrombin, $0.5 \mathrm{nM}$ factor Xa, no added factor $\mathrm{Va}(\boldsymbol{\Delta}-\boldsymbol{\Lambda}) ; 4 \mu \mathrm{M}$ prothrombin, $0.5 \mathrm{nM}$ factor Xa, $1 \mathrm{nM}$ factor $\mathrm{Va}$ (1-D); $4 \mu \mathrm{M}$ prothrombin, $15 \mathrm{nM}$ factor $\mathrm{Xa}$ and $30 \mathrm{nM}$ factor $\mathrm{Va}(\mathbf{O}-0)$.

Factor $X$ activation was measured at $0.5 \mu \mathrm{M}$ factor $X, 50$ nM factor IXa and 0.1 nM factor VIIIa (O-O). Rates obtained with 30 min stimulated platelets, set at $100 \%$, were respectively $750 \mathrm{nM} I I a / m i n, 423 \mathrm{nM} I \mathrm{Ia} / \mathrm{m} 1 \mathrm{n}, 44.2 \mathrm{nM} \mathrm{ITa} / \mathrm{min}$ and $18.5 \mathrm{nM} \mathrm{Xa} / \mathrm{min}$. When no phosphollpase was added the activity of the platelets remained virtually constant. The dotted line represents the effect of the extra addition of $2 \mathrm{IU} / \mathrm{ml}$ phospholipase $\mathrm{A}_{2}$.

equal time of incubation of coagulation factors with phospholipase $A_{2}$. This enzyme is added at time 0 (after activation of platelets for 30 mith with thrombin plus collagen) and the coagulation factors are added at $2,4,6,8,10$ or $15 \mathrm{~min}$ to probe the remaining procaagulant surface. Also the fact that phosphollpase treated control platelets after proper dilution st111 become active in prothrombin and factor $X$ activation, and show a normal reaponse in aggregation and release upon stimulation with thrombin andor collagen demonstrates that the action of phospholipase $A_{2}$ is restricted to phosphollplds exposed at the membrane exterlor (Table III). Platelet aggregation and release are even not affected when control platelets are treated at a 10-fold higher phospho1 ipase $\mathrm{A}_{2}$ concentration.

Effect of different synthetic phosphollpid mixtures in prothrombin and factor $x$ activation. It was investigated whether differences in time course of gene- 
Table IIL. The effect of phosphollpase $\mathrm{A}_{2}$ treatment of unstimulated platelets on variou platelet functions.

Human platelets at a concentration of $5 \times 10^{8} / \mathrm{ml}$ were incubated at $37^{\circ} \mathrm{C}$ for 70 min wth 3 will $\mathrm{CaCl}_{2}$, elther in the absence or presence of $0.1 \mathrm{I} . \mathrm{U} . / \mathrm{mI}$ phospho11 pase $A_{2}$ (waja naja). After treatment, the plateletis were difluted to $5 \times 10^{7} / \mathrm{ml}$ (for theasurement of platelet aggregation, release) or $5 \times 10^{6} / \mathrm{ml}$ (for measurement of thelr procoagulant properties). The diluted platelet suspensions were at tmulated for $15 \mathrm{~min}$ with $1.3 \mathrm{n} M$ thrombin and/or $10 \mu \mathrm{g} / \mathrm{m} 1$ collagen. The prothrombin and factor $X$ converting activities were measured as described in the expertmental. procedures at $15 \mathrm{nM}$ factor $\mathrm{Xa}, 30 \mathrm{nM}$ factor $\mathrm{Va}, 4 \mu \mathrm{M}$ prothrombin and 50 nM factor IXa, 0.1 nM factor VIIla and 0.5 HM factor $X$, respectively.

\section{Non treated platelets}

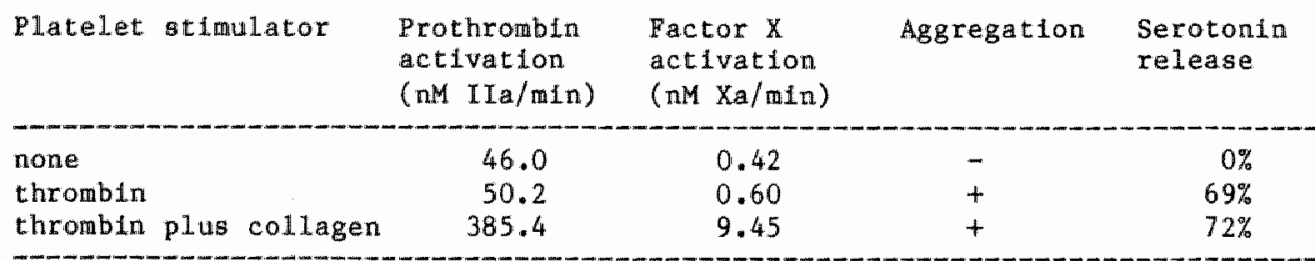

Phospholipase $\mathrm{A}_{2}$ treated platelets

\begin{tabular}{|c|c|c|c|c|}
\hline Platelet at fmulator & $\begin{array}{l}\text { Prothrombin } \\
\text { activation } \\
\text { (nM IIa/min) }\end{array}$ & $\begin{array}{l}\text { Factor X } \\
\text { activation } \\
\text { (nM Xa/miln) }\end{array}$ & Aggregation & $\begin{array}{l}\text { Serotonin } \\
\text { release }\end{array}$ \\
\hline
\end{tabular}

$\begin{array}{lrrrr}\text { none } & 16.2 & <0.1 & - & 0 \% \\ \text { thrombin } & 23.4 & <0.1 & + & 65 \% \\ \text { thrombin plus collagen } & 297.6 & 7.8 & + & 75 \%\end{array}$

ration of a procoagulant platelet surface probed at varying coagulation factor concentrations and the accompanying different sensitivities to phospholipase $A_{2}$ treatment could be related to differences in phospholipld requirement. Therefore, prothrombin and factor $X$ activation were measured in the presence of phosphollpld veslcles with varylng lipld composition. These vesicles were composed of 11 plds present in platelet membranes. The mole fraction of each phospholipid was fixed at the same value as found in a total lipld extract of platelets, with the exception of phosphatidylserine and phosphatidylcholine. prothrombtn activation was measured in the absence of factor Va and at the suboptimal and saturating factor $X_{a}$ and factor Va concentrations also employed in Fig.4. Factor X activation was measured in the absence of factor VIIIa and at the same coagulation factor concentrations as used in F1g.4D.

Large differences between prothrombin and factor $X$ activation at different coagulation factor concentrations were observed when the mole fraction phosphatidylserine in a vesicle was varied at the expense of phosphatidylcholine 

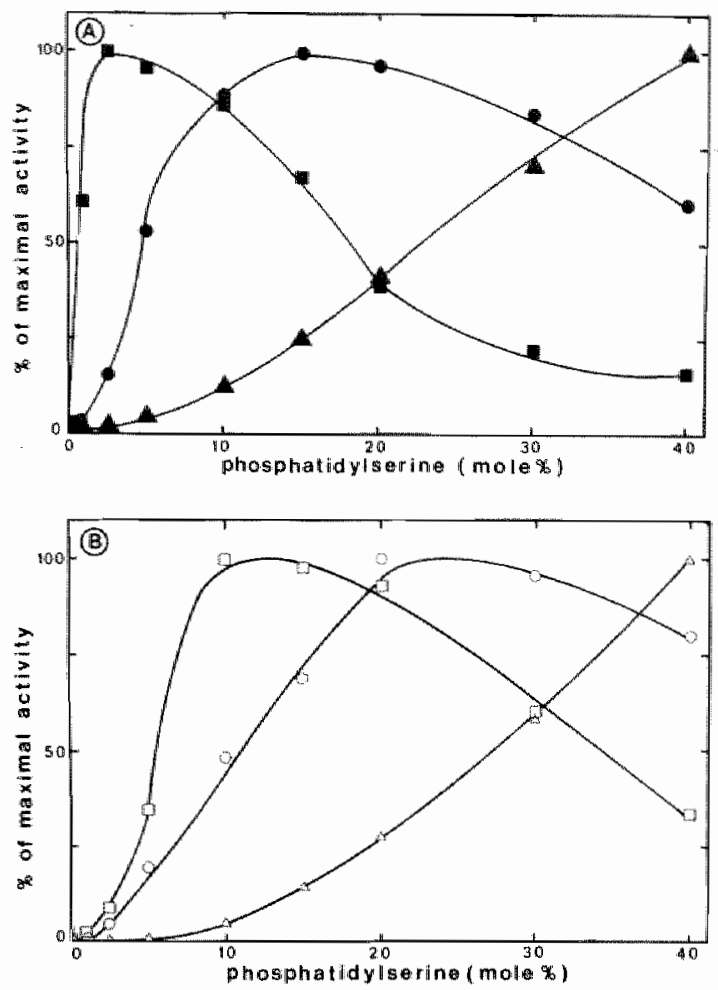

Fig.7A,B. The effect of phospholipid vesicles with varylug mole percentage phosphatidylserine in prothrombin and factor $\mathrm{X} a \mathrm{c}$ tivation. The phospholipid composition of the vesicles in mole $\%$ of total phospholipid was: $28 \%$ phosphatidylethanolamine, 19.6\% sphingomyelin, phosphatidylserine as indicated in the flgure, supplemented to $100 \%$ with phosphatidylcholine. Cholesterol was present in a $1: \mathbb{1}$ molar ratio to total phospholipid. The preparation of vesicles and the assay systems for prothrombin and factor $X$ activation are described in the experimental procedures.

A: Prothrombln activation: ( $\Delta-\Delta) 2 \mu \mathrm{M}$ phospholipid, $4 \mu \mathrm{M}$ prothrombin, $15 \mathrm{nM}$ factor $\mathrm{Xa}$, no factor $\mathrm{Va}, 100 \%=4.2 \mathrm{nM} I I a / m i n,(-0) 2 \mu M$ phospholipid, 4 $\mu \mathrm{M}$ prothrombin, $0.5 \mathrm{nM}$ factor Xa, $1 \mathrm{nM}$ factor $\mathrm{Va}, 100 \%=803 \mathrm{nM} \mathrm{IIa/min,}$ (a-口) $2 \mu \mathrm{M}$ phosphollpld, $4 \mu \mathrm{M}$ prothrombin, $15 \mathrm{nM}$ factor Xa, $30 \mathrm{nM}$ factor Va, $100 \%=2900 \mathrm{rM}$ II $\mathrm{I} / \mathrm{min}$.

$B$ : Factor $X$ activation: $(\Delta-\Delta) 25 \mu \mathrm{M}$ phospholipid, $0.5 \mu \mathrm{H}$ factor $X_{3} 50 \mathrm{nM}$ factor IXa, no factor VIIIa, $100 \%=1.5 \mathrm{nM} \mathrm{Xa} / \mathrm{min},(0-0) 2 \mu \mathrm{M}$ phospholipld, $0.5 \mu$ factor $X, 50 \mathrm{nM}$ factorIKa, $0.1 \mathrm{nM}$ factor VIIL, $100 \%=71.5 \mathrm{nM} \mathrm{Xa} / \mathrm{min}$

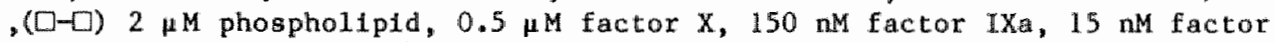
VIIIa, $100 \%=250 \mathrm{nM} \mathrm{Xa/min}$.

(Fig.7A,B). The mole fraction phosphatidylserine required for maximal st1mulation of prothrombin and factor $X$ activation varled at different coagulation factor concentrations. In prothrombin activation the optimal phosphatidy 1serine mole fraction varied from 2.5 mole \% at saturating factor Xa and factor Va concentration to more than 40 mole\% when prothrombin activation was measured in the absence of factor $\mathrm{Va}$ (Fig.7A). Phosphollpld vesicles with more than $40 \mathrm{~mole} \%$ phosphatidylserine were not used in this experiment since they aggregate in the presence of $10 \mathrm{~m} \mathrm{CaCl}_{2}$. For factor $\mathrm{X}$ activation the same phenomenon was observed. The phosphatidylserine optimum was dependent on the 
amount of factor IXa and factor VIIa present in the assay system for factor $X$ activation (H1.7B). At high concentrations of factor IXa and factor WIIa the optum 1 observed at 10 mole\% phosphatidylserine, while silmilar to prothrombinase the optimum in the absence of the non-enzymatic cofactor factor VIIIa 1 at 40 mole\% phosphatidylserine or higher. These differences in phosphatidylserine requirement at different coagulation factor concentrations can explain the observed differences in time course of generation of a procoagulant platelet surface and sensitivity to phospholipase treatment measured under the same conditions (see discussion).

\section{DISCUSSION}

The experiments presented in this paper show that platelets stimulated with thrombin plus collagen expose a procoagulant surface that highly promotes prothrombin and intrinsic factor $X$ activation. With unstimulated and thrombinstimulated platelets markedly lower activities were observed. In previous papers $(13,14)$ we have shown that the negatively charged phospholipid phosphatidylserine, which in unstinulated platelets is localized in the inner membrane monollayer, becomes exposed in the outer membrane monolayer when platelets are activated with collagen plus thrombin. Negatively charged phospho1ipids are required in synthetic phospholipid vesicles that are used as a procoagulant surface in prothrombin and factor $X$ activation. We therefore propose that the phosphatidylserine exposed at the outer surface of activated platelets plays an important role in the interactions of the platelet membrane wh the protelno of the prothrombin and factor $X$ activating complexes and that these interactlons are essential for the observed rate enhancements of prothrombin and factor $X$ activation. This concept is supported by the finding that the activity of stimulated platelets in prothrombin and factor $X$ activation is almost completely abolished when the collagen plus thrombin stimulated platelets are treated with phospholipase $A_{2}$ (Table I). In this experiment phospholipase action was 1.1mited to phosphollpids of the outer membrane monolayer and the membrane integrity was left intact.

Our experiments do not rule out an involvement of platelet membrane protelns In the Interactions with the coagulation factors. Majerus and co-workers (32) described a patient with a bleeding disorder whose platelets lack a surface component requlred for the binding of the factor Xa-Va complex. In a recent paper (4) they proposed that this component presumably is a protein. The group 
of Mann reported that unstimulated bovine platelets bind factor Va three orders of magnitude tighter than synthetle phospholipid vesicles (3). Although "a highly specialized phospholipid structure" at the platelet surface can cause this affinity difference, it can also be visualized that a platelet membrane protein is responsible for this phenomenon. Tuszynski et al. (33) demonstrated that platelet-bound factor Va is associated with components from the platelet cytoskeleton. The ablilty of the cytoskeleton to promote factor Xa-catalyzed prothrombin activation is, however, still dependent on the presence of 11pid. Our experiments were designed in such a way that rates of prothrombin and factor $X$ activation are limited by the avallability of a negatively charged procoagulant phospholipid surface. Saturating coagulation factor concentrations were employed, so that the binding affinitles of the membrane for the coagulation factors became less lmportant. Therefore, we cannot rule out the possibility that besides phosphatidylserine other membrane components play a role in the assembly of the prothrombin and factor $X$ activating complexes at the surface of platelets stimulated with collagen plus thrombin.

Kinetic experiments have shown that the activation of prothrombin and factor $X$ In the absence of phospholipids are very Inefficlent processes $(15,16)$. Phos pholipids dramatically stimulate these reactions since they promote the assembly of the prothrombin and factor $X$ activating complexes in such a way that phospholipid bound substrates (prothrombin or factor $X$ ) are activated by phosphollpid bound enzymes (factor Xa-Va or factor IXa-VIIIa). In experiments with thrombin plus callagen stimulated platelets such high rates of prothrombin and factor $X$ actlvation were observed that it seems justifled to assume that the activation of coagulation factors takes place at the platelet nernbrane surface. This would mean, that in analogy with the model system $(15,16)$, platelet bound prothrombin and factor $X$ are activated by a platelet bound factor Xa-Va and factor IXa-VIIIa complex, respectively. Also the fact that descarboxyprothrombin, a prothrombin derivative that lacks the r-carboxyglutamic acid resldues responsible for the $\mathrm{Ca}^{2+}$-dependent binding of prothrombin to phospholipids, is activated in the presence of platelets with a 50-fold lower catalytic efficlency than prothrombin (34) indicates that the prothrombin which becomes activated is bound to negatively charged platelet phospholfplds. Binding of prothrombin to the platelet membrane, however, has not yet been demonstrated. If the binding affintty of platelets for prothrombin is similar to that of synthetic phospholipids it is possible that it escaped detection since the affinity would than be $3-4$ orders of magnitude lower than observed 
For factor $\mathrm{Xa}$ and Va.

Both bovine and human platelets possess high affuity binding sites for factor Va $(3,4)$. 1000-2000 blinding sites with an approximate $\mathrm{K}_{\mathrm{d}}$ of $10^{-10} \mathrm{M}$ are detected per platelet. Independent whether the platelets are stimulated with thrombit or not. Platelet bound factor Va is the receptor for factor Xa. 200-300 bunding ates for factor Xa are present per platelet efther from human (5) or bovine source $(3,6)$. In these studies there was no Investigation of platelets stlimulated with collagen plus thromblin. The platelet bound factor Xa participates in prothrombin activation. From reports of other laboratories, it can be calculated that thrombin stimulated human (5) and bovine platelets (34), in which factor $V$ released from platelets is the source of factor Va, activate prothrombin at a cate of 4-8 nM thrombin formed/min with $10^{7}$ platelets/ml. Thts correlates very well with the $1.9 \mathrm{nM}$ thrombin formed/min that we observed with $0.3 \times 10^{7}$ thrombin stimulated platelets/ml when we measured prothrombin activation 1 in the absence of added factor Va (Table I). Platelets have, however, a much higher capacity to promote prothrombin activation. Table I also shows that platelets stimulated with collagen plus thrombin exhibit a 170-fold higher activity. In this experiment saturating amounts of factor Xa and factor Va were present. It is essential that a 11mited amount of platelets is used in these experiments. At high platelet concentrations ( $\left.5 \times 10^{7} / \mathrm{m} 1\right)$ such a large number of procoagulant sites is exposed, that even if enough factor $\mathrm{Xa}$ and factor Va could be added to saturate these sites the prothrombin available in the assay systems would be completely converted within a few seconds. It should also be emphasized that platelets have to be stirred during stimulation in order to obtain procoagulant activity. Stirring of platelets is also essential for the expresston of other platelet functions. Non-stirred platelets activated with the proper stimull do not aggregate. Also the release of serotonin Is drastlcally dininished or even absent when non-stirred platelets are actlwated with collagen (2), ADP (35) or the lonophore A23187 (36). We have ruled out possible artefacts like platelet lysis and platelet fragmentation. Activation of stirred platelets with thrombin plus collagen does not induce Itberation of cytoplasmic lactate dehydrogenase and fragmentation of platelets is unlikely since more than $90 \%$ of the procoagulant activity sediments with platelets upon centrifugation. We do not know why stirring of platelets is requited for the expression of procoagulant activity. It is possible that an efflctent interaction of platelets wh collagen fibers requires stirring or that a minimal shear stress is essential for the generation of a procoagulant surface. The latter would be an important blologlcal phenomenon since circula- 
Table IV. Procoagulant sites on human platelet membranes.

The number of procoagulant sites per plgtelet is calculated with the formula: number of sites/platelet $=$ V/Vmax $\times 10^{-9} \times$ Avogadro"s number/platelets. $\mathbb{L}^{-1}$, In which $v$ is the rate of prothrombin or factor $x$ activation deterwined in the experiments presented in table $I$ and vmax is the maximal rate of prothrombin activation (16) or factor X activation (15).

\begin{tabular}{lcccc} 
Platelet stimulator & $\begin{array}{l}\text { Prothrombin } \\
\text { activation } \\
\text { (sites/platelet) } \\
\text { activation }\end{array}$ & Factor Xa Factor Va \\
\hline none & 2400 & 850 & $<10^{\mathrm{b}}$ & $2000-3000^{\mathrm{C}}$ \\
thrombin & 2800 & 1150 & $200-300^{\mathrm{b}}$ & $\mathrm{n} \cdot \mathrm{d} \cdot$ \\
thrombintcollagen & 24100 & 17500 & $\mathrm{n} \cdot \mathrm{d}$. & $\mathrm{n} \cdot \mathrm{d}$.
\end{tabular}

n.d. = not determined

a. functional sites/platelet (this paper)

b. binding sites, from ref.5.

c. binding sites, from ref. 4 .

ting platelets in vivo are also subject to shear stress. Since the flow regime of a solution stirred with a stirring bar consists of very complex time varying laminar flow streams it is, however, not posstble to express procoagulant activities as a function of the hydrodynamic force on the platelets.

The data presented in Table I can be used to quantitate the number of functional sites that participate in prothrombin and factor $X$ activation at the platelet surface. Since the coagulation factors were present in saturating amounts both activitles were measured at Vmax conditions. For thls calculation the Vmax of prothrombin activation is taken as 2700 mole thrombin/min/mole factor Xa (16) and the Vmax of factor X activation as 500 mole factor $\mathrm{Xa} / \mathrm{min} / \mathrm{mole}$ factor IXa (14) and it is assumed that the platelet-bound factor Xa-Va and factor IXa-VIIIa complexes have the same activity as found in the model systems. The latter assumption seems to be justifled since so far we never found a procoagulant surface (either from synthetic or platelet orlgin) that gave Vmax values higher than those published earlier $(15,16)$. The Vmax of prothrombin activation by factor Xa in the presence of synthetlc phospholiplds and a saturating concentration of factor Va 1 s constant when the amount of phosphatidylserine present in the phospholipid vestcles 1 s varled between 2 and 40 mole \% (37). The results of these calculations are presented In Table IV. Unstimulated and thrombin-stimulated platelets have a low number of functional binding sites for the prothrombin- and factor $X$ activating complexes (850-2800/platelet). This number correlates very well with the number of factor Va binding sites (2000, ref. 4) determined in a binding study under these conditions. We do not know, however, whether this correllation $1 \mathrm{~s}$ purely 
accidental or that it means that the factor Va binding sites detected on unstimulated platelets are functional sites, that participate in prothombin activation. For collagen plus thrombin stimulated platelets approximately 24000 functional binding sites for the prothrombinase complex and approximately 18000 for the factor $x$ activating complex are calculated. An Identical number of functional sites for prothrombin and factor $X$ activation is to be expected when the phosphatidylserine exposed is an essential component of the procoagulant stee. (Also the fact that the collagen and thrombin requirements for generation platelet activity in prothrombin and factor $X$ activation are the same supports this).

It cannot be excluded that phosphatidylserine is also part of the procoagulant site (factor Xa-Va receptor) at the surface of unstimulated platelets. This posslbility is supported by the following observations: a) a small amount of phosphatidylsertne (probably sufficient to explain the low rate of prothrombin activation) is determined in the outer monolayer of unstimulated human platelets $(9)$. Thts phosphatidylserine can even be present in domatns with high density (see below). b) prothrombin converting activity of unstimulated platelets 1 s aboltshed upon treatment with phospholipases (31) c) des (1-44) factor $X a$, a factor Xa derivative that lacks $Y$-carboxyglutamyl residues, does not bind to the platelet factor Xa receptor $(4)$. We do not fieel that the experiments in whlch a monoclonal antibody against negatively charged phospholipids does not block platelet prothrombin activation and factor Xa binding (38) can be used as an argument against phospholipid involverent. This antibody only blacks prothrombin activation on synthetic phospholipid vesicles and does not interact with sonicated platelets, for which it can hardly be argued that negatively charged phospholipids are absent. The authors suggest that the phosphatidylserine in platelet membranes may be relatively inaccessible to the antibody.

Two other phenomena observed during our studies on the properties of the procoagulant sites of platelets need further discussion:

a) The time course of generation of the procoagulant surface on collagen plus thrombin stimulated platelets is different when prothrombin and factor $X$ activation are measured at different coagulation factor concentrations $(\mathrm{Fig} \cdot 4)$.

b) Phospholfpese treatment of thrombin plus collagen stimulated platelets more rapidly destroys the procoagulant surface when this is measured at low coagulation factor concentrations, than at high concentrations.

The results obtalned with synthetic phospholipid vesicles show that there are 
remarkable differences in phosphatidylserine requirement in the assay systems employed in the above mentioned experiments. At low concentrations of factor Xa/factor Va or factor IXa/factor VIlla procoagulant surfaces containing low amounts of phosphatidylserine hardly stimulate prothrombin and factor $x$ activation. Optimal rates are observed at 40 mole $\%$ phosphatidylserine or hilgher. At high concentrations of coagulation factors the optimal mole $\%$ phosphatidy1serine required is wuch lower (as low as $2.5 \%$ for prothrombin activation at saturating factor $\mathrm{Xa}$ and factor Va concentrations). Under these condtions procoagulant surfaces with low phosphatidylserine still have an appreciable activity. Based on these obserwations it can be hypothesized that the phosphatidylserine exposed at the surface of collagen plus thrombin stimulated platelets is not homogeneously distributed in the outer lipld leaflet of the membrane bilayer. Domains with high phosphatidylserine density, which rapidly appear at the surface of stimulated platelets are measured at low coagulation factor concentrations. Domatns with low phosphatidylsertne denstty which appear slower, can only be probed at high coagulation factor concentrations. This would also explain why the activity of the procoagulant surface measured at low coagulation factor concentrations is more sensitive to phosphollpase treatment. It has been shown, that phosphatidylserine monolayers, at surface pressures found in the platelet membrane (34 dyne/cm, ref. 10), are more rapidly degraded by phospholipase $A_{2}$ than monolayers of phosphatidylchollne $(39,40)$. It is therefore likely that platelet membrane surface areas contalning high local phosphatidylserfne concentrations are more susceptible to phospholipase $A_{2}$ than surface areas contalnlng low phosphatidylserine concentrations.

If such lateral phase separations occur in the outer leaflet of the platelet plasma membrane after or during platelet activation, it presumably requites other components to induce or malntain them. An involvement of extra-cellular calclum in this process cannot be excluded, but it is also posstble that membrane protelns particlpate in the properties of activated platelets to produce at least two different lipld domalns th different phospholdpid compostions.

\section{REFERENCES}

1. Walsh, P.N. and Biggs, R. (1972) Brtt.J.Haematol. 22,743-760.

2. Walsh, P.N. (1978) Brit.J.Haemato1. 40, 311-331. 
3. Tracey, P.B., Peterson, J.H., Heshein, M.E., MeDuffle, F.C., Mann, K.G. (1979) J.BLol.Cher. 254, 10345-10361.

4. Kane, H.H., Ma jerus, P.W. (1982) J.Biol.Chem. 257, 3963-3969.

5. M1lethch, J.P., Jackson, C.M., Majerus, P.h. (1978) J.Biol.Chem.253, $6908-6916$.

6. Dahibäck, B., Stenflo, J. (1978) Blochemistry 17, 4938-4945.

7. Kane, H.H., Lindhout, M.J., Jackson, C.M., Majerus, P.W. (1980) J.B101. Chem. $255,1170-1174$.

8. Tracy, P.B., Nesheln, M.E., Mann, K.G. (1981) J.BLol.Chem. 256, 743-751.

9. Peret, B., Chap, H.J., Douste-Blazy, L. (1979) Blochlm.Blophys.Acta 556, $434-446$.

10. Chap, H.J., Zwaal, R.F.A., van Deenen, L.L.M. (1977) Biochim.Biophys.Acta $467,146-164$.

11. Zwaal, R.F.A., Comfurlus, P., van Deenen, L.L.M. (1977) Nature 268, $358-360$.

12. Zwal, R.F.A. (1978) BLochtm.BLophys.Acta 515, 163-205.

13. Bevers, E.M., Comfurlus, R., van Rijn, J.L.M.L., Hemker, H.C., Zwaial, R.F.A. (1982) Eur.J.Blochem. 122, 429-436.

14. Bevers, E.M., Comfurius, P., Zwaal, R.F.A. (1983) Blochim.Blophys.Acta $736,57-66$.

15. van Dieljen, G., Tans, G., Rosing, J., Hemker, H.C. (1981) J.Bial.Chem. $256,3433-3442$.

16. Rosing, J., Tans, G., Govers-Rlemslag, J.W.P., Zwaal, R.F.A., Herker, H.C. (1980) J.BLol. Chem. 255, 274-283.

17. Comfurlus, P., Zwaal, R.F.A. (1977) B1ochim. Biophys.Acta 488, 36-42.

18. de Kruljff, B., Cull1s, P.R., Radda, G.K. (1975) Biochim.Biophys.Acta 406, $16-20$.

19. Böttcher, G.J.F., van Gent, C.M., Pries, C. (1961) Anal.ChIm.Acta 24, 203-207.

20. Reed, C.F., Swisher, S.N., Marinett1, G.V., Eden, E.G. (1960) J.Lab.Cl1n. Med. 56, 281 .

2.h. Zwaal, R.F.A., Roelofsen, B., Comfurlus, P., van Deenen, L.L.M. (1975) Blochtm. Btophys. Acta 406, 83-96.

22. Stenf1o, J. (1976) J.B101.Chem. 251, 355-363.

23. Schiffman, S., Theodor, I., Rapaport, S.I. (1969) Blochemistry 8, 1397-1405.

24. Lindhout, M.J., Govers-Riemslag, J.W.P., van de Waart, P., Hemker, H.C., Rosing, J. (1982) Blochemistry 21, 5494-5502.

25. Vehar, G.A., Davie, E.W. (1980) Biochemistry 19, 401-410.

26. van Rijn, J.I.M.L., Rosing, J., van Dle1jen, G. (1983) Eur.J.B1ochem. 133, $1-10$.

27. Chase, T., Jr and Shaw, E. (1969) Blochem1stry 8, 2212-2224.

28. Smith, R.L. (1973) J.Btol. Chem. 248, 2418-2423.

29. Byrne, R., Link, R.P., Castellino, F.J. (1980) J.Biol.Chem. 255,5336-5341.

30. van Dieljen, G., Rosing, J., van Rijn J.L.M.L., Bevers, E., Henker, H.C., Zwal, R.F.A. (1982) ln: Current toples in haemophlila (Wensly, R.T., ed.) 3-14, NDT Print, Brunswick Mill, Manchester.

31. Bevers, E.M., Comfurtus, P., Zwal, R.F.A. (1982) Eur.J.Blochem. 122, $81-85$.

32. Mlletich, J.P., Kane, W.H., Hofmann .S.L., Stanford. N., Majerus, P.W. (1979) Blood 54, 1015-1022.

33. Tuszynski, G.P., Walsh, P.N., Piperno, J.R., Koshy, A. (1982) J.Biol.Chem. $257,4557-4563$.

34. Dahibäck, B., Stenflo, J. (1980) Eur.J.Blochem. 104, 549-557.

35. Charo, I.F., Felmman, R.D., Detwiler, T.C. (1977) J.Clin.Invest. 60, $866-874$. 
36. Holmsen, H., Dangelmaier, C.A. (1981) J.B101. Chew. 256, 10449-10452.

37. $\operatorname{van}$ Rljn, J.L.M.L., Govers-Rlemslag, J.W.P., Zwaal, R.F.A., Rosing, J. Biochemistry, in press.

38. Thiagarajan, P. "Shapiro, S.S., De Marco, L. (1980) J.Clin. Invegt. 66, $397-405$.

39. Deme1, R.A., Geurts van Kessel, W.S.M., Zwaal, R.F.A., Roelofsen, B., wan Deenen, L.L.M. (1975) Biochim.Blophys.Acta 406, 97-107.

40. Verhe1j, H.M., Boffa, M.C., Rothen, C., Bryckaart, M.C., Verger, R., de Haas, G.H. (1980) Eur.J.Blochem. 112, 25-32. 

CHAPTER IY

ACTIVITY OF HUMAN BLOOD PLATELETS IN PROTHROMBIN AND IN FACTOR X ACTIVATLON

INDUCED BY IONOPHORE A23187

SUMMARY

Two reactions of the blood coagulation cascade are highly stimulated by membranes contalning negatively charged phosphollplds. These are the activation of prothrombin to throubin by factor Xa with factor $V a$ as cofactor, and the conversion of factor $X$ into Xa by factor IXa with factor VIITa as cofactor. It is thought that under physiological conditions these reactions take place with the clotting factors adsorbed at the surface of blood platelets.

The role of blood platelets $\mathbb{f n}$ the two reactions was studied using two assay systems consisting of highly purifled clotting factors. The rates of formation of thrombln and factor $X_{a}$, measured with specific chromogenic substrates, were dependent on the quantity of negatively charged phospholipid present in the reaction mixture. Phospholipid vesicles with platelet phospholipld composition were highly active in the two reaction systems. When the purified lipids were substituted by disrupted platelets, containing the same quantity of lipids, the same high activities were found. With intact human blood platelets a low but significant activity was observed. Incubation of the platelets with the calcium 1onophore A23187, resulted in a 50-60 fold activity increase in formation of thrombin and factor Xa. Platelet disruption increases procoagulant activity, since the negatively charged phosphollpids, originally situated in the Inner leaflet of the lipid bllayer of the platelet membrane become exposed upon platelet disruption. Ionophore activation of platelets was however not due to lysis since discharge of platelet lactate dehydrogenase was less then $3 \%$. The activity of A23187-activated platelets In formation of thrombin and factor $\mathrm{Xa}$ was completely abolished after incubation with phospholipase $A_{2}$, which is to be expected if negatively charged 11pids are present at the platelet outer surface. In contrast to platelets, erythrocytes could not be activated by the lonophore.

As found by ather workers, A23187 tnduces release of ATP and factor V(a) and results in platelet aggregation. The appearance of procoagulant activity, ATP and factor $V(a)$ release were all dependent on the A23187 concentration and were too rapld to study the time course. All platelet activities were induced

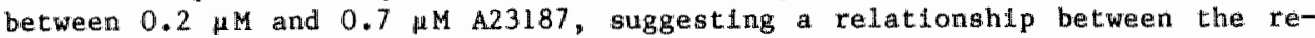
lease processes and the appearance of procoagulant activity.

\section{INTRODUCTION}

The formation of the haemostatic plug which stops bleeding upon lnfury, involves platelet reactions $11 \mathrm{ke}$ adheston, release and aggregation, as well as activation reactions of the plasma clotting factors that reault in fibrin formation $(1,2)$. 
Methods to purtfy the clotting factors are now avallable, and this has promoted detalled study of the function of these factors in the sequence of actiation reactions that results in fibrin formation (3). Two of these reactiong, the activation of prothrombin to thrombin by factor Xa and the activation of factor $X$ to factor $X a$ by factor IXa are strongly accelerated in the presence of the respective cofactors Va and VIIIa and in the presence of membrames contaluing negatively charged phospholipids. Detalled kinetic analysis of these reactions resulted in the finding that the cofactors Va and fictor viria respectively increase the $V_{\max }$ of formation of thrombin and factor Xa, whereas the presence of phospholipid lowers the $\mathrm{Km}$ values for the substrates factor II and $X(4,5)$. The results support the concept that during activation, enzyme, cofactor and substrate are complexed at a phosphollpid surface.

Miletich et al. found that after stimulation of platelets by thrombin, 200-300 high affinlty receptors for factor Xa appear at the platelet surface (6). The receptor was identifled as factor Va released from the platelet by thrombin (7) and from the results by the groups of Majerus (6-8), of Stenflo $(9,10)$, and of Mann $(11,12)$ abtained with human and bovine platelets, it can be concluded that platelets, independent of thrombin stimulation, have 200-900 binding sites for factor Xa-Va complexes. The chemical nature of the binding sites has not been elucldated but is most likely comprised of negatively charged phospholipid (13) which is in agreement with older proposals that platelets $\mathbb{1 n}$ vivo provide procoagulant phospholipids $(14,15)$. Paradoxical$\mathbb{l} y$, In platelets, as in most other eukaryotic cells, the negatively charged phospholiplds, phosphatidylserine and phosphatidylinositol are nearly all localized at the Inner leaflet of the 11pld bllayer of the platelet membrane and therefore 1 inaccessible for particlpation in clotting reactions $(16,17)$. Results from our laboratory indicate that after incubation of platelets with collagen plus thrombln about $25 \%$ of the platelet phosphatidylserine is exposed at the platelet surface, presumably by a flip-flop or transbllayer transport mecharism (13). It was further shown that collagen + thrombin-activated platelets accelerate prothrombin actlvation, by factors $\mathrm{Xa}$ and $\mathrm{Va}(13,18)$, and Intrinstc factor $X$ activation by factors $I X a$ and VIILa (Rosing et al., unpublished results).

The divalent cation Ionophore A23187 activates several platelet functions and is known to Induce rellease of ATP, serotonin and factor V and to cause platelet aggregation $(6,19-21)$. Moreover, Bevers et al. (22) found that $50 \%$ of the platelet phosphatidylserine 1 s exposed at the surface of A23187-activated 
platelets and that A23187 stimulation leads to highly increased activity of the platelets in a platelet factor-3 clotting assay (23). It was therefore of interest to study the properties of lonophore-stimulated platelets in prothrombin- and factor $X$ activation, using reaction systems consisting of highly purified proteins. We also studied release of platelet factor $V$, ATp release and aggregation in order to detect possible relationships between the vartous platelet activities.

\section{MATERIALS AND METHODS}

S2238 and S2337 were purchased from AB Kabi Diagnostica, Stockholm, Sweden. DEAE-Sephadex A-50, QAE-Sephadex A-50 and Sephadex G-100 and G-200 were products of Pharmacia. Ionophore A23187 was obtained from Calblochem-Hoechst, USA. Factor VIII-deficient plasma was from Georg King Biomedicall (Overland, KS, USA). Echis Carinatus and RVV venoms were from Siguna. Naja naja venom from Koch Light. Reaction tubes were 2-ml plastic flatbottorn tubes obtained from Sterilln Ltd. (Teddington Middlesex, England). Teflon-coated magnetic spluning bars, 7 x 2 mm were from Bel-Art Products USA. Phosphatidyllnositol and sphingomyeline were purchased from Koch Light. Phosphatidylcholine $\left(18: 1_{\mathrm{cls}} /-\right.$ 18:1 $\mathrm{cls}$, dioleoylglycerophosphocholine) was from Sigma (USA), ATP-monitoring reagent contalning luciferin and luctferase was from LKB, Sweden. Lactate dehydrogenase reagents were from Boehringer (Mannheim, FRG). All reagents used were of the highest grade commerclally avallable.

Preparations of phospholipids and phospholipid vesicles. Phosphatidylethanolamine and phosphatidylsertne (both $18: 1_{\mathrm{c}} / \mathrm{s} / 18: 1_{\mathrm{cls}}$ ) were prepared from phosphatidylcholine by enzymatic syathesis according to the method of Comfurius and Zwal (24). Single bilayer vesicle solutions were prepared according to the method described by de Kruyff (25) by sonication of 11posomes for 10 minutes in $50 \mathrm{mM}$ Tris- $\mathrm{HCl}$ and $175 \mathrm{mM} \mathrm{NaCl}$ buffer at pH 7.9 at $0^{\circ} \mathrm{C}$. Sontcation was performed by using a MSE Mark II 150 W ultrasonic desintegrator set at 6 micron peak to peak amplitude. Phosphollpid concentrations were determined by phosphate analysis according to Böttcher et al. (26).

Prateins. Phospholipase $A_{2}$ was purifled from Naja naja venom according to Zwaal et al (27). Prothrombin, thrombin, factor $X$, factor Xa, factor IX, factor IXa and contactproduct (factor XIa) were purifled according to established procedures (28) as described prevlously $(4,5)$. RVV-X was purifled from the crude venom as described by schiffmann et a1. (29). Bovine factor V was purified according to Lindhout et al ( 30 ) by a method Blmilar as described by 
Kane et al (8). Pactor $V$ was actwated by incubation wh thrombin and stored In buffer contalning $50 \mathrm{mM} T \mathrm{Tr}$, $175 \mathrm{mM} \mathrm{NaCl}$ and $10 \mathrm{mM} \mathrm{CaCl}$, pH 7.9. No changes in activity were found wen activated factor $V$ solutions were kept at $0^{\circ} \mathrm{C}$ for $24 \mathrm{~h}$ or when stored at $-70^{\circ} \mathrm{C}$ for a one year period. Factor VIII was purifled from bovine blood according to the method of Vehar and Davie (31). The method was followed up to and Including the sulfate-sepharose step. After this step the factor VIII preparation had a specific activity in a clotting assay of 324 unfts/mg. Factor VIII stock solutions were dialysed against a buffer contalaing $10 \mathrm{mM} \mathrm{Mes,} 175 \mathrm{mM} \mathrm{NaC1}, 10 \mathrm{mM} \mathrm{CaCl}, 2$ adjusted to pH 6.5 with 1 M Tris. Factor VIII was diluted with the same buffer containing $10 \%$ glycerol and $10 \mathrm{mg} / \mathrm{ml}$ human serum albumin. Factor VIII activities were determined with a one-stage coagulation assay using factor VIII-deficient human plasma. Act1vities of factor VIII were expressed in unts/ml, assuring 1 unit/ml present In normal bovine plasma.

The protein preparations were stored at $-70^{\circ} \mathrm{C}$ after dialysis against 50 mM Tris-HCl $175 \mathrm{mM} \mathrm{NaCl}$ at $\mathrm{pH} 7.9$. Before storage at $-70^{\circ} \mathrm{C}$, prothrombin and the preparations of factor $X_{1}, X_{2}$ and $I X$ were passed through a colum of soybean trypsin inhibltor coupled to agarose $(0.5 \times 10 \mathrm{~cm})$ to reduce the small amounts of factor Xa that might be present in these preparations. No thrombin or factor Xa could be detected in our proteln preparations as determined with the chromogenic substrates $\$ 2238$ and $\$ 2337$. Factor Va and factor VIII were stored at $-70^{\circ} \mathrm{C}$ in $\mathrm{Ca}^{2+}$-containing buffers as indicated above.

Protein concentrations. Concentrations of thrombin, factor Xa and factor IXa concentrations were determined by active site titration with p-nitrophenyl-pguantdinobenzoate hydrochloride $(32-34)$. Prothrombin concentrations were determined after complete activation wh Echlis carinatus venom followed by active sthe titration. Stmilarly, factor $X$ concentrations were obtained by active site titration after complete activation of factors $X_{1}$ or $X_{2}$ by $R V V-X$. Factor Va concentrations were determined by kinetic analysis (30). When protelu concentrations are expressed $1 \mathrm{n} \mathrm{mg} / \mathrm{ml}$, they were callculated from values for the absorbance at $280 \mathrm{~nm}$ using an $A_{280}^{1 \%}$ of 15.5 for factor II (35) an $A_{280}^{1 \%}$ of 14.9 and 14.5 for factors $I X$ and $I X a(36)$ and an $A_{280}^{1 \%}$ of 12.4 for factors $x_{1}$ and $x_{2}$ (37). The molar concentration of factor VIII was determined by kinetic andysis, similar to the method described for factor $v(37 a)$. Activation of factor VIII. Earlier we reported the conditions for activation of factor VIII complex by thrombin (5). In the present work factor VIII:C is used prepared according to Vehar and Davie (31) which does not contaln von Willebrand factor. The optimal conditions for activation of factor VIII:C by 
thrombin were determined, by direct measurement of the effect of factor virim on the rate of factor $X$ activation. Incubation of factor VII 10 whth thrombin, dependent on concentration and incubation time, caused a rapld increase in factor VIIIa activity followed by a decrease very similar to the throubin effects on factor VIII complex (cf ref 5). Based an these results and considering the amounts of thrombin required for platelet stimulation, we decided to activate factor WII:C for 1 min at $37^{\circ} \mathrm{C}$ at a thrombin concentration of $3.65 \mathrm{nM}(0.13 \mu \mathrm{g} / \mathrm{ml})$.

Isolation of human platelets. Blood was drawn by venepuncture from healthy male volunteers, who had not taken any medication for at least one week. As anticoagulant, one volume of acid/citrate/dextrose $60.18 \mathrm{M}$ glucose/0.08 $\mathrm{M}$ trisodium citrate/0.052 M citric acid) was added to flve volumes of whole blood. Platelet-rich plasma was obtained after centrifugation at $220 \times \mathrm{g}$ for 15 min. Platelets were 1 solated by centrifugation $1000 \mathrm{x} g$ for $20 \mathrm{~min}$ and the peillet was gently resuspended in a calcium-free buffer pH 6.7 containing 136 $\mathrm{mM} \mathrm{NaCl}, 2.68 \mathrm{mM} \mathrm{KCl}, 2 \mathrm{mM} \mathrm{MgCl} 2,10 \mathrm{mM}$ Hepes, $5 \mathrm{mM}$ glucose and $0.05 \%$ fattyacid- free human serum albumin. The platelets were washed twice in this buffer by centrifuging $600 \times \mathrm{g}, 15 \mathrm{mln}$. Before centrifugation acid/citrate/dextrose was added to the suspension ( 1 volume to 14 volumes). Finally the platelets were resuspended in Hepes buffer at $\mathrm{pH} 7.5$. The entire procedure for platelet preparation took about $2 \mathrm{~h}$ and was carried out at room temperature $\left(22^{\circ} \mathrm{C}\right)$. Platelet concentration was determined with a Coulter counter. Platelets were kept at room temperature and no loss of platelet functions (prothrombin- and factor X activation, release of ATP and factor V) was found for at least $15 \mathrm{~h}$. Platelet stimulation and determination of prothrombin- and factor $X$ converting activity was carried out in 2-ml flatbottom plastlc tubes, that were stirred at $350 \mathrm{rev} / \mathrm{min}$ with teflon stirring bars. A stirring assembly wa constructed such that 8 reaction tubes could be simultaneously stirred at $37^{\circ} \mathrm{C}$. To a reaction tube containing $307 \mu 1$ of a platelet suspension was added $13 \mu 1$ of 75 mM $\mathrm{CaCl}_{2}$. The tube content was stirred for $5 \mathrm{~min}$ at $37^{\circ} \mathrm{C}$ and platelet atimulation was started by adding $5 \mu 1$ of A23187 dissolved in Me ${ }_{2}$ SO resulting In a final volume of $325 \mathrm{\mu l}$ and $\mathrm{CaCl}_{2}$ concentration of $3 \mathrm{mM}$. After a varlable time period at $37^{\circ} \mathrm{C}$ and stirring, termed platelet activation time, the components for elther prothrombin activation or for factor $X$ activation were added, to determine rates of thrombin- or factor Xa formation. 
Reaction system for prothrombin activation used to assay platelet procoagulant activity. Two ninutes before the start of the thrombin forming reaction, 25 HI factor Va $(600 \mathrm{mM}$ ) and 25 H faccor Xa (300 nM) were added to the triggered platelet suspenston to allow equilibration with the platelets. Prothrombin activation was started wth the addition of 125 w1 of a prewarmed mixture contalning $16 \mu \mathrm{M}$ prothrombin and $14.2 \mathrm{mM} \mathrm{CaCl}{ }_{2}$ in $50 \mathrm{mM} \mathrm{Tris}-\mathrm{HCl}, 175 \mathrm{mM} \mathrm{NaCl}$ and $0.5 \mathrm{mg} / \mathrm{ml}$ of human erum albumln, $\mathrm{pH} 7.9$, to result in a final volume of $500 \mu 1$. The final concentrations of the reactants are: $15 \mathrm{nM}$ factor $\mathrm{Xa}, 30 \mathrm{nM}$ factor Va, $4 \mathrm{M}$ prothrombin and 6 m $\mathrm{CaCl}_{2}$ at a $\mathrm{pH}$ of 7.9 . After 15 and 30 seconds aliquots (usualiy 5 or $10 \mu 1$ ) were taken from the reaction mixture to determine the amount of thrombin formed.

Reaction system for factor $X$ activation for the assay of platelet procoagulant actlvity. Forty flwe seconds before the start of the factor Xa forming reaction $25 \mu \mathrm{IXa}(1 \mu \mathrm{M})$ and $33.4 \mu \mathrm{I} \mathrm{CaCl}{ }_{2}(60.6 \mathrm{mM})$ were added to the triggered platelet suspension and the reaction was started with $16.6 \mu$ factor $\mathrm{X}_{2}$ ( $\left.15 \mu \mathrm{M}\right)$ and $100 \mu 1$ of activated factor VIII to result in a final volume of $500 \mu 1$. The final reaction concentrations of the reactants are $50 \mathrm{nM}$ factor IXa, $0.1 \mathrm{nM}$ factor VIIIa, $0.5 \mu \mathrm{M}$ factor $\mathrm{X}_{2}$ and $6 \mathrm{mM} \mathrm{CaCl}_{2}$ at $\mathrm{pH} \mathrm{7.9.} \mathrm{Forty} \mathrm{five} \mathrm{and} 90$ seconds after starting the reaction aliquots were taken from the reaction mixture to determine the amount of factor Xa formed.

Measurement of rate of thrombin formation. Allquats of the reaction mixture for prothrombin activation were brought into cuvettes (thermostated at $37^{\circ} \mathrm{C}$ ) containing a buffer of $50 \mathrm{mM} T \mathrm{Tr} 1 \mathrm{~s}-\mathrm{HCl}, 175 \mathrm{mM} \mathrm{NaCl}, 0.5 \mathrm{mg} / \mathrm{ml}$ ovalbumin and 20 mM EDTA at $\mathrm{pH} 7.9 \mathrm{im}$ such amounts that the final volume was $2 \mathrm{~m} 1 ; 235$ pM of the thrombin specific chromogentc substrate $\$ 2238$ was also present. Further activation of prothrombin 1 s prevented by dilution and the presence of EDTA. The absorbance change recorded at $405 \mathrm{~nm}$ minus $500 \mathrm{~nm}$ on an Aminco DW2 spectrophotometer (set in the dual wavelength mode) is a measure of the amount of thrombin present in the aliquots. From a callbration curve made with known amounts of active ste-titrated thrombin, determined under the same conditions as described above, the amount of thrombin present in the reaction mixture is calculated. Under the conditions used, the formation of thrombin in the reactlon mixtures was linear in time, the rate of thrombin formation was calculated from the amount of thrombin present after 15 and 30 seconds.

Measurement of the rate of factor Xa formation. The experinental set up is essentially the same as described by measurement of thrombin formation, with the exception that the absorbance change at $405 \mathrm{~nm}$ minus $500 \mathrm{~nm}$ was measured 
using the factor $\mathrm{Xa}$ specific chromogenic substrate 5233 ) (concentration 192 $\mu \mathrm{M})$. The factor $\mathrm{Xa}$ forming reaction is linear in time after a lag pertod of about 15 seconds. Therefore the interval between 45 and 90 seconds after starting was used to calculate the rate of factor Xa formation.

Platelet aggregation. Platelet aggregation studies were carried out in a Lumi-aggrometer (Chronolog Corporation) as follows. Platelets suspended in a Hepes buffer at $\mathrm{pH} 7.5$ (see above) were brought to a cylindrical siliconized glass cuvette in a volume of $614 \mathrm{\mu l}$ and stirred with a teflon-coated spiming bar. This cuvette was placed in the aggregoneter thermostated at $37^{\circ} \mathrm{C}$, and $26 \mu 1$ of a $75 \mathrm{mM} \mathrm{CaCl}{ }_{2}$ solution was added. The platelets were prewarmed for 5 min and stirred. Then $10 \mu 1$ of the lonophore A23187 dissolved $10 \mathrm{Me}_{2}$ SO was added and the aggregation pattern was recorded.

Measurement ATP release of platelets. Platelets were stimulated as described for factor $X$ and prothrombln activation. After stimulation for 5 min with ionophore, $300 \mu 1$ of the activated platelet suspension was drawn and centrifuged in an Eppendorf 5412 centrifuge in $1.5 \mathrm{ml}$ tubes during $5 \mathrm{~min}$ at room. temperature, $7000 \times \mathrm{g}$. $200 \mu 1$ of the supernatant was added to $250 \mu 1$ Hepes buffer $\mathrm{pH} 7.5$ (see above) in a round glass cuvette placed in the holder of the lumi-aggrometer and prewarmed for $5 \mathrm{~min}$. Then under stirring with a spinning bar $50 \mu 1$ of a firefly lantern extract, containing luciferin-luctferase, was added and light emission was quantified.

Measurement of lactate dehydrogenase. From the activated platelet suspension $475 \mu 1$ was added to a cuvette containing $250 \mu 1$ Hepes buffer ( $\mathrm{pH} 7.5$ see above), $50 \mu 1$ pyruvic acid $(30 \mathrm{mg} / \mathrm{ml})$ and $25 \mu 1 \mathrm{NADH}$ disodiumsalt $(3 \mathrm{mg} / \mathrm{mi})$. The absorbance change at $340 \mathrm{~nm}$ minus $400 \mathrm{~nm}$, determined on an Aminco DW-2 spectrophotometer in the dual wavelength mode, is a measure for the lactate dehydrogenase activity.

Determination of the release of factor $V$. platelets in presence of $\mathrm{Ca}^{2+}$ were stirred and stimulated th $\mathbb{1}$ onophore exactly as described for determination of the activity in prothrombin- and factor $X$ activation. After the desired stimulation time were added in rapid succesion: $25 \mu 1$ factor $X a(300 \mathrm{mM})$. 25 $\mu 1$ of sonicated phospholipid vesicles ( $25 \%$ phosphatidylserine, $75 \%$ phosphat1dylcholine, $0.400 \mathrm{mM}$ ) and $125 \mathrm{\mu l}$ of a prewarmed mixture containing prothrombln and $\mathrm{CaCl}_{2}$ as used in the reaction system for prothrombin activation. The final concentration of reactants were: $15 \mathrm{nM}$ factor Xa, $4 \mu \mathrm{M}$ prothromb1n,20 $\mu \mathrm{M}$ phosphollpid westcles and $6 \mathrm{mM} \mathrm{CaCl}_{2}$ at $\mathrm{pH} \mathrm{7.9.} \mathrm{After} 15$ and 30 seconds samples of the reaction mixture, were transferred to cuvettes contalning 52238 , to determine the amounts of thrombin present. 
Properties of two reaction systems for assay of synthetic and platelet phosphollplda based on prothrombln- and on intrinstc factor $X$ activation. The detection and quantification of procoagulant phospholipids at the platelet surface requires sensltive assays. We have used the phospholipld requirement for prothrombin actiwation by factor Xa in presence of factor Va, and intrinLe factor $x$ activation by factors IXa and VIIIa, to develop two assay systems that contaln highly purifled bovine clotting factors, in which rates of prothrombln- and factor $X$ activation, are proportional with the amount of procoagulant phospholipid present. Both reaction systems are described in detail in Materials and Methods. The final concentration of proteins in the prothrombin activating syten are: $15 \mathrm{nM}$ factor Xa, $30 \mathrm{nM}$ factor Va, $4 \mu \mathrm{M}$ prothrombin. For the factor $X$ activation aystem: $50 \mathrm{nM}$ factor IXa, $0.1 \mathrm{nM}$ factor VIIIa and 0.5 $\mu M$ factor $X$. Under these conditions $1 \mathrm{t}$ is found that the rates of thrombin and factor Xa formation are completely dependent on and directly proportional to the amount of procoagulant liptd present. All activation rates shown in this work were determined with the lipids or activated platelets present within the linear range (compare $f 1 g .4 \mathrm{~A}, \mathrm{~B}$ ).

The dependence of the rates of thrombin- and factor Xa formation on increased enrlchment of phosphollpid membranes with phosphatidylsertine (such a process may take place during platelet activation) was studied with vesicles of platelet lipid composition that contain varying mole fractions of phosphatidylserine. The results presented in table 1 indicate that the presence of phosphatidylsertne $1 \mathrm{~s}$ essential for prothrombln- and factor $X$ activation. At low mole fractions phosphatldylserine, high rates of thrombin formation are found In the prothrombin activation system. Rates of thrombin formation are optimal at $2.5-5 \%$ phosphatidylgerine and lower activation rates are found at higher mole fractions phosphatidylserine. In contrast, the rates of factor Xa formation in the reaction system for factor $X$ activation, increase with Increased phosphatidylserine content of the vesicles. Thus the two measuring systems usied here, show a different requirement for the presence of phosphatidylserine in the membranes. When $4 \%$ phosphatidylinositol was included in vestcles contalning 10-11\% phosphatidylserine, to simulate platelet 1ipld composition, no Increase in the rates of thrombin- and factor Xa formation was found. 
Table 1. Effect of increasing phosphatidylserine content of phospholipid vesicles on the rates of prothrombin- and factor $X$ activation under our reaction conditions.

The phospholipid composition of the vesicles was expressed in mole percentage of total phospholipid: $28 \%$ phosphatidylethanolamine, $19 \%$ sphlngoinyelin, phosphatidylserine as given in the table, supplemented up to $100 \%$ with phosphatidylcholine. Cholesterol was present in the same (1:1) raolar concentration as total phospholipid. The total phospholipid concentration in the reaction mixture was $0.5 \mu \mathrm{M}$. The composition of the reaction mixtures and determination of the rates of thrombin and factor Xa formation were exactly as described in Materials and Methods.

\begin{tabular}{|c|c|c|}
\hline $\begin{array}{l}\text { Phosphatidylserine } \\
\text { in vesicle }\end{array}$ & $\begin{array}{l}\text { Rate of thrombin } \\
\text { formation }\end{array}$ & $\begin{array}{l}\text { Rate of factor } \mathrm{Xa} \\
\text { formation }\end{array}$ \\
\hline moile\% & $\left(\mathrm{nM} I \mathrm{Ia} \cdot \mathrm{min}^{-1}\right)$ & $\left(\mathrm{nM} \mathrm{Xa} \cdot \mathrm{mun}^{-1}\right)$ \\
\hline 0 & 47 & 0.1 \\
\hline 1 & 417 & 0.1 \\
\hline 2.5 & 843 & 0.2 \\
\hline 5 & 931 & 2.6 \\
\hline 10 & 804 & 13.0 \\
\hline 15 & 467 & 23.0 \\
\hline
\end{tabular}

Effect of 1 intact washed platelets, sonicated platelets, lonophore-stimulated platelets and similarly treated erythrocytes on rates of thrombin-and factor Xa formation in our assay systems.

The lipids of the human blood platelet membrane are asymetrically distributed over the two leaflets of the lipld bilayer $(16,17)$. The negatively charged phospholipids, phosphatidylserine and phosphatidylinositol (respectively 11 and $4 \%$ of total platelet phospholipids), that are known to be active in coagulation, are localized almost excluslvely at the platelet membrane interior. Intact platelets therefore hardly stimulate clotting reactions whereas disrupted platelets do. The effect of increased platelet disruption by sonication on the ability of platelets to support prothrombin and factor $X$ activation $1 \mathrm{n}$ our assay systems 18 shown in fig.1. The release of lactate dehydrogenase indicating platelet discuption, runs parallel with the activity of the platelet sonicates in both activation assays. Apparently, sonication has changed the platelet membrane, such that the negatively charged 11p1ds become exposed and can participate in the two activation reactions.

An interesting non-physiological platelet activator 18 the divalent cation Ionophore A23187 which is a potent trigger of various platelet reactions (19-21). The activity of ionophore stimulated platelets in our reactions was tested by incubation of washed platelets with $1 \mu \mathrm{M}$ A23187 or with Me $2^{\text {SO }}$, the 


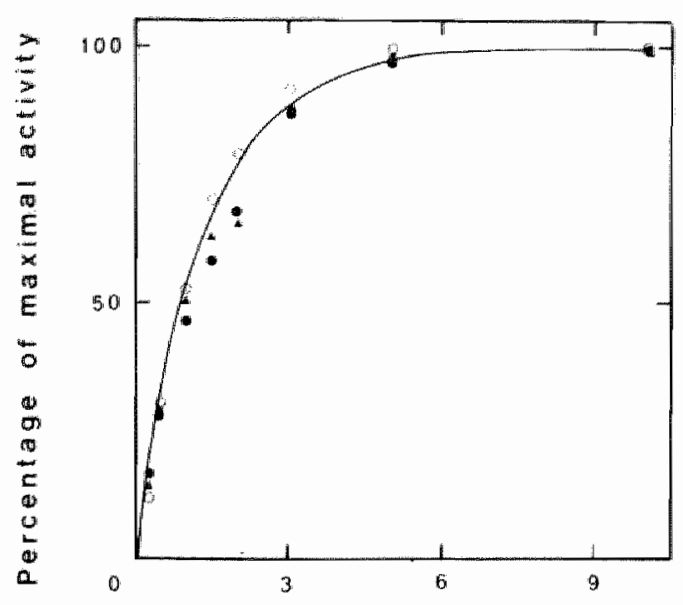

Time of sonication $(\min )$
Fig.1. Effect of sonication time on platelet release of lactate dehydrogenase and on the activities in factor $X$ - and prothrombin activation.

Washed platelets $\left(3 \times 10^{6} / \mathrm{ml}\right)$ were sonlcated for varying time perlads in the MSE sonicator set at the lowest power output. Samples $(0.475 \mathrm{~m} 1)$ from the sonlcate were taken to determine the amount of lactate dehydrogenase present. Samples of 0.312 $\mathrm{ml}$ were taken to deterwine the activity of the sonicates in the reaction systems for prothrombin- and for factor $X$ activation. The three assays were carried out exactly as described for activated platelets in $\mathrm{Ma}-$ terlals and Methods. $(0-0)$, lactate dehydrogenase activity; (-) ), activity in prothrombin activation; $(\boldsymbol{\Delta}-\boldsymbol{\Delta})$, activity in factor $X$ activation.

solvent for A23187, as control. After $5 \mathrm{~min}$ stirring at $37^{\circ} \mathrm{C}$ and with $3 \mathrm{mM}$ $\mathrm{CaCl}_{2}$ present, the protelns for activation of elther prothrombin- or factor $X$ were added and the rates of thrombin- and factor Xa formation determined. The results are presented in table 2 . Unstimulated platelets have a low activity in both systems. Incubation with A23187 resulted in a 50-60 fold increase of platelet activity in both systems, equal to $71 \%$ and $62 \%$ of the activity of sonicated platelets in activation of prothrombin and factor $X$ respectively. The ionophore effect is not due however to platelet $1 \mathrm{ys}$ is, because the platelet lactate dehydrogenase discharged from the platelets was $3 \%$ of that total present. Addition of A23187 to sonicated platelets or artiflcial phospholipld vestcles did not influence the rates of thrombin or factor Xa formation. The Lonophore and the solvent $\mathrm{Me}_{2}$ So therefore do not influence membrane structure or the activity of the clotting factors under our reaction conditions. When the lonophore atimulated platelets were centrifuged $(10 \mathrm{~min}, 7000 \mathrm{x} g), 17 \%$ of the platelet activity both in intrinsic factor $X$ actiwation and in prathrombin activation remained in the supernatant. This indicates that $83 \%$ of the activity 1 s platelet bound and is not released.

Table 2 also gives the rates of prothrombin- and factor $X$ activation found wth vesicles composed of purifled lipid components as present in the human platelet. The data shown are for $1 \mu M$ of total phospholipid present in the 
Table 2. Effect of platelets, erythrocytes, and vesicles of platelet 1ipld composition on the rate of thrombin- and factor Xa formation.

The effect on the rates of thrombin- and factor Ka formation by platelets, erythrocytes and synthetic membranes was measured in our reaction system for prothrombin and factor $X$ activation as described in Materials and methods. The final concentration of platelets and of erythrocytes in the reaction mixture was $2.5 \times 10^{6} / \mathrm{ml}$. Therefoxe the concentration of phospholipids in the reaction mixtures as provided by erythrocytes, platelets and synthetic vesicles was ljM (the platelet phosphollpid content was measured to be $0.4 \mu \mathrm{Moles} / 10^{9}$ platelets). The synthetlc vesticles were composed of (in mole percentage): phosphatidylserine $11 \%$, phosphatidy1inositol $4 \%$, phosphatidylethanolamine $28 \%$, sphingomyeline $19 \%$, phosphatidylcholine $38 \%$ and cholesterol in a cholesteral to phospholipid ratio of 1: l. Preparation of platelets, erythrocytes and synthetic vesicles is described in Materials and Methods.

\begin{tabular}{|c|c|c|}
\hline & $\begin{array}{l}\text { Rate of } \\
\text { thrombin formation }\end{array}$ & $\begin{array}{l}\text { Rate of } \\
\text { factor Xa formation }\end{array}$ \\
\hline & $\left(\mathrm{nM}\right.$ IIa.min $\left.{ }^{-1}\right)$ & $\left(\mathrm{nM} X \mathrm{xa} \cdot \mathrm{min}^{-1}\right)$ \\
\hline $\begin{array}{l}\text { Washed platelets, not } \\
\text { stimulated }\end{array}$ & 17 & 0.3 \\
\hline $\begin{array}{l}\text { P1atelets stimulated by } 1 \mu M \\
\text { A23187 during } 5 \text { min }\end{array}$ & 843 & 19.4 \\
\hline Platelets disrupted by sonication & 1188 & 31.5 \\
\hline $\begin{array}{l}\text { Vesicles with a phospholipid } \\
\text { composition found in platelets }\end{array}$ & 1214 & 34.2 \\
\hline Human erythrocytes & 7 & 0.0 \\
\hline $\begin{array}{l}\text { Human erythrocytes incubated with } \\
1 \text { M A23187 during } 5 \text { min }\end{array}$ & 19 & 0.0 \\
\hline $\begin{array}{l}\text { Human erythrocytes disrupted } \\
\text { by sonication }\end{array}$ & 1325 & 28.9 \\
\hline
\end{tabular}

reaction mixture, which allows direct comparison with the results for the platelet experiments that were carried out at $2.5 \times 10^{6}$ platelets/m1. (10 ${ }^{11}$ platelets contain $40 \mu$ moles of phosphollptd; P. Comfurtus, unpublished). It can be seen that vesicles of platelet lipld composition have the same activity in prothrombin- and factor $X$ actlvation as platelets disrupted by sonleation. Table 2 also shows results of experiments with erythrocytes, which have a phospholipid composition and membrane asymetry similar to platelets $(16,27)$. Washed erythrocytes are not active in our two assays, but as with platelets, activity appears after sonication ( 38 ). In contrast to platelets, incubation 


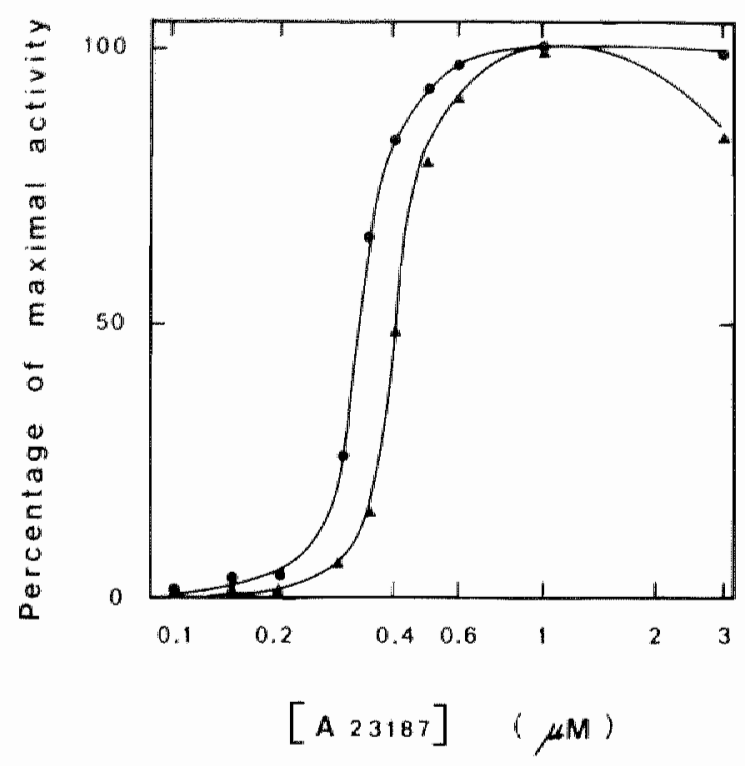

F1g.2. Dose-response curves showing the relationship between the activity of platelets in the reaction systems for prothrombin- and factor $\mathrm{X}$ activation after stimulation with various concentrations of ionophore A23187.

Platelet suspensions contain1ng $3 \times 10^{6}$ pilatelets/ml were adjusted to $3 \mathrm{mM} \mathrm{CaCl}$, and stirred at $350 \mathrm{rev} / \mathrm{min}$. To the platelets was added $5 \| 1$ of an appropriate A23187 dilution in dimethyl sulfoxide. After 10 min at $37{ }^{\circ} \mathrm{C}$, elther release of lactate dehydrogenase was measured (not shown) or the components of our reaction systems for prathrombin- or factor $X$ activation were added to determine rates of thrombin and factor $X a$ formation as described in Materlals and Methods. (-) Activity in prothrombin activation; ( $\Delta$ ) activity in factor $X$ activation.

of the red blood cells with $1 \mu M$ A23187 fails to enhance the activity of erythrocytes in prothrambin- and factor $X$ activation. The effect of $A 23187$ on platelet activation was investigated further by varying the lonophore concentration, the activation time by ionophore, and the platelet concentration at optimal and suboptiral ionophore concentration.

Flg.2 Indlcates that the major effects of lonophore are obtained in the range between 0.2 and $0.5 \mu \mathrm{M} \mathrm{A23187}$, and that the activity of platelets in prothrombin activation 19 seen at slightly lower A23187 concentrations than the activity in factor $X$ activation.

The appearance of activity in time is shown in $f 1 g .3 \mathrm{~A}, \mathrm{~B}$. In our assays, thrombin and factor Xa formation are determined over time periods of 30 and 90 seconds respectively, which precludes measurement of platelet activation times shorter than 1 min. With optimal A23187 (1 $\mu M$ ), maximal activation is already seen after $1 \mathrm{~min}$. With suboptimal A23187 $(0.4 \mu \mathrm{M})$ the activity in prothrombin activation appears rapid and $1 \mathrm{n}$ factor $X$ activation somewhat slower. Platelet activitles after activation remalned stable for at least 15 min. A small decline in factor $X$ - activating activity is seen. Prolonged incubation at suboptimal A23187 concentration, did not increase the level of 


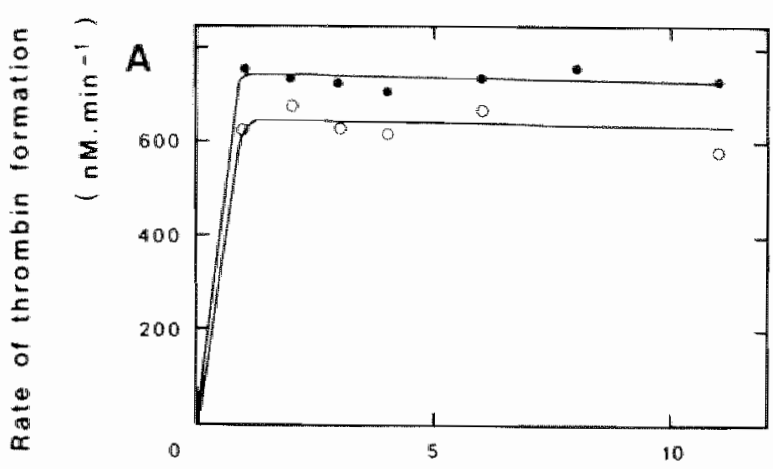

Time of stimulation (min)

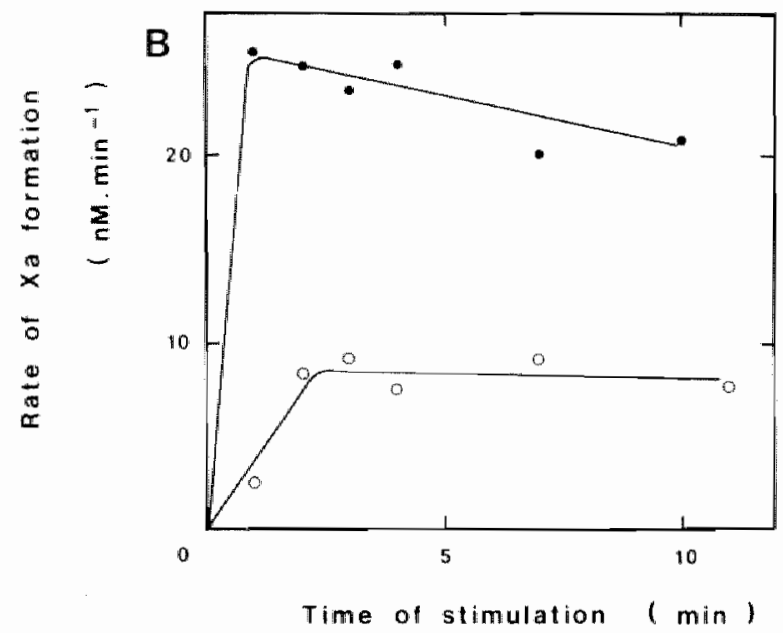

Fig.3. Thme course of appearance of platelet activity in factor $I I-$ and factor $X$ activation after triggering of the platelets at two A23187 concentrations.

platelets $3 \times 10^{6} / \mathrm{ml}$ at $3 \mathrm{mM}$ $\mathrm{CaCl}_{2}(320$ 11) were incubated at $33^{\circ} \mathrm{C}$ whle stirring and 5 al of lonophore A23187 was added to a concentration (in $325 \mu 1$ ) of either $1 \mu \mathrm{M}$ (closed circles) or $0.4 \mu \mathrm{M}$ A23187 (open c1rcles). After the time intervalls indicated in the figures, the components for efther the prom thrombin- or the factor $x$ activation system were added and the rates of prothrombinand factor $X$ activation were determined as described in Materials and Methods. (A) Activity of platelets in prothrombin activation; (B) activity in factor $X$ activation.

activity.

Fig. 4 shows the rates of thrombin- (f1g.4A) and factor Xa formation (fIg.4B) when varying amounts of platelets are stimulated for 5 min wth either $3 \mu \mathrm{M}$ or

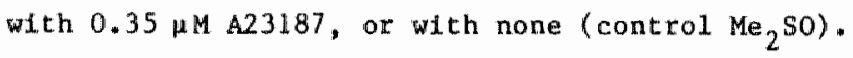

For comparison, we also determined the activities after platelet distuption by sonication. The rate of prothrombin activation $1 \mathrm{~s}$ proportional to the amount. of sonicated platelets up to $10 \times 10^{6}$ platelets/mi; at higher platelet concentration, the rate levels off, because of prothrombin depletion. The reaction system for factor $X$ activation begins to devlate from linearlty at lower platelet sonicate concentrations ( $5 \times 10^{6}$ platelets/mi), possibly because the factor VIIIa concentration becomes 1imiting. When platelets are stimulated with $3 \mu \mathrm{M}$ A23187, the rates of prothrombin- and factor $X$ activation Increase in parallel with the rates found for sonicated platelets. We conclude that 

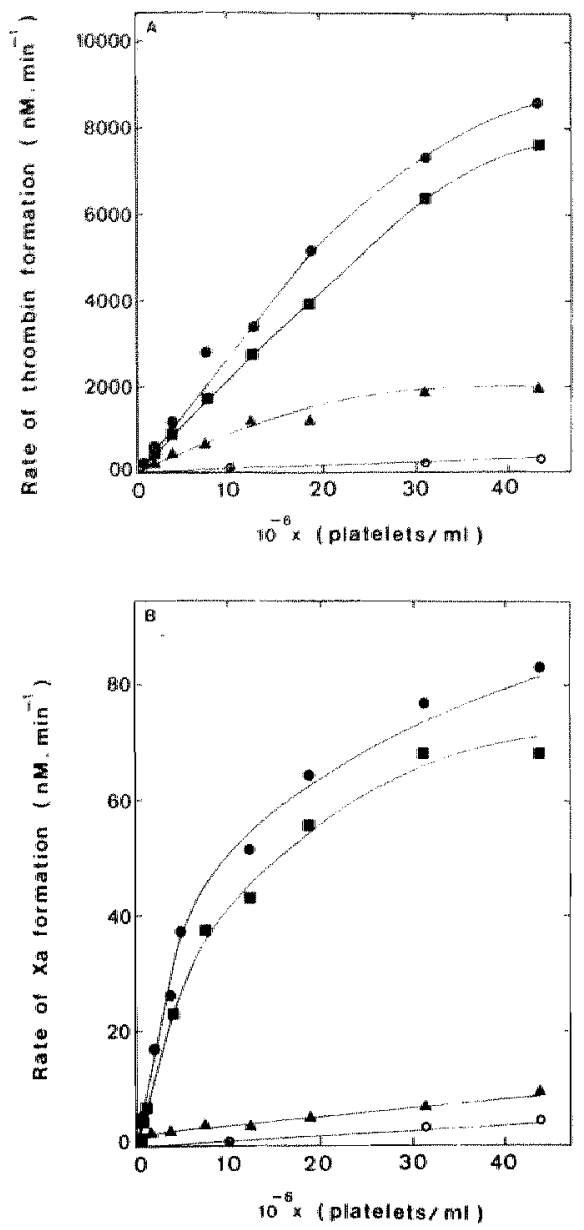

Pig.4. Relationship between the rates of prothrombin- and factor $x$ activation and the concencration of ether sonicated platelets or lonophore-stimulated platelets.

Platelets were sonicated or stimulated with either $3 \mu \mathrm{M}$ or $0.35 \mu \mathrm{M}$ A23187 or with Me $\mathrm{SO}_{2}$ at platelet concentrations as indicated in the figure. After 5 min, the platelet suspensions $(0.325 \mathrm{ml})$ were supplemented to a final volume of $0.5 \mathrm{ml}$, with the components for activation of prothrombin- and factor $X$ and the rates of thrombin- and factor Xa formation were determined as in Materials and Methods.(A) Activity in the reaction system for prothrombin activation; ( $B$ ) activity in the reaction system for factor $X$ activation. (O) Washed platelets, (A) $0.35 \mu \mathrm{M} \mathrm{A23187,} \mathrm{(E)} 3 \mu \mathrm{M}$ A23187, ( $\bullet$ ) after sonication.

stimulation at 3 MM A23187 results in optimal activation ower the whole range of platelet concentrations shown in fig.4A, B. With suboptimal A23187 (0.35 $\mu \mathrm{M})$ proportionality, particularly in factor $X$ activation, is only seen in the lower concentration ranges. It appears that at higher platelet concentrations, the effective Lonophore concentration is lowered, such that a constant intermedlate level of activation is not achleved. In agreement with $\mathrm{fig} .2$ is the observation that platelets activated with $0.35 \mu \mathrm{M}$ A23187 are relatively more active in prothrombin- than in factor $X$ activation.

Phospholipase $A_{2}$ treatment of A23187-activated platelets. If A23187 stimulation results in appearance of phosphatidylserine at the platelet surface, it 


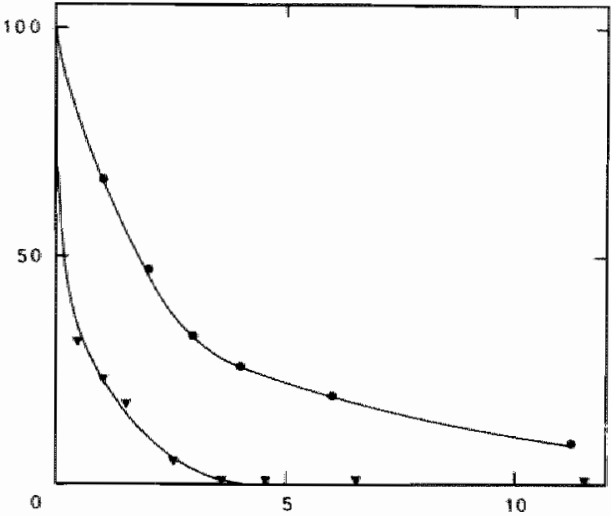

Time of incubation with phosphollipase A2 $(\min )$
Elg.5. Effect of phospholipase A incubation on the activity of Lonophore A23187 stlmulated platelets in the reaction systems for prothrombin- and factor X activation.

Platelets were stimulated by A23187 while stirring at $37^{\circ} \mathrm{C}$, in a volume of $0.325 \mathrm{ml}$ contalning $3 \mathrm{mM} \mathrm{Ca}, 1 \mu \mathrm{M}$ A23187 and $10^{\circ}$ platelets/ml. After 1 min at $37^{\circ} \mathrm{C}, 5 \mu 1$ of phospholipase $A_{2}(20 \mathrm{IU} / \mathrm{ml})$ was added and after the timeintervals indlcated in the figure the components for prothrombin- and factor $X$ activation were added, and the rates of factor IIa- and $\mathrm{Xa}$ formation determined as described in Materials and Methods. (O) Rate of thrombin formation; ( $\nabla$ ) rate of factor $X a$ formation. Rates measured 1 min after platelet stimulation. were chosen as 100\% activities.

was of interest to test whether elimination of phosphatidylserine would lead to loss of activity in the two activation reactions.

Therefore A23187-stimulated platelets were treated with phospholipase $A_{2}$ from Naja naja. This particular 1ipase was found to abolish activity of platelets in prothrombin activation and was also able to hydrolyse phosphatidylserine $(13,39)$. A time course of the effect of phospholipase $A_{2}$ incubation on the capacity of A23187 stimulated platelets to support prothrombin- and factor $X$ activation $1 \mathrm{~s}$ shown $1 \mathrm{n}$ fig.5. We find that the activity of A23187 stimulated platelets in both assays can be completely abolished by incubation with phosphollpase $A_{2}$. However, the activity of platelets in factor $X$ activation decreases faster than the activity in prothrombln activation. Phosphollpase treatment was not accompanied by platelet 1ysis, since lactate dehydrogenase release was less than $5 \%$ of that found after sonication. The phospholipase $A_{2}$ preparation was highly purifled and did not inactivate any of the protein components of the reaction systems for prothrombln- and factor $X$ activation. Effect of 1onophore A23187 on platelet aggregation and release. Soon after characterfzation of A23187 (40) 1 ts effect on platelets was atudied (19-21). A23187 induces release of serotonin and ATP; tobllizes intracellular $\mathrm{Ca}^{2+}$ stores, and causes aggregation. In view of the activity of A23187-stimulated 

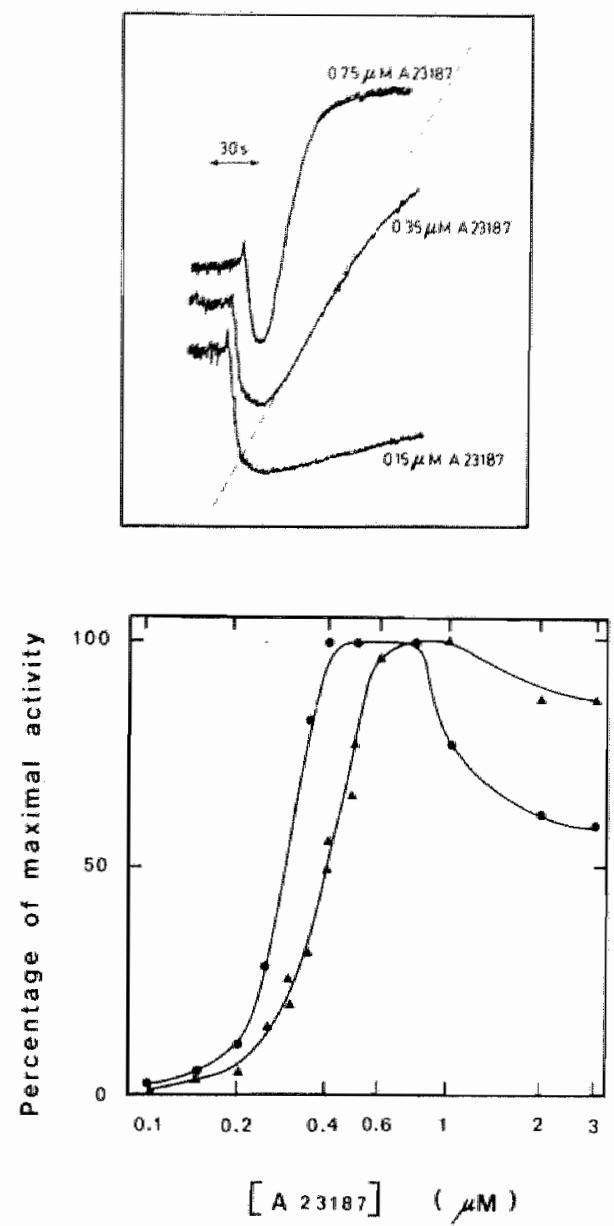

F1g.6. Aggregation of washed platelet suspenslons with ionophore A23187. Washed placelecs $\left(3 \times 10^{\prime} / \mathrm{ml}\right)$ were stirred at $37^{\circ} \mathrm{C}$ in an aggregometer with $3 \mathrm{mM} \mathrm{CaCl}$. 23187 was added to a final concentration of $0.75 \mathrm{HM}, 0.35$ $\mu . M$ and $0.15 \mu M$. The figure shows the recorder tracings observed at these concentrations. The rate of aggregation was taken as the slope of the dotted line. The bar represents 30 seconds.

Fig.7. Dose response curves Indicating the relationship between platelet aggregation and ATP release and the concentration of fonophore A23187.

platelets $\left(3 \times 10^{7} / \mathrm{m} 1\right)$ were aggregated with varying A23187 concentrations in the aggregometer. The rates of aggregation were calculated as described in fig.6 and presented as percentage of the maximal aggregation rate found at 1 HM A23187. The release of ATP was determined in the supernatants of platelets $\left(3 \times 10^{7}\right)$ mi) which were incubated for 5 min at $37^{\circ} \mathrm{C}$ at the $\mathrm{A} 23187$ concentration shown in the figure. ATP determination was as described in Materials and Methods. Release activity was presented as percentage of maximal released ATP found at $0.75 \mu \mathrm{M} \mathrm{A23187}$

(•) ATP release, (4) aggregation.

platelets in prothrombin- and factor $X$ activation described here it was of interest to investigate the relationship of these activities with release and aggregation. The aggregation reactions were done by stirring washed platelets $\left(3.0 \times 10^{7} / \mathrm{ml}\right)$ at $37^{\circ} \mathrm{C}$ in presence of $3 \mathrm{mM} \mathrm{CaCl}$, , in the aggregometer. The recorder tracings obtained at three different A23187 concentrations are shown in $\mathrm{fig.6}$. In the absence of added $\mathrm{Ca}^{2+}$ very little aggregation can be induced by $A 23187$ under our conditions, but upon addition of $\mathrm{Ca}^{2+}$ rapld aggregation is observed (not shown). Slopes were determined, as indicated by the dotted line In fig.6, and considered a measure for the rate of aggregation. A plot of aggregation rates versus A23187 concentration is shown in fig.7. The curve with closed circles in fig.7 represents ATP rellease in the platelet super- 


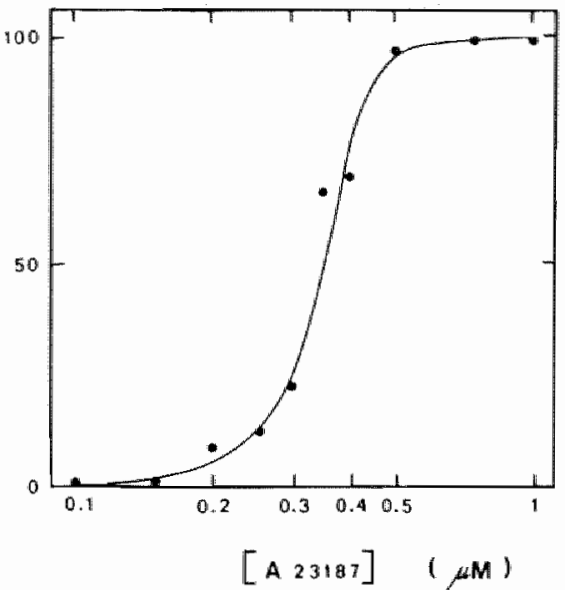

Fig.8. Dose response curve Indicating the dependence of factor $\checkmark$ release from platelets on the concentration A.23187.

Washed platelets $\left(1 \times 10^{7} / \mathrm{mL}\right)$ were stirred at $37^{\circ} \mathrm{C}$ and stimulated for 2 min at the 423187 concentrations ind 1 cated in the figure. Factor Va release was determined by addition of phospholipid vesicles, factor $\mathrm{Xa}$ and prothrombin and measurement of the rate of thrombin formation as described In Materlals and Methods. Maximal released activity was $89.6 \%$ of the factor Va activity found after the platelets were lysed ith $0.025 \%$ Triton $\mathrm{X}-100$, with $10 \mathrm{mM} \mathrm{CaCl}$, added to maintain Va activity.

matant in response to A23187 activation. ATP release is seen within a narrow range of A23187 concentrations and excess ionophore inhibits ATP release.

Since ATP, like ADP, $\mathrm{Ca}^{2+}$ and serotonin are situated in the platelet dense bodies, it was of interest to study the release of factor $V$, one of the proteins stored in the alpha-granules, a different platelet storage organe1. (41). Factor $V$ release was studied with a new assay. In the assay factor Xa, prothrombin, $\mathrm{CaCl}_{2}$ and phospholipid are added to the platelets. Excess phosphollpid is present to minimize the platelet lipid contribution. Reaction conditions were chosen such that the rate of prothrombin activation is proportional to the concentration of factor Va present. An advantage of the assay is that no centrifugation step is involved, thus avoiding the possibility that released but platelet bound factor $V$ is not measured leading to an underestimation of factor $V$ release. The rate of thrombin formation in the assay is linear in time, indicating that under our reaction conditions factor $V$ is present as factor va. The results abtained when $1 \times 10^{7}$ platelets/ml are stimulated with varying A23187 concentrations are shown in 1 1g.8. As found for platelet activitles in prothrombin- and factor $X$ activation and in ATP release, the release of factor $V$ was complete within 1 min, even at suboptiral A23187 concentration at which not all factor $V$ is released. Maximal factor $V$ releasie induced by $A 23187$ represented $90 \%$ of the factor $V(a)$ activity found in platelets 1ysed with $0.025 \%$ Triton X-100. Table 3 sumnarizes the A23187 concentrations to obtain half-maximal response of the various platelet functione. Half maximal activities of ATP release, factor $V$ release, activity in factor II- and $X$ activation and aggregation are found between 0.30 and $0.41 \mu M$ A23187. The concentration differences are not large enough to conclude that 
Table 3. Ionophore concentration requlred to obtain half-maximal effect on platelet function.

The A23187 concentrations at which $50 \%$ of optimal activity is obtained were conpiled fron the results shown in figs.2,7 and 8 .

\begin{tabular}{lc} 
Platelet function & concentration A23187 ( $1 M)$ \\
\hline release of ATP & 0.30 \\
prothronbin actiqution & 0.33 \\
release of factor $V(V a)$ activity & 0.35 \\
aggregation & 0.40 \\
intrinstic factor X activation & 0.41 \\
\hline
\end{tabular}

certaln processes are mutually unrelated but do not rule out a relationship between release of $x$-granules and appearance of procoagulant activity in factor II- and $X$ activation.

\section{DISCUSSION}

The main result presented in this paper is, that human platelets after a short Incubation with the divalent cation ionophore A23187 are stimulated 50 -60 fold in their capacity to support the prothrombin- and the intrinstc factor $X$ activation reactions. The effect is not due to platelet $1 y s i s$, and is specific in the sense that erythrocytes cannot be stimulated. The activity is platelet- bound, since $83 \%$ of the activity can be sedimented with the platelets. The increased activity of platelets after A23187 stimulation in prom thrombin-and factor $X$ activation, can be attributed to increased exposure at the platelet surface of negatively charged procoagulant phospholfpid, most likely phosphatidylsertne. This conclusion was obtalned using two lipld dependent measuring systems, in whlch rates of thrombin- and factor Xa formation are directly proportional to the 11pid concentration. Proportionality was observed for phosphollpld vesicles, for platelet sonlcates and for A23187 triggered platelets, which allowed direct comparison of activity of these preparations.

Phospholipid vesicles of platelet lipld composition, in a concentration as present in platelets gave the same rates of activation as a platelet sonicate. Therefore the platelet membrane proteins, that are present in the sonicate do not Influence the activity of the phospholipid present in the sonicate in factor $X-$ and prothrombin activation. Moreover the ionophore triggered platelets show activities in prothrombin- and factor $X$ activation well below those 
of vesicles of platelet phospholipid composition (69\% and $57 \%$ respectively). Thus, sufficlent procoagulant phosphollplid is present in the platelet menbrane, to account for the activities of A23187-activated platelets in prothrombin and factor $X$ activation. There appears no compelling reason to suppose a role for platelet membrane proteins in prothrombin- and factor $x$ activation, nor to postulate the existence of non-1ipid structures that bind clotting factors.

The negatively charged procoagulant phospholipids phosphatidylserine and phosphatidylinositol comprise $11 \%$ and $4 \%$ respectively of the total platelet phospholipid. In the unstimulated platelet most of these are located at the immer leaflet of the platelet membrane. Bevers et al. reported that after A23187 stimulation 50\% of the phosphatidylserine and $90 \%$ of the phosphatidylethanolamine was exposed at the platelet surface, no signiflcant amount of phosphatidylinositol was found (22). By 1tself, phosphatidylethanolamine 18 not procoagulant, therefore phosphatidylserine exposure most 11 kely explains the procoagulant activity of platelets after A23187 stimulation. The experiments with vesicles of variable phosphatidylserine content indicate a different phosphattdylserine requirement for the factor $X$ - and prothrombin activation reactions. The quotient of the rate of prothrombin- and the rate of factior $X$ activation is high at $2.5 \%$ phosphatidylserine and much lower for vesicles of 10-15\% phosphatidylserine. The quotlent of the rates of prothrombin- and factor $X$ activation found for platelets after sonication or after A23187 stimulation corresponds best with the quotient of the rates found for vesicles containing 10-15\% phosphatidylserine. Th1s suggests that the phosphatidylserine content of platelets after sonication or after stimulation by A23187 is between 10-15\%. This 1ndicates that sonication and platelet istimuLation by $A 23187$ result in rearangement of membrane lipids such that phosphatidylserine is nearly equally distributed over the two membrane leaflets.

When stimulated at suboptimal A23187 concentration, the platelets are relatively more active in prothrombin- than in factor $X$ activatlon. For example, the concentrations $A 23187$ required to induce half-maximal activity are $0.33 \mu \mathrm{M}$ and $0.41 \mu \mathrm{M}$ A23187 respectively. Aga1n, the comparison with vesicles of varying phosphatidylserine content provides an explanation. Vesicles containing low mole percentages of phosphatidylserine, were relative$1 y$ more active in prothrombin- than in factor $X$ activation. Th1s suggests that with suboptimal ionophore, Incomplete phosphatidylserine exposure at the platelet surface is obtained. Thus, platelets stimulated at 1ncreasing A23187 concentrations are most likely increasingly enriched in phosphatidylserine 
content in the platelet outer membrane leaflet.

The digestion experiments wh phospholipase $\mathrm{A}_{2}$ provide additional evidence for the presence of negat1vely charged phosphollplds like phosphatidylserine at the platelet outer surface after triggering by A23187. The progress1ve decline and abolimhent of activity of A23187-stimulated platelets in the reactions actlvating factor II and $X$ upon phospholipase treatment can be explained by progressive degradation of phosphatidylserine molecules at the platelet outer surface. The more rapid fall of platelet activity in factor activation compared to prothrombin activation, can be explained by the different phosphatidylserine requirements of the two reaction systems. If the phosphatidy1sertne content after A23187 stimulation is between 10 and $15 \%$, then a decline of this percentage would decrease the rate of factor $X$ activation more strongly than it would affect the rate of prothrombin activation, which stil proceeds rapidly at $2.5 \%$ phosphatidylserine.

An important step forward 4 the understanding of the role of platelets in clotting reactions was Miletich's finding that platelets that have undergone the release reaction possess 200-300 high affinity binding sites (receptors) for factor Xa (6). Factor Xa binding was dependent on platelet release induced by thrombin or by A23187. Later, it was found that thrombin merely served to release platelet factor Va and that released factor Va functioned as a receptor for factor Xa, by strongly enhancing factor Xa binding to platelets (7). When factor Va was added exogenously to non-stimulated platelets, the same number of factor $X a$ binaing sites were found $(8,12)$. The effect of A23187 on factor Xa binding, as the effect of thrombin, must be ascribed to factor Va release by the lonophore. However, the effect of exogenously added factor Va, on factor Xa blinding to lonophore atimulated platelets has not been investigated. From the results published by the group of Majerus $(6-8)$, by Dahlbäck and Stenflo $(9,10)$, and by the group of Mann $(10,12)$, It can be concluded that Irrespective of thromb1n stimulation human platelets possess 200-400 sites, whereas 900 blnding sttes for the factor Xa-Va complex are present on the bovine platelet. Unt11 now no detalled reports have appeared on the binding of factor IXa, and how 1t is Influenced by presence of factor VIILa, to phosphollpid vesteles or to activated platelets. The simflarities between the factor II- and $X$ actlvating systems $(4,5)$ and our own unpublished data suggest that In the presence of negatively charged phospholiplds factor VIIIa enhances the binding of factor IXa In the same way as the binding of factor Xa is increased by the presence of factor Va (30,42). Thus, if in the presence of platelets, factor $\mathrm{Va}$ is a receptor for factor $\mathrm{Xa}$, one may consider platelet 
Table 4. Calculation of binding sltes for the prothrombin activating complex at untriggered and at ionophore A23187-stimulated human platelets. Binding sites were calculated from kinetic data show in table 2 . The activation rates were devided by the Vmax for prothrombin activation (4). The maximally possible concentration is $15 \mathrm{mM}$ factor Xa-Va, given enzyme and cofactor concentrations present in our reaction mixtures.

Multiplication with Avogadro's number and division by the platelet concentration $\left(2.5 \times 10^{6}\right.$ platelets/mi) results in the number of enzyme complexes bound at the platelet surface.

\section{Prothromin activation}

no trigger

A23187

Rates of thrombin formation

from table 2 ( $\mathrm{MM}$ IIa.min ${ }^{-1}$ )

17

843

Platelet bound concen-

tration of factor Xa-Wa (nM)

$8.5 \times 10^{-3}$

$421 \times 10^{-3}$

Number of factor Xa-Wa

complexes bound per platelet

2040

101200

bound factor VIIIa a receptor for factor IXa. From the kinetic data presented In this paper, binding data can be inferred if it is assumed that the observed actlvation rates for prothrombin, were produced by platelet bound factor Xa-Va enzyme complexes. Further assumptions are that all the platelet binding sites are filled with factor $\mathrm{Xa}-\mathrm{Va}$, that sufficient substrate is present to achleve Vmax and that the Vmax with platelets is the same as determined with phosphoIipid vesicles. These assumptions are met for the prothrombin activating system, considering the various dissociation constants and kinetic parameters reported in the literature $(4,30,42,43)$. For the intrinsic factor $X$ activation system a similar calculation will be posslble as soon as information is aval1able on the binding of factors IXa and VIIa to platelets.

The binding data calculated from our kinetic data are presented in table 4. Unstimulated washed platelets contain 2040 binding sites per platelet for the prothrombin activating complex, comparable with the 200-900 binding sites per platelet reported in the literature that were ldentifled by direct binding experiments. After stimulation by ionophore, the 50 fold eahancement of the rate of thrombin and factor Xa formation corresponds to an increase in sltes Erom 2040 to about 100000 sites per platelet for the prothrombinase complex.

Erythrocytes have a similar phospholipid and membrane asymetry as platelets $(16,27)$, but cannot be activated by A23187. Sickled erythrocytes w111. accelerate clotting $\mathbb{t n}$ vitro (44), due to exposure of phosphatidylserine at the sickle-cell surface. The altered membrane asymmetry may have resulted from 
transbilayer phosphollpld movement or flip-liop across the membane, a mechanism also proposed for platelets (38). Both cell types may therefore possess the postulated flip-flop mechanism. Why A23187 only activates the process in platelets is unknown.

Ionophore A23187 induces several platelet responses, including rapid shape change, release, aggregation, liberation of arachidonic acid from endogenous phospholipids $(19-21,45-47)$, and as shown here increases activity in prothrombin- and factor $X$ activation. The mechanism of A23187 action is thought to involve the Liberation of $\mathrm{Ca}^{2+}$ from endagenous platelet stores into the cytoplasm. The various responses might be triggered by increases in the level of cytoplasmic $\mathrm{Ca}^{2+}$. It may be speculated that erythrocytes cannot be activated by 23187 because in these cells the Ca-stores are absent. For a discussion of the role of $\mathrm{Ca}^{2+}$, see: Gerrard et al (48). The appearance of procoagulant activity 18 not directly related to arachidonic acid liberation. Both thrombin and A23187 release arachidonic acld, but thrombin alone is an inefficient Inducer of procoagulant activity (13).

The effect of A23187 on the procoagulant activity of platelets described in this paper may be an important tool in further elucidation of the mechanism by which a platelet procoagulant surface is generated under physiological conditions.

\section{REFERENCES}

1. Gordon, J.L. (1981, editor). Platelets in Blology and Pathology-2. Elsevier/North-Holland Biomedical Press, Amsterdam.

2. Jackson, C.M. Nemerson, Y. (1980) Annu. Rev. Biochem. 49,765-81l.

3. Davie, E.h. (1981) 1n: Methods in Enzymol. 80 (L. Lorand, ed.), 153-157 Acaden1c Press, New York.

4. Roslag, J., Tans, G., Govers-Rlemslag, J.W.P., Zwal, R.F.A. \& Hemker, H.C. (1980) I. B1ol. Chem. 255,274-283.

5. wan Dieljen, G., Tans, G., Rosing, J. \& Hemker, H.C. (1981) J. Biol. Chem. $256,3433-3442$.

6. Mllettch, J.P., Jackson, C.M. \& Majerus, P.W. (1977) Proc.Nat1.Acad.Sc1. USA, 74, 4033-4036.

7. Miletich, J.P., Jackson, C.M. \& Majerus, P.W. (1978) J.Bio1.Chem.253, 6908-6916.

8. Kane, W.H., Lindhout, M.J* Jackson, C.M. \& Majerus, P.W. (1980) J.Blol. Chern. $255,1170-1174$.

9. Dahlbäck, B. Stenflo, J. (1978) Blochemlstry 17,4938-4945.

10. Dahlbäck, B. \& Stenflo, J. (1980) Eur. J. Blochem. 104,549-557.

11. Tracy, P.B., Peterson, J.M., Nesheim, M.T., McDuffie, F.C. \& Mann, K.G. (1979) J.Blol.Chem. 254,10345-10361. 
12. Tracy, P.B., Neshe1m, M.E. \& Mann, K.G. (1981) J.BLo1.Chem. 256,743-751.

13. Bevers, E.M., Comfurius, P. , van Rijn, J.L.M.L., Henker, H.C. \& zwaal, R.F.A. (1982) Eur.J.Biochem. 122,429-436.

14. Walsh, P.N. \& Biggs, R. (1972) Brit.J.Haematol. 22,743-760.

15. Walsh, P.N. (1978) Brit.J.Haemato1. $40,311-331$.

16. Chap, H.J., Zwad, R.F.A. \& van Deenen, L.L.M. (1977) Blochim.Blophys. Acta $467,146-164$.

17. Schick, P.K., Kurica, K.B. \& Chacko, G.K. (1976) J.Clin.Invest. 57, $1221-1226$.

18. Zwaal, R.F.A., Henker, H.C. (1982) Haemostasis 11, 12-39.

19. White, J.G., Rao, G.H.R. \& Gerrard, J.M. (1974) Am.J.Pathol. 77,135-149.

20. Feinnan, R.D. \& Detwiler, T.C. (1974) Nature 249,172-173.

21. Feinstein, M.B. Eraser, C. (1975) J.Gen.Phys. 66,561-581.

22. Bevers, E.M., Comfurius, P.C. \& Zwall, R.E.A. (1979) Thromb.Haemostas.42, 211 (Abstract)

23. Zwaal, R.F.A., Rosing, J., Tans, G., Bevers, E.M. \& Henker H.C. (1980) 1n: The Regulation of Coagulation (Mann, K.G. \& Taylor, F.B., eds.) P. 95, Elsevier-North-Holland, Amsterdam.

24. Comfurius, P. \& Zwaal, R.F.A. (1977) Biochlm. Biophys.Acta 488, 36-42.

25. de Kruijff, B., Cullis, P.R. \& Radda, G.K. (1975) Blochlm.Blophys. Acta $406,16-20$.

26. Böttcher, G.J.F., van Gent, C.M. \& Pries, C. (1961) Anal.Chim.Acta 24, $203-207$.

27. Zwaal, R.F.A., Roelofsen, B. Comfurius, P. \& van Deenen, L.L.M. (1975) Blochim. Blophys. Acta 406,83-96.

28. Stenflo, J. (1976) J.Biol. Chem. 251,355-363.

29. Schiffman, S., Theodor, I. \& Rapaport, S.I. (1969) Blochemistry 8, $1397-1405$.

30. Lindhout, M.J., Govers-Riemslag, J.W.P., van de Waatt, F., Hemker, H.C. \& Rosing, J.(1982) J.Biol. Chemistry 21,5494-5502.

31. Vehar, G.A.\& Davie, E.W. (1980) Biochemistry 19,401-410.

32. Chase, T., Jr \& Shaw, E. (1969) Blochemlstry 8, 2212-2224.

33. Smith, R.L. (1973) J.B1o1.Chem. 248, 2418-2423.

34. Byrne, R., Link, R.P. \& Castellino, F.J. (1980) J.Biol.Chem. 255, 5336-5341.

35. Owen, W.G., Esmon, C.T. \& Jackson, C.M. (1974) J.Biol.Chem. 249,594-605.

36. Fujikawa, K., Legaz, M.E., Kato, H. \& Davde, E.W. (1974) Blochemistry 11, 4892-4899.

37. Jackson, C.M., Johnson, T.F. \& Hanahan, D.J. (1968) B1ochemistry 7 , 4492-4502.

37a.van Dieijen, G., Rosing, J., van Ri.jn, J.L.M.L., Bevers, E.M., Hemker, H.C., Zwaal, R.F.A. (1983) Current Toples in Haenophilla 3-14 (Wensley, R.T. ed.)

38. Zwaal, R.E.A., Comfurlus, P. \& van Deenen, L.L.M. (1977) Nature 261. 358-360.

39. Bevers, E.M., Comfurius, P. Zwal, R.F.A. (1982) Eur.J.Blochem. 122, 81-85.

40. Reed, P.W. \& Lardy, H.A. (1972) J.BLol.Chem. 247,6970-6974.

41. Chesney, C.M. Pifer, D. \& Colman, R.W. (1981) Proc.Nat1.Acad.Sc1. USA 78, 5180-5184.

42. Nesheim, M.E., Taswe11, J.B. \& Mann, K.G. (1979) J.B1o1.Chern.254, 10952-10962.

43. Nesheim, M.E., Eld, S. Mann, K.G. (1981) J.B101.Chem. 256,9874-9882.

44. Chiu, D., Lubin, B., Roelofsen, B. \& van Deenen, L.L.M. (1981) Blood 58, 398-401

45. Rittenhouse-Simmons S. \& Deykin, D. (1977) J.C11n. Invest * 60,495-498. 


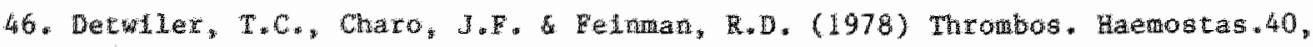
$207-21$.

47. Holden, H. (1978) Adv, Pharmaco1. Ther, 4,97-109.

48. Gerrard, J.M. Peterson; D.A. G White, J.G. (1981). In: platelets in 810logy and Pathology-2 (Gordom, J.L.ed) pp 407-436, Elsevier/Nartholland Donedcal press, Ansterdam. 
ASSEMBLY OF THE INTRINSIC FACTOR X ACTIVATING COMPLEX; INTERACTIONS BETWEEN FACTOR IXa, FACTOR VIIIa, AND PHOSPHOLIPID

\author{
SUMMARY
}

The activation of blood coagulation factor $X$ by factor IXa is strongly stimulated by the non-enzymatic cofactors phospholipld, Ca $2+$ and activated factior VIII. In this paper we derived an expression, which enabled the determination of binding parameters of factor IXa for phospholipids (elther in the absence or presence of factor VIIIa) from kinetic measurements of factor $X$ activation. It is shown that rates of factor $X$ activation in the presence of phosphollplds could be saturated with an excess factor VIrIa at liniting amounts of factor IXa and vice versa. These data indicate that the enzymatic unit in the $1 n t r i n-$ sic factor $X$ activator is a $1: 1$ stolchiometrical complex of factor IXa and factor VIIIa bound to phospholipid. Titrations with factor IXa at Elxed concentrations of phospholipid and factor $X$ show that the appagent dissocilation constant of factor IXa for phospholipid is lowered from $10^{-6} \mathrm{M}$ to $10^{-8} \mathrm{M}$ by the presence of factor VIIIa. We conclude that in analogy to the factor Xafactor Va interaction in the prothrombinase complex, factor VIIIa functions as a high-affinity binding site ("receptor") for factor tXa in intrinsic factor $X$ activation. Therefore, factor VIIIa increases the Vmax of factor $X$ activation by 1) enhancing the $k$ cat of the reaction and 2) increasing the amount of phosphollpid-bound factor IXa that participates in factor $X$ activation.

\title{
INTRODUCTION
}

During blood coagulation the zymogen factor $X$ is converted into factor Xa by the serine protease factor IXa (For a review see ref. 1). The rate of factor $X a$ formation is strongly increased by the presence of negatively charged phospholiplds, $\mathrm{Ca}^{2+}$ lons and activated factor WIII (For a review on factor VIII see ref.2). It ts thought that during factor $X$ actlvation, factor IXa and VIIIa are associated in a complex adsorbed at the phospholipld surface, that 1s termed the intrinstc factor $X$ activator or the intrinsic factor $X$ activating complex (3-7). A detalled understanding of the mode of action of this complex ultimately requires quantification of the interactions between the components. Binding parameters 1.e. dissociation constants and number of binding sites have been determined for interaction of factors IXa and $X$ wth phospholipid vesicles of varying composition $(8,9)$. Until now no data are avallable, however, on interactions that involve factor VIII. 
The organisation of the components of the factor $x$ activating complex as postulated above strongly resembles the structure of the prothrombinase complex (3-10). Data on the interactions between the components of the latter complex have been obtained by several methods. One technique was to infer blinding parameters from the kinetics of prothrombin activation $(11,12)$. The binding data presented in this paper, derived from kinetic studies of factor $X$ activation, provide evidence that a factor IXa-factor VIILa-phospho11pld complex is the catalytlc unit in factor $x$ activation and further indicate that the 1ncorporation of factor IXa in the enzymatic complex is strongly promoted by activated factor VIII.

\section{MATERIALS AND METHODS}

Materials. S2337 (Bz-Ile-Glu (P1per1dy1)-G1y-Arg-p-nitroanilide) was purchased from Kabi AB, Sweden; Sephacryl-S300 was from Pharmacia Sweden. Phosphat1dy1-

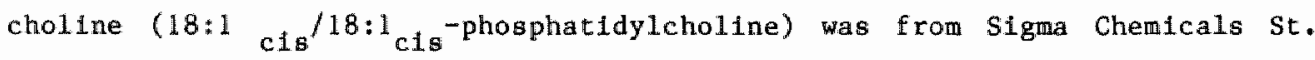
Louls USA; Sphingonyelin was from Koch-Light, England. All reagents were of highest grade avallable supplied by Merck, Darmstadt, Germany and by Sigma Chemicals, St. Louis USA.

Phosphol1plds and phospholipid vesicles. Phosphatidylethanolamine and phosphatidylserine (both $18: 1_{\mathrm{c} 1 \mathrm{~s}} / 18: 1_{\mathrm{cls}}$ ) were prepared by enzymatic synthesis (13). Vestcles were prepared by sonication in a buffer contalning $50 \mathrm{mM} T r i s-$ HCl and $175 \mathrm{mM} \mathrm{NaCl} \mathrm{pH} 7.9$ as described before (10). The composition of the vesticles was: $25 \%$ phosphatidylserine, $28 \%$ phosphatidylethanolanine, $19 \%$ sphingomyelin, 28\% phosphatidylcholine and cholesterol in a $1: 1$ molar ratio with respect to the total phospholiptd concentration.

Protelns. Bowlne factors $x_{2}$, IXa and thrombin were prepared as described previously (6). Factor VIIL:C was purified from bovine blood using the method of Vehar and Davie (14), modifled as follows. After chromatography on sulfatesepharose we onitted the factor $X$-sepharose step because factor VIrI falled to bind to this colum. The final purification step for factor VIII consisted of gelfiltration on Sephacry1-5300. Factor VIII eluted as a broad peak corresponding to the elution position of bovine catalase $\left(M_{r} 232000\right)$. Analysis of the colum fractions by SDS-polyacrylamide gelelectrophorests followed by silver staining showed two predominant bands at 250000 and 74000 . Factor VIII stock solutions were dialyzed against a buffer contalning $10 \mathrm{mM}$ morpholinoethane 
sulfonic acid, $175 \mathrm{mM} \mathrm{NaCl}, 10 \mathrm{mM} \mathrm{CaCl}_{2}$, $10 \%$ glycerol, adjusted to pH 6.5 with 1 Mr1s. Factor VIII was diluted in the same buffer containing $10 \mathrm{mg} / \mathrm{ml}$ human albumin.

Activation of factor VIII. Factor VIII was actlvated by thrombin. Optimal conditions were determined as described before by direct measurement of the effect of factor VIIIa on the rate of factor $x$ activation (6). In a typical experiment factor VIII was activated for $1 \mathrm{~min}$ at $37^{\circ} \mathrm{C}$ and $\mathrm{pH} 7.9$ at a thrombin concentration of $3.65 \mathrm{nM}(130 \mathrm{ng} / \mathrm{m} 1,0.36 \mathrm{NIH}-$ units/mi).

Factor X activation. Rates of factor Xa formation were determined with the specific chromogenic substrate $\$ 2337$ as described before (6).

Quantification of factor VIII. The concentration of factor VIII was deternined by a one-stage clotting assay using factor VIII defictent plasma and was expressed in units/m1, assuming the presence of 1 untt/ml of factor VIII in plasma pooled from 10 cows. The purifled factor VIII preparation had a spectfic activity of 1600-3000 units/mg in a clotting assay, assuming a $A_{280} 1 \%$ nm 10.0. It is uncertain which of the bands in the factor VIII:C preparation as seen on SDS-gels are assoclated with procoagulant activity. Therefore the concentration of active factor VIII:C camnot be determined from absorbamce at $280 \mathrm{~nm}$. The results in this paper provide evidence for factor IXa-factor VIIIa complex formation at the phospholipld surface. When it is assumed that factor IXa and factor VIIIa are present in a $1: 1$ molar stolchiometrical complex, it appeared possible to determine the molar concentration of factor VIII. The method involves saturation of a limiting known amount of factor IXa with factor VIIIa, which provides the activity of the factor IXa-VIIIa complex; followed by saturation of a limiting unknow amount of factor VIIIa with factor IXa. With $V$ (VIIIa) and $V$ (IXa) being the rates of factor X activation determined for a known concentration of factor IXa saturated with factor VIILa and for an unknown amount of factor VIILa saturated with factor IXa, respectively, the molar factor VIIIa concentration can be calculated from the equation:

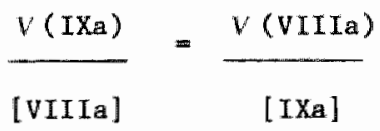


Derivation of binding parameters from kinetic measurements. In previous studies (6) we have demonstrated that the actlvation of factor $X$ by factor IKa is increaged 3 orders of magnitude by negatively charged phospholipids and that the presence of the non-enzymatic protein cofactor VIIIa causes an additional 200 000-fold rate enhancement. Rinetic analysis (6) revealed that factor viIIa Increases the Ymax of factor $X$ activation whereas the presence of phosphollpid bilayers decreases the $\mathrm{Km}$ for factor $\mathrm{X}$. These effects of accessory components on the kinetic parameters of factor $X$ activation do explain the above mentioned rate enhancements. The drop of the $\mathrm{Km}$ in the presence of phospholipids is explained in a model in which phosphollpids promote the formation of the enzyme-substrate complex by binding both factor $I X a$ and factor $X$. The factor $X$ and Factor IXa concentrations $\mathbb{I n}$ the presence of phospholipids can be chosen wuch that only factor IXa molecules which are incorporated in elther factor IXa-phosphollpid- or factor IXa-factor VIIla-phospholipld complexes (factor IXa bound) contribute to the rate of factor $X$ activation ( $V$ ). In that case

$$
V=c \cdot[I X a]_{\text {bound }}
$$

where $c$ is a proportionality factor determined by the kinetic parameters of factor $X$ activation. The dissociation constant Kd for dissociation of factor lXa from kinetically functional binding sites is given by

$$
\mathrm{Kd}=\frac{[\text { IXa }]_{\text {free }}\left([\text { sites }]_{\text {tota }}-[\text { IXa }]_{\text {bound }}\right)}{[\text { IXa }]_{\text {bound }}}
$$

where [IXa] free is the concentration factor IXa free in solution and [altes] total ls the total concentration of factor IXa binding sites (phospholipld or factor VIILa-phospolip1d).

Rearrangement of equation II yields:

$$
\frac{1}{[I X a]_{\text {bound }}}=\frac{k d}{[I X a]_{\text {free }}[\text { [s1tes }]_{\text {total }}}+\frac{1}{[\text { [stes }]_{\text {tota }}}
$$

Substitution of equation $I$ in III results in:

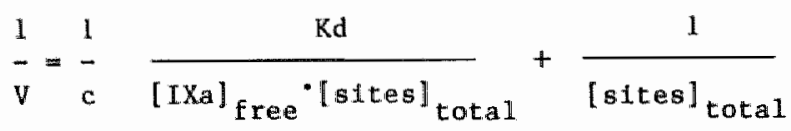

A pllot of $V^{-1} \mathrm{vs}$. [XXa] free 15 linear, with the intercept at the ordinate being $\mathrm{c}^{-1}\left[\right.$ sites] ${ }_{\text {total }}^{-1}$ and the intercept at the abclssa equal to $-\mathrm{Kd}^{-1}$. The $\mathrm{Kd}$ is the 

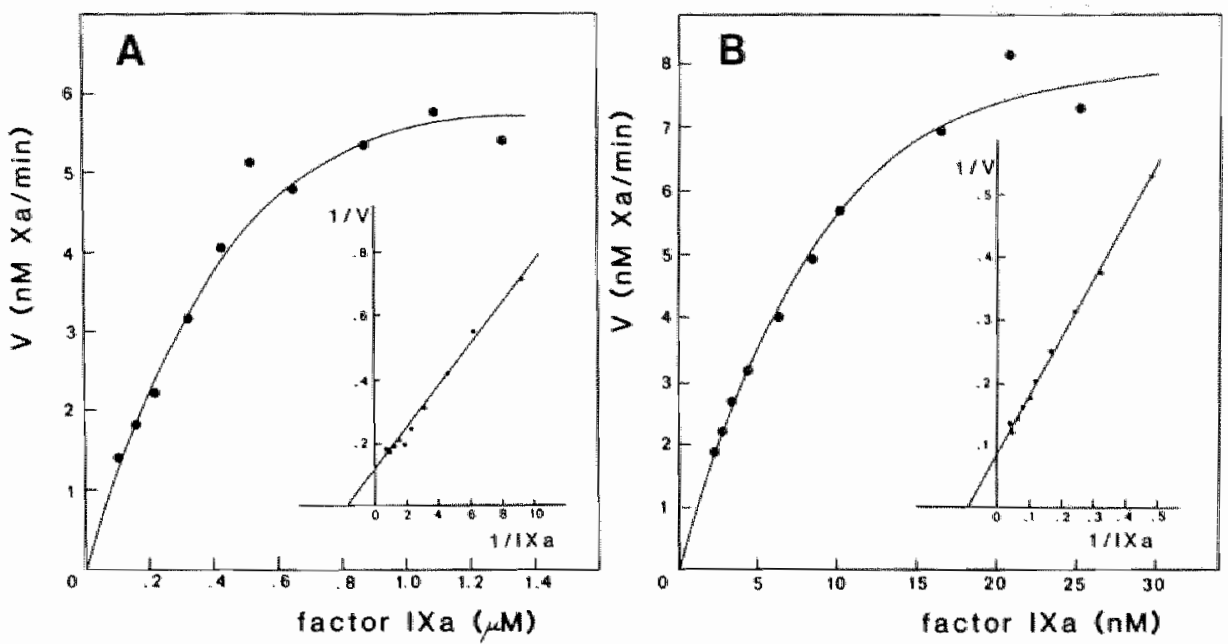

FIG.1. Effect of factor IXa on the rate of factor $X$ activation in the absence (A) and presence (B) of factor VIIIa. Factor IXa and phospholipid vesicles were prewarmed at $37^{\circ} \mathrm{C}$ in $0.3 \mathrm{ml}$ of a buffer containing $50 \mathrm{mM} \mathrm{Tr} 1 \mathrm{~s}-\mathrm{HC} 1,175$ $\mathrm{mM} \mathrm{NaCl}, 10 \mathrm{mM} \mathrm{CaCl}, \mathrm{pH} 7.9$. Factor $\mathrm{X}$ activation was started by addition of $0.2 \mathrm{~m} 1$ prewarmed factor $X$ (panel A) or $0.1 \mathrm{ml}$ of actlwated factor VIIL plus $0.1 \mathrm{ml}$ of factor X (panel B). After $60 \mathrm{~s}$ and $120 \mathrm{~s}$ (A) or $45 \mathrm{~s}$ and $90 \mathrm{~s}$ (B) samples were taken and assayed for factor Xa as described in Expertmental Procedures. The final composition of the reaction mixtures was: factor IXa as Indicated, $25 \mu \mathrm{M}$ phospholip1d, $0.5 \mu \mathrm{M}$ factor $\mathrm{X}, 50 \mathrm{mM} \operatorname{Tr} 1 \mathrm{~s}-\mathrm{HCl}, 175 \mathrm{mM} \mathrm{NaCl}$, $\mathrm{pH} 7.9,6 \mathrm{mM} \mathrm{CaCl}, 0.5 \mathrm{mg} / \mathrm{ml}$ human albumin. The composition of the reaction mixtures of the experiments shown in pane1 B were 1dentical to panel $A$, except for the presence in $\mathbb{B}$ of thrombin-actlvated factor VIII in a final concentration of $0.012 \mathrm{nM}(0.011$ units $/ \mathrm{ml})$. The 1nsets deplct double-rectprocal plots of the titration curves.

concentration [IXa] free required to occupy $50 \%$ of the stestotal, which w11. result in half-maximal factor $X$ activation rates. When [IXa] bound $\ll[I X a]_{\text {free }}$ (a condition met in the experiments presented in this paper), the free factor IXa concentration equalis the total concentration of factor IXa, which allow the estimation of the binding parameters of factor IXa for phosphollpld from intercepts in plots of $\mathrm{V}^{-1} \mathrm{vs}[\mathrm{IXa}]_{\text {total }}^{-1}$

Assembly of the 1ntrinslic factor $X$ activating complex, studied by varying the factor IXa concentration. The relationship between the rate of factor $X$ activation and the concentration of factor IXa, in the presence of phosphollplde, was examined to determine whether binding data for factor IXa could be derived from kinetic experiments. In the two experiment show 1 f $f 1 g .1$, inftial rates 
Table 1 . Assembly of the lntrinsic factor $X$ activating complex in absence and presence of factor VIIIa at varylng phospholipld and factor $X$ concentration. The reaction conditions were as described in flgure 11 . The concentration of factor VIILa, when present, was $0.017 \mathrm{nM}$. V(IXa) ls the rate of factor $\mathrm{X}$ activation at infintely high concentration of factor IXa. Kd ${ }^{2}$ is the factor IXa concentration required to obtain $0.5 \mathrm{~V}$ (IXa).

\begin{tabular}{|c|c|c|c|c|c|}
\hline \multicolumn{2}{|c|}{$\begin{array}{l}\text { Components in } \\
\text { reaction mixture }\end{array}$} & \multicolumn{2}{|c|}{$\begin{array}{l}\text { Absence of } \\
\text { factor VIIIa }\end{array}$} & \multicolumn{2}{|c|}{$\begin{array}{l}\text { Presence of } \\
\text { factor VIIIa }\end{array}$} \\
\hline $\begin{array}{l}\text { Eactor } X \\
(\mu M)\end{array}$ & $\begin{array}{l}\text { Phospho- } \\
\text { lipld } \\
\text { (HM) }\end{array}$ & $\begin{array}{l}\mathrm{Kd}^{\mathrm{app}} \\
\text { factor IXa } \\
\text { (nM) }\end{array}$ & $\begin{array}{c}V(\mathrm{IXa}) \\
(\mathrm{nMXa} / \mathrm{min})\end{array}$ & $\begin{array}{l}\text { Kd } \\
\text { factor IXa } \\
\text { (nM) }\end{array}$ & $\begin{array}{c}V(\text { IXa }) \\
(\mathrm{nM} \mathrm{Xa} / \mathrm{mIn})\end{array}$ \\
\hline $\begin{array}{l}0.5 \\
0.5 \\
0.5 \\
0.2 \\
0.05\end{array}$ & $\begin{array}{l}10 \\
25 \\
50 \\
50 \\
50\end{array}$ & $\begin{array}{r}370 \\
770 \\
1110 \\
830 \\
480\end{array}$ & $\begin{array}{r}2.8 \\
10.4 \\
23.2 \\
14.3 \\
4.2\end{array}$ & $\begin{array}{r}6.7 \\
10.0 \\
16.1 \\
5.1 \\
3.0\end{array}$ & $\begin{array}{r}9.1 \\
11.4 \\
12.3 \\
7.2 \\
4.1\end{array}$ \\
\hline
\end{tabular}

of factor $X$ activation were determined as a function of the concentration factor IXa at fixed concentrations of phospholipid vesicles $(25 \mu \mathrm{M})$ and factor $X(0.5 \mu M)$. In panel $A$ no factor VIIla was added and in panel $B$ thrombin activated factor VIII at a concentration of $0.012 \mathrm{nM}(0.011$ units/m1) was present. In both experiments the rate of factor $X$ activation reached a plateau value and could, therefore, be saturated with respect to factor IXa. However the factor IXa concentration required for saturation was considerably lower in the presence of factor VIIIa (B) than in its absence (A). Double-reciprocal plots of the data of $1 \mathrm{fg} .1$ show a linear relationship between the plotted variables. Straight lines in double-rectprocal plots are in accordance with equation IV. This expression was derived for titration of single identical binding sites with factor IXa, whlch upon accupation, contribute to the rate of factor X activation. By applying equation IV to the kinetic data, apparent Kd values for the dissociation of factor IXa from factor IXa-phospholipid and factor IXa-factor WIIIa-phosphollpid complexes could be calculated. The Kdapp found in the absence of factor Vlila was $770 \mathrm{nM}$ and in the presence of factor vilia $10 \mathrm{mM}$.

Additional factor IXa titration experiments in the absence and presence of factor VII were carried out at varylng phosphollpid and factor $X$ concentrations. All double-reciprocal plots were linear, and binding and kinetic data calculated from the plots are summarized in table 1 . It is shown that all $\mathrm{Kd}^{\mathrm{aPp}}$ values for factor IXa are 50-100 fold lowered by the presence of factor VIIIa, indlcating that factor IXa has a higher affinity for factor VIIIaphosphollpld complexes than for phosphollpid alone. The small effects of 


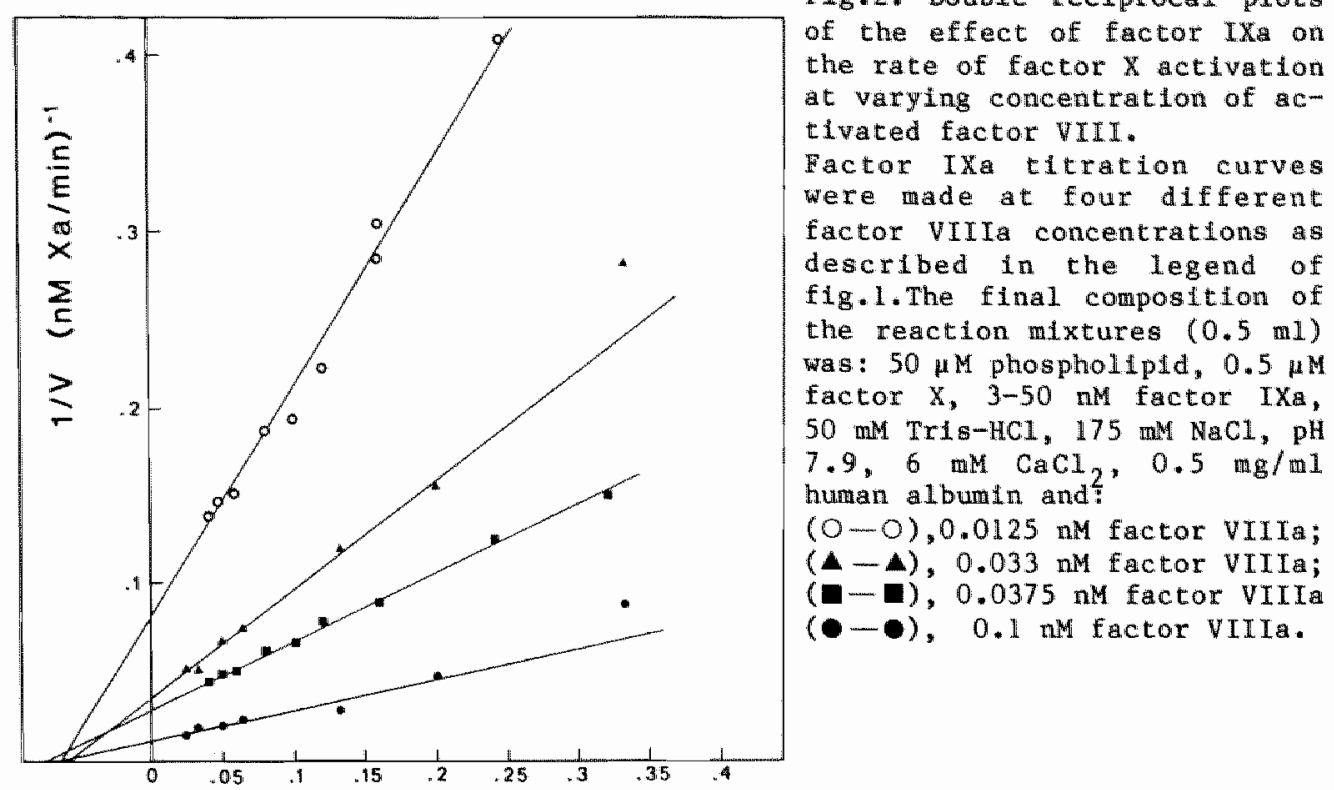

Fig.2. Double reclprocal plots of the effect of factor IXa on the rate of factor $X$ activation at varying concentration of $a c-$ tivated factor WIII.

Factor IXa titration curves were made at four different factor VIIIa concentrations as described in the legend of fig.l. The final composition of the reaction mixtures $(0.5 \mathrm{ml})$ was: $50 \mu \mathrm{M}$ phosphollp $1 d, 0.5 \mu \mathrm{M}$ factor $\mathrm{X}, 3-50 \mathrm{nM}$ factor IXa, $50 \mathrm{mM}$ Tris-HC1, $175 \mathrm{~mm} \mathrm{NaC1}, \mathrm{pH}$ $7.9,6 \mathrm{mM} \mathrm{CaCl}, 0.5 \mathrm{mg} / \mathrm{ml}$ human albumin and:

$(0-0), 0.0125 \mathrm{nM}$ factor VIIIa;

$(\Delta-\Delta), 0.033 \mathrm{nM}$ factor VIIIa;

(a- $), 0.0375 \mathrm{nM}$ factor VIITa

$(\bullet-), 0.1 \mathrm{nM}$ factor VIIIa.

$1 / 1 \times a(n M)^{-1}$

varying phospholipid and factor $X$ concentrations on $\mathrm{Kd}^{\mathrm{app}}$ will be further considered in the discussion.

In the absence of factor VIIIa, the $V$ (IXa) values (rates of factor X activation obtained by extrapolation to infinitely high concentration of factor IXa) Increased at increasing phospholipid concentrations. The proportional increase of $V$ (IXa) with the phospholipid concentration is consistent with an Increased number of sites for factor IXa avallable at the phospholipld surface. In the presence of factor VIIIa, $V(I X a)$ was hardly affected by the phospholipid concentration, suggesting that under these conditions factor VIIIa rather than phospholipid limits the total amount of factor IXa-factor VIIIa-phosphollpld complexes whlch can be formed. Both in the absence and presence of factor VIIIa, decrease of the factor $X$ concentration resulted in a decrease of V(IXa) "which is due to the fact that rates of factor $X$ activation were measured at

a factor $X$ concentration around the $\mathrm{Km}$. The $\mathrm{Km}$ for factor $\mathrm{X}$ at $50 \mu \mathrm{M}$ phospho1.pid was $0.15 \mu \mathrm{M}$ in the absence of factor VIIIa and was $0.053 \mu \mathrm{M}$ th factor VIIa (data not shown).

To test the suggestion that, at the phospholipld concentrations given in table 1 and fig.1, factor WIIIa is the limiting component for the functional binding 
Table 3p Factor IXa titrations at four different factor VIIIa concentrations. The Kd And (IXa) values were calculated from the double reclprocal plots shown $1 \mathrm{fn} \mathbb{1 8 . 2}$.

\begin{tabular}{lccc}
\hline Pactor VIIIa & $\mathrm{Kd}$ app & $V(\mathrm{IXa})$ & $V(\mathrm{IXa}) /[\mathrm{VIIIa})$ \\
\hline \multicolumn{1}{c}{$(\mathrm{nM})$} & $(\mathrm{nM})$ & $(\mathrm{nM}$ Xa/min) & $(\mathrm{nM}$ Xa/min per nM VIIIa) \\
0.0125 & 16.7 & 12.3 & 984 \\
0.033 & 17.8 & 28.2 & 855 \\
0.0375 & 14.0 & 35.2 & 939 \\
0.1 & 16.0 & 92.6 & 926 \\
\hline
\end{tabular}

sites for factor IXa, titration experiments with factor IXa were carried out at four different factor VIIIa concentrations. The double-reciprocal plats obtalned are show in fig.2 and the blinding and kinetic parameters derived from these plots are summarized in table 2. The $V$ (IXa) increases proportionally with the amount of factor Vilia present. The $\mathrm{Kd}^{\text {app }}$ is not influenced by the factor VIIla concentration indicating that the affinty of factor IXa for functional binding sites is independent of the amount of factor VIIIa present. These results and the observation that in the presence of factor VIIIa warlation of the phospholipld concentration does not affect the $V$ (IXa), strongly suggest that in these experiments most of the factor VIIIa molecules are bound to the phospholipid bllayers where they form the kinetically functional binding sites for factor IXa.

Assembly of the factor $X$ activating complex at increasing factor VIIIa concentrations. Having shown that the rate of factor Xa formation at 1 imiting factor VIIla concentrations is saturable with respect to factor IXa, 1t was of interest to examine whether with 11miting amounts of factor IXa, the rate of factor Xa formation could also be saturated with factor VIIIa. Varylng amounts of activated factor VIII were added to reaction mixtures containing factor IXa, phospholipld, Ca ${ }^{2+}$ and factor $X$. The factor IXa concentration determined by active-site titration (15) was $0.017 \mathrm{nM}$. As shown $1 \mathrm{ni}$ fig.3, the rate of factor $X$ activation was also saturable with factor VIIIa. The double-reciprocal plot is 1lnear and from the intercept at the ordinate the value for $V$ (VIILA) is calculated, which represents the rate of factor Xa formation when al factor IXa molecules are complexed with factor VIILa. With V(VIIIa) and $V$ (IXa) determined under the same experimental condttions the molar concentration of factor viria can be calculated as outlined in materials and methods. This enabled the plotting of factor viria in molar terms (fig.3). The $\mathrm{Kd}^{\text {app }}$ thus found for the binding of factor VIIIa to factor IXa in the presence of 


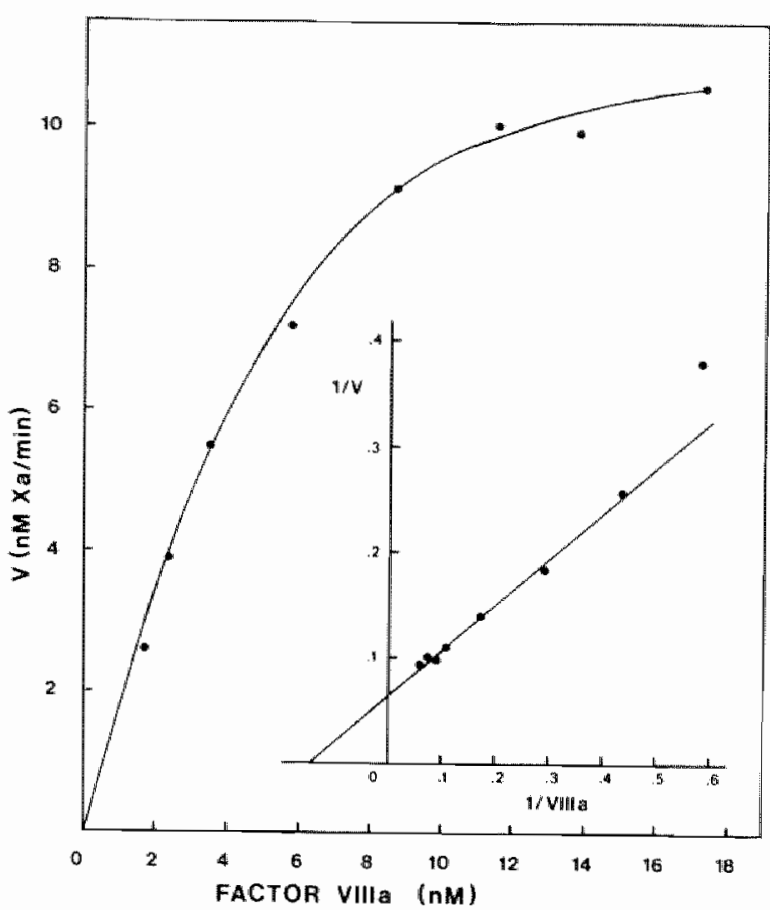

Fig.3. Effect of varying amounts of activated factor VII on the rate of factor $x$ activation in the presence of a limiting anount of factor IXa :

Factor $X$ activation rates were measured as in $\mathrm{fig} \cdot \mathrm{lB}$. Factor VIII activation was at constant concentration of 70 units/ml of factor VIII and $3.65 \mathrm{nM}$ of thrombin. The final composition of the reaction mixture for factor $X$ activation was: 50 mM Tris$\mathrm{HCl}, 175 \mathrm{mM} \mathrm{NaCl}, 6 \mathrm{mM} \mathrm{CaCl}$, $\mathrm{pH} 7.9,2.5 \mathrm{mg} / \mathrm{ml}$ human albumin, factor VIIIa as indlcated $1 \mathrm{n}$ the flgure, $0.9 \mathrm{nM}$ thrombin, $0.017 \mathrm{nM}$ factor IXa $25 \mu \mathrm{M}$ phospholipld vesicles and $0.5 \mu \mathrm{M}$ factor $X_{2}$.

phospholipid ts $6.7 \mathrm{nM}$. Thts value is in the same range as the $\mathrm{Kd}^{\text {app }}$ values for factor IXa binding to factor VIIIa in the presence of phospholipids (table 1).

\section{DISCUSSION}

In this paper we present evidence for the hypothesis that durdig intrinstc factor $X$ activation, factor IXa and factor VIIIa are complexed together at the phospholipid surface. Evidence for factor IXa-factor VIIIa interaction 18 provlded by the observation that the rate of factor X activation 18 saturable with excess factor IXa in the presence of 11 iting amounts of factor VIIIa and vice versa. The amount of complex formed appeared proportional to the amount of $11 m$ iting component present. The saturation curves were hyperbollc suggesting that single identical sites were titrated in each case. By titration of a limited amount of factor VIIIa with factor IXa in the presence of phospholipid a $\mathrm{Kd}^{\mathrm{app}}$ for factor IXa between 3-16 $\mathrm{nM}$ was found. Tutration of a limited amount of factor IXa with factor VIIIa in the presence of phosphollp1d re- 
sulted in a kdapp of $6.7 \mathrm{n}$ for factor VILIa. We further carried out factor $x$ activation experiments in the absence of factor VIIIa. The Kapp for factor IXa binding to phosphollpids obtalned from kinetic experiments varied between $0.4-1.1 \mathrm{M}$. These values are comparable to binding parameters determined by Melsestuen et al. (8) in direct binding studies. At a suboptimal Ca ${ }^{2+}$ concentration they observed a Kd of $2 \mu$ for dissoclation of factor IX or for $R$ WVactivated factor IX from phospholipid vesicles. Comparison of factor $x$ actiwation experiments in the absence and presence of factor VIIIa indicates that the apparent kd for factor IXa binding is lowered 50-100 fold in the presence of factor VIIla. We conclude that factor VIIIa functions as a high affinity binding site for factor IXa at the phospholipid surface. It is likely that the comblnation of factor IXa-phopholipld and factor IXa-factor VIIIa Interactions promote the 1ncorporation of factor IXa into the factor $X$ activating complex. In that respect factor VIIIa has a simllar function as factor Va in prothrombin activation. Neshelm et al. (11) and Lindhout et al. (12) reported that factor Va promotes the binding of factor Xa to negatively charged phospholipld curfaces.

The dependence of $\mathrm{Kd}^{\mathrm{app}}$ from the phospholipid and the factor $\mathrm{X}$ concentration is not completely understood. The following factors may contribute to the observed dependence: a) Up to $15 \%$ of added factor IXa is bound, which at the hlgher phosphollpid concentration results in somewhat higher $\mathrm{Kd}^{\text {app }}$ values b) Factor X binds to phospholipids with a Kd of $50 \mathrm{nM}$ (9) and may compete with factor IXa for binding to the phospholipld surface. To appreciate the interaction of factor VIIIa with factor IXa and phospholipids it would be important to study factor VIIIa binding using a direct binding assay. Presently, however, the instability of activated factor VIII preparations does not allow such an approach

In our previous experiments on the intrinsic factor $\mathbb{X}$ activator we used factor VIII complex consisting of factor VIII:C and won W11lebrand factor (6). In the present work we used a factor VIII:C preparation (14) that contalns little or no von Willebrand factor. Using factor VIII complex, a Vmax of 500 moles of factor Xa min ${ }^{-1}$ per mol of factor IXa was reported, whereas in this study the Vmax value 18900 . This result suggests that the von w11lebrand factor does not strongly influence the Vmax of factor Xa formation.

The physlological implications of the high-affinity binding sites for factor IXa, formed by factor VIIIa at a lipid- or activated platelet surface appear important. The concentration of factor VIII in human plasma is $0.25 \mathrm{nM}$ (unpublished observations). The concentration of factor IX, which is at least 
200-fold higher, is approximately $60 \mathrm{mM}(16)$. During the clotting process only small amounts of factor IX are conwerted Into factor IXa and the concentrations of factors VIIIa and IXa will remain in the nanomolar range. The 50-100 fold lowering of the Kd for factor IXa binding (co the nM range) by factor VIrTa therefore allows more efficient factor IXa-factor VIIIa complex formation. Previously we found that factor VIIla caused a 200000 fold enhancement of the Vmax of factor Xa formation (6). It now appears that the overall enhancement is explained by two major effects of factor VIIIa: a) greatly enhanced catalytic power of factor IXa-WILla-phospholipld, compared to factor IXa-phosphol1pid; b) enhanced factor IXa affintty for the 11pid surface in the presence of factor VIIIa, which increases the amount of phospholipid-bound factor IXa that particlpates in factor $X$ activation.

\section{REFERENCES}

1. Jackson, C.M. and Nemerson, Y. (1980) Ann.Rev.Biochem. 49, 765-811.

2. Hoyer, L.W. (1981) Blood 58, 1-13.

3. Hemker, H.C. and Kahn, M.J.P. (1967) Nature 215, 1201-1202.

4. Heterud, B. and Rapaport, S.I. (1970) Biochemistry 9, 1854-1861.

5. Hultin, M.B. and Nemerson, Y. (1978) Blood 52, 928-940.

6. van Dieljen, G., Tans, G., Rosing, J. and Hemker, H.C. (1981) J.Biol.Chem. $256,3433-3442$.

7. Griffith, M.J., Reisner, H.M., Lundblad, R.L. and Roberts, H.R. (1982) Thromb. Res. 27, 289-301.

8. Nelsestuen, G.L., Kiese1, W. and DiSciplo, R.G. (1978) Blochemistry 17, 2134-2138.

9. van Dieijen, G., Tans, G., van Rijn, J.L.M.L., Zwaal, R.F.A. and Rostng, J. (1981) Biochemistry 20, 7096-7101.

10. Rosing, J., Tans, G., Govers-Rlemslag, J.W.P., Zwaal, R.F.A. and Hemker, H.C. (1980) J.B1ol. Chem. 255, 274-283.

11. Nesheim, M.E., Taswe11, J.B., and Mann, K.G. (1979) J.B1o1.Chem. 254, $10952-10962$.

12. Lindhout, T., Govers-Rliemslag, J.W.P., van de Waart, P., Henker, H.C. and Rosing, J. (1982) Blochemistry 21, 5494-5502.

13. Comfurlus, P. and Zwaal, R.F.A. (1977) Blochin. Blophys. Acta 488, 36-42.

14. Vehar, G.A. and Davie, E.W. (1980) Blochemistry 19, 401-410.

15. Tans, G., Janssen-Claessen, T., van Dieljen, G., Herker, H.C. and Roslng, J. (1982) Thromb.Haemostas. 48, 127-132.

16. Discipio, R.G., Hermodison, M.A., Yates, S.G. and Davie, E.W. (1977) Biochemistry $16,698-706$. 


\title{
KINETIC STUDIES OF PROTHROMBIN ACTIVATION
}

\author{
The effect of factor Va and phospholipids on the formation \\ of the enzyme-substrate complex.
}

SUMMARY

The kinetic parameters of bovine prothrombin activation by factor Xa were determined in the absence and presence of factor Va as a function of the phospholipid concentration and composition.

In the absence of factor Va the $\mathrm{Km}$ for prothrombin increases proportional. with the phospholipid concentration and correlates well with the affinity of: prothrombin for the different membranes. Phospholipid vesicles with a high affinity for prothrombin yield low $\mathrm{km}$ values compared to membranes with less favourable binding paraneters. At limited phospholipld concentrations the Wax of prothrombin activation correlates wth the binding affinity of factor Xa for the various phospholipid vesicles. Membranes with a high affinity for factor Xa have high Vmax values, whlle for membranes with a low affintty a low Vmax is observed. Extrapolation of double reclprocal plots of $1 /$ Vmax versus 1/[phosphollpld] to Infinite phospholipid concentrations, a condition at whlch all factpr Xa would participate in prothrombin activation, yields a $k$ cat of 2-4 $\mathrm{min}^{-1}$ Independent of the type and amount of acidic phosphollpid present in the vesicles. Also in the presence of factor Va the $\mathrm{Km}$ for prothrombin vartes proportional with the phospholipid concentration. There is, however, no correlation between the binding parameters and the $\mathrm{Km}$. Factor Va drastically lowers the $\mathrm{Km}$ for prothrombin for vesicles which have low affinity for prothrombin. Vesicles composed of 20 mole\% phosphatidylglycerol and 80 mole\% phosphatidylcholine have a $\mathrm{kin}$ of $0.04 \mu \mathrm{M}$ when factor Va is present, compared to $2.2 \mu \mathrm{M}$ determined in the absence of factor Va. Vesicles that contain low amounts of phosphatidylserine also have constderably lower Km values for prothrombin in the presence of factor Va than in 1 t absence. Whet factor Va is present the Vmax of prothrombin activation 18 virtually independent of the affinity of factor Xa for phosphollpid. Over a wide range of phospholipid concentrations and compositions a $k_{\text {cat }}$ of $4500 \mathrm{mln}^{-1}$ is abserved. Our data establish that prothrombin activation by factor xa in the presence of factor $\mathrm{Va}$ and phospholipid is Independent of the prothrombin density at the phospholipid surface. A model in which the enzymatic unt of prothrombinase consists of a three component complex (factor Xa-factor Va-phosphollpld) with an increased affinity for soluble prothrombin can explain the observed effects of factor $V a$ on the $\mathrm{Km}$ for prothrombin. Therefore, factor Va accelerates prothrombin activation by: 1) increasing the $k_{\text {cat }}$ of prothrombin activation; 2) promoting the binding of factor Xa; 3) promoting the assumbly of the enzymeaubstrate complex. 
The activation of the blood coagulation factor prothrombin is catalyzed by prothrombinase, an enzmatic complex composed of the serine protease factor xa and the non-enzymatic cofactors factor Wa, phosphollpld and $\mathrm{Ca}^{2+}$ (1). Previous kinetic aculies revealed that prothrombln activation by factor Xa alone is an inefflcient process with a low Vmax of thrombin formation and a high kin for prothrombin (2). Negatively charged phospholipids plus $\mathrm{Ca}^{2+}$ sttmulate prothrombin activation by lowering the Km for prothrombin, while factor Va great$1 y$ enhances prothrombln activation by increasing the Wax $(2,3)$.

All protein components of the prothrombinase complex bind to phospholipid. This led to the proposal that phosphollpid membranes act as a surface at which the protelns involved In prothrombin activation interact with each other. The Increased prothrombin concentration at the phospholipld-water interface explains the observed decrease of the Kn for prothrombin in the presence of phosphollpld. Th1s model, In which the $\mathrm{Km}$ is determined by the local density of prothrombln at the membrane surface $(2,4)$ also explains the increase of the Km observed at increasing phospholip1d concentration.

In an alternative model postulated by Nelsestuen (5), the prothrombinase complex $1 \mathrm{~s}$ viewed as a dissoclable three-component enzyme (Factor Xa-factor Va-phospholipid) that acts on soluble prothrombin. The Increased affinlty for prothrombin is the result of additive free energles of prothrombin-factor Va and rrothrombin-phosphollpld interactions occurring at the active site of prothrombinase. Recent1y, Pusey and Nelsestuen (6) indeed demonstrated that the $\mathrm{Km}$ for prothrombin is independent of the prothrombin density at the menbrane surface when factor Va is present. However, previous kinetic studles on prothrombin activation in the absence of factor Va showed that the observed Kim did correlate with the prothrombin denslty at the phospholipld surface (2). These observations suggest that factor $V a$ may alter the mechanism by which prothrombin enters the catalytic site of the prothrombin activating complex. The present report concerns a detalled kinetic analysis of the effects of factor Va on the kinetic parameters of prothrombinase. Phospholipld vesicles that contain varlous amounts of different acidic phospholipids were used in order to vary the affinity of the membranes for prothrombin and to test whether a correlation exists between the prothrombin density at the phospholipld surface and the observed $\mathrm{Km}$ for prothrombin. It is shown that in the absence of factor $\mathrm{Va}$ the $K \mathrm{~K}^{\mathrm{n}}$ correlates with the affinity of prothrombin for phospholipid, while in the presence of factor $V a$ such a correlation does not 
exist. These flndings suggest that the mode of action of phospholipldi in prothrombin activation with and whout factor Va cannot be described in one unique nodel.

\section{MATERIALS AND METHODS}

Reagents. $\$ 2238$ was purchased from $A B$ Kabi Dfagnostica, p-NPGB was from Mutritional Biochemicals. Ovalbumin, human serum album (fatty actd free). soy bean trypsin Inhibitor, $R V W-X_{*}$ Echis Carlnatus venom and 1,2-dioleoyl-snglycero-3-phosphocholine (PC) were obtained fron Signa. DEAE-Sephadex A-50, QAE Sephadex A-50, SP-Sephadex C-50, Sephadex G-100 and CNBr activated Sepharose-4B were purchased from Pharmacla. Soybean trypsin inhibttor was coupled to CNBr-act1vated Sepharose 4B according to the method of Cuatrecasas (7). Al1 reagents used were of the highest grade commercially avallable.

Proteins. Bovine prothrombin and prethrombin-1 were purifled according the method of Owen et a1. (8). Thrombin was purlfied as descrtbed earlier (2). Bovine Factor $X$ was purifled as described by Fujlkawa et al. (9). RVV-X was purified from the crude venom by the method of Schiffman et al. (10). Factor Xa was prepared from factor X activated with $\mathbb{R V W}-\mathrm{X}$ (11). Factor $V$ and Factor Va were obtalned as described by Lindhout et a1. (12). Factor Xa, prothrombin and thrombin were stored at $-80^{\circ} \mathrm{C}$ in 50 m $\mathrm{Tr} 1 \mathrm{~s}-\mathrm{HCl}, 175 \mathrm{mM} \mathrm{NaCl}, 0.5 \mathrm{mg} / \mathrm{ml}$ hunan serum albumin ( $\mathrm{pH} 7.9)$. Factor Va was stored in the same buffer contalning $5 \mathrm{mM} \mathrm{CaCl}_{2}$.

Protein concentrations. The molar concentration of thrombin was determined by active site titration with $\mathrm{p}$-NPGB according to Chase and Shaw (13). Prothrombin and prethrombin-1 concentrations were determined by the same method after complete activation with Echis Carinatus venom. Factor Xa concentrations were determined by active slte titration according to Smith (14). The concentration of factor Va was determined by kinetic analysis as described by Lindhout et: a.1. (12).

Phospholipld and phosphollp1d vesicle preparations. 1,2-dioleoy1-sn-glycero3-phosphoserine (PS), 1,2-dloleoyl-sn-glycero-3-phosphoglycerol (PG) and 1,2-dioleoyl-sn-glycero-3-phosphate (PA) were prepared from 1,2-dioleoylsn-glycero-3-phosphochollne (PC) by enzymatic synthesis as described by Comfurius and Zwal (15). Lipld analysis was carrled out as described previousiy (16). Single bilayer phospholipid vesicles were prepared according to the method of De Kruijff et a1. (17). Phospholipid concentrations were determined by phosphate analysus as described by Böttcher at all. (18). 
Measurement of rates of prothrombin activation. Factor $\mathrm{Xa}$ and phospholipids with or without factor Va were incubated for $5 \mathrm{~min}$ at $37^{\circ} \mathrm{C}$ in a buffer con-

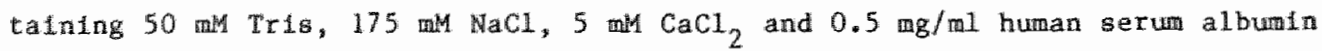
at pH 7.9. Prothrombin activation was started by the addition of prewarmed prothrombin in the same buffer. The final concemtration of factor Xa in expertmencs in wich factor Va was absent, was 1 nM. In the presence of factor Va (5 nM) prothromblin activation was carrled out at 1 pM factor Xa. After different time intervals samples were taken from the prothrombin activating mixture and transferred to cuvettes containing the thrombin spectfic chromogentc substrate $\$ 2238$. The cuvettes (thermostated at $37^{\circ} \mathrm{C}$ ) contalned 1 ill of $50 \mathrm{mM}$ TrL-HCl (PH 7.9), $175 \mathrm{mM} \mathrm{NaC1}, 20 \mathrm{mM}$ EDTA, $0.5 \mathrm{mg} / \mathrm{ml}$ ovalbumin and 235 HM S2238. The thrombln concentration was determined by measuring the rates of absorbance change recorded at 405 minusi $500 \mathrm{~nm}$ on an Anilnco DW-2A spectrophotometer in the dual-wavelength mode. The amount of thrombin was calculated from a callbration curve made with known amounts of active slte-titrated thrombin.

Kinetlc analysis. Michaelis-Menten kinetics was applied to analyse the kinetic data of prothrombin activation. The kinetic parameters were obtained from Initial rate meagurements. Thrombin formation rates were linear in time and care was taken that small amounts of substrate were converted during the time course of the experiments. Rates of thrombin formation were calculated and expressed as thrombin formed per min per factor Xa. Km and Vmax, were determined by statistical analysis of the Lineweaver-Burk plots as described by Elsenthal and Cornish-Bowden (19). The Lineweaver-Burk plots were straight lines over a wide range of prothrombin concentrations. No deviation from 11nearity could be detected with prothrombin concentrations that were rore than 5-fold above or below the $\mathrm{Km}$ for prothrombin. 
The effect of phospholipid vesicles contalning different polar headgroups on the kinetic parameters of prothrombin activation.

Previous kinetic studies revealed that negatively-charged phosphollplds promote factor Xa-catalyzed prothrombin actiwation by lowering the km for prothrombin and that the observed Kn increased proportional with the amount of phospholipid present (2). Two models have been proposed to explain the effects of phospholipld on the $\mathrm{Kn}$ for prothrombin:

1. In the so-called "bound substrate model" $(2,4)$ it is suggested that the overall prothrombin density at the phosphollpid surface determines the rate of prothrombin activation by phospholipid-bound factor Xa. When phosphom 1ipids are present, the prothrombin concentration in a shell surrounding the phospholipid surface greatly exceeds that in free solution, which explains the drastic drop of the Kin for prothrombin. Increasing the phospholipld concentration lowers the prothrombin density at the phospholipld surface with a consequential increase of the observed $\mathrm{Km}$.

2. In the so-called "free substrate mode1" (5) the soluble prothrombin concentration directly determines the rate of prothrombin activation by phospholipid-bound factor $\mathrm{Xa}$. The enzymatic unft of the prothrombin activating complex is thought to consist of a dissociable two component (factor Xaphospholipid) or three component (factor Xa-factor Va-phospholipid) complex, that binds prothrombin from solution with increased affinity. The affinity for soluble prothrombin $\# s$ determined by the additional free energies of prothrombin binding to the induvidual components of this complex. Increasing the phospholipid concentration lowers the free prothrombin concentration since prothrombin binds to phospholipld outside the enzymatic domatn; hence more prothrombin has to be added to obtain the free prothrotnbin concentration required for half saturation of the enzymatic unit. Therefore, also in the free substrate model the $\mathrm{Km}$ for prothrombln increases proportional with the phosphollpld concentration.

The fundamental difference between the two models $1 \mathrm{~s}$ that in the bound substrate model lateral diffusion of prothrombin across the phospholipld aurface Is am essential step in the formation of the enzyme-substrate complex, while In the free substrate model the enzyme-substrate complex 1 s formed by direct interaction of prothrombin wh the enzymatic unit.

The bound substrate model predicts that the Vmax and $\mathrm{Km}$ are directly 
Tabli I. The effect of factor $\mathrm{Va}$ on the kinetic parameters of prothrombin activation measured in the presence of vesicles containing various acldic phosphollpld. Varying amounts of prothrombin were activated in a

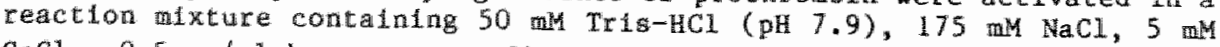
$\mathrm{CaCl}_{2}, 0.5 \mathrm{mg} / \mathrm{ml}$ human serum aIbumin, $50 \mathrm{M}$ phospholipid and $1 \mathrm{nM}$ factor $X a$ and no factor Va or 1 pM factor Xa and 5 nM factor Va. Throwbin formation rates and kinetic parameters were determined as described in Materials and Methods.

Vesicle phospholipld composition $\mathrm{Km}(\mu \mathrm{M}) \quad \mathrm{Vmax}\left(\mathrm{IIa}_{\mathrm{m}} \mathrm{m}^{-1} \mathrm{Xa}^{-1}\right.$ )
- factor $\mathrm{Va}$

$\begin{array}{lll}P S / P C(25 / 75 ; M / M) & 0.11 & 2.56 \\ P A / P C(25 / 75 ; M / M) & 0.10 & 2.78 \\ P G / P C(25 / 75 ; M / M) & 1.81 & 0.17\end{array}$

\pm factor Va

$\begin{array}{lll}\text { PS/PC }(25 / 75 ; M / M) & 0.14 & 4050 \\ \text { PA/PC }(25 / 75 ; M / M) & 0.11 & 4184 \\ \text { PG/PC }(25 / 75 ; M / M) & 0.04 & 3345\end{array}$

related to the binding parameters of, respectively, factor $X a$ and prothrombin for phospholipld. Vesicles with increased affinity for factor Xa bind more factor $\mathrm{Xa}$, hence more factor $\mathrm{Xa}$ wll participate in prothrombin activation and higher Vnax values will be observed. Vealcles with an Increased affinity for prothrombin will yleld lower Km values since less prothrombin is required to obtaln the prothrombin density at the phospholipid surface at which half of the phosphollpld-bound factor Xa is saturated. In order to test these predictions we determined kinetic parameters of prothrombin activation for vesicles that contaln negatively charged phosphollpids with different polar headgroups (PS, PA, PG), which are known to have different binding parameters for factor Xa and prothrombin (20). Table I shows, that in the absence of factor Va, both the Wwax and the $\mathrm{Km}$ depend on the type of acldic phosphollpld present in the phospholipld vesicles. PS and $\mathrm{PA}$, which at the experimental pH have 2 negative charges in the1r headgroup (PS also contalns 1 positive charge), glve conslderably higher Vmax and lower Km values than $P G$, which contains only one negative charge. The observed kinetic parameters relate very well to previous1y reported binding parameters. Membranes, that contain PS and PA have a higher affinty for prothrombin and factor Xa, than those contalning PG. Table I also reveals that the kinetic parameters, determined in the presence of factor Va, do not reflect the differences in binding parameters for factor Xa and prothrombin. When factor $\mathrm{Va}$ is part of the prothrombin activating complex the Vmax is hardly affected by the type of acidic phospholipld present in the 


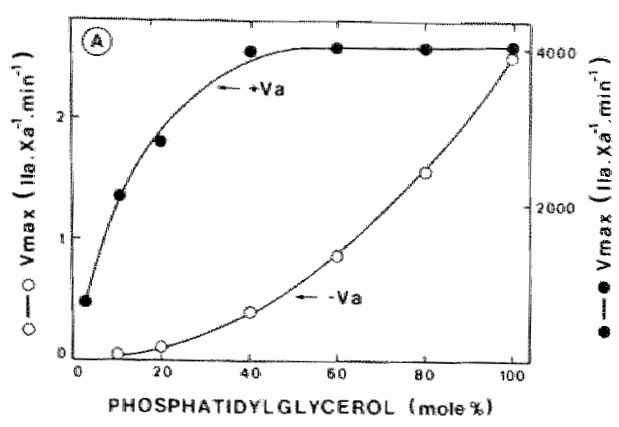

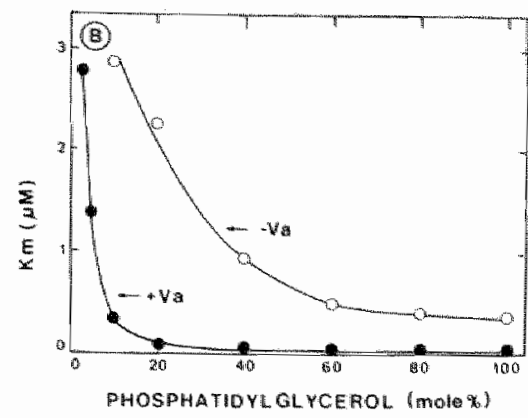

Fig. 1. The effect of the mole percentage PG in PG-PC vesicles on the kinetic parameters of prothrombin activation. Various amounts of prothrombin were activated in a reaction mixture contalning $50 \mathrm{mM}$ Tris-HCl ( $\mathrm{pH} \mathrm{7.9),} 175 \mathrm{mM} \mathrm{NaC1}$, $5 \mathrm{mM} \mathrm{CaCl}, 0.5 \mathrm{mg} / \mathrm{ml}$ human serum albumin, $50 \mu \mathrm{M}$ phospholipid and $1 \mathrm{nM}$ factor $\mathrm{Xa}$ and no factor $\mathrm{Va}(\mathrm{O}-\mathrm{O})$ or $1 \mathrm{pM}$ factor $\mathrm{Xa}$ and $5 \mathrm{nM}$ factor $\mathrm{Va}(-0)$. The mole percentage PG present in the phospholipid vesicles is indicated in the figure. Thrombin formation rates, Vmax (figure lA) and $\mathrm{Km}$ (figure lB) were determined as described in Materials and Methods.

membrame bilayer. This can be attributed to the fact that factor va promotes the binding of all added factor Xa to phospholipld vesicles, stace rates of prothrombin activation 1 in our experiments were optimized wth respect to the amount of factor Va present. Moreover, the Kn does not relate to the binding parameters of prothrombin for the phospholipid vesicles per se. Vesicles contalning $P G$, which have the lowest affinity for prothrombin, have the most favourable $\mathrm{km}$ for prothrombin. Therefore, we have to conclude that in the presence of $P G$ contalning vesfcles and factor $\mathrm{Va}$, the $\mathrm{Km}$ far prothrombin $\mathrm{is}$ not determined by the prothrombin density at the membrame surface.

Kinetic parameters of prothrombin activation for vesicles containing varlous mole percentages of acidic phospholipid.

The question arises whether the effects of factor Va on the kinetic parameters of prothrombin activation (especially on the km) are a unique feature of $P G$ contalning vesicles or that they must be attributed to the low affinity of these vesicles for prothrombin and factor $\mathrm{X} a$. To this end we determined the $\mathrm{Km}$ and Viax for vesicles that contain various mole percentages of the acldic phospholipids PG or PS. Lowering the mole percentage of actatc phospholipid in these vesicles results in weaker binding of factor Xa and prothrombin (20). Fig lA shows the Vmax values determined for vesicles that contain varlous mol percentages PG. Wthout factor Va there is a considerable increage of the Vuax 

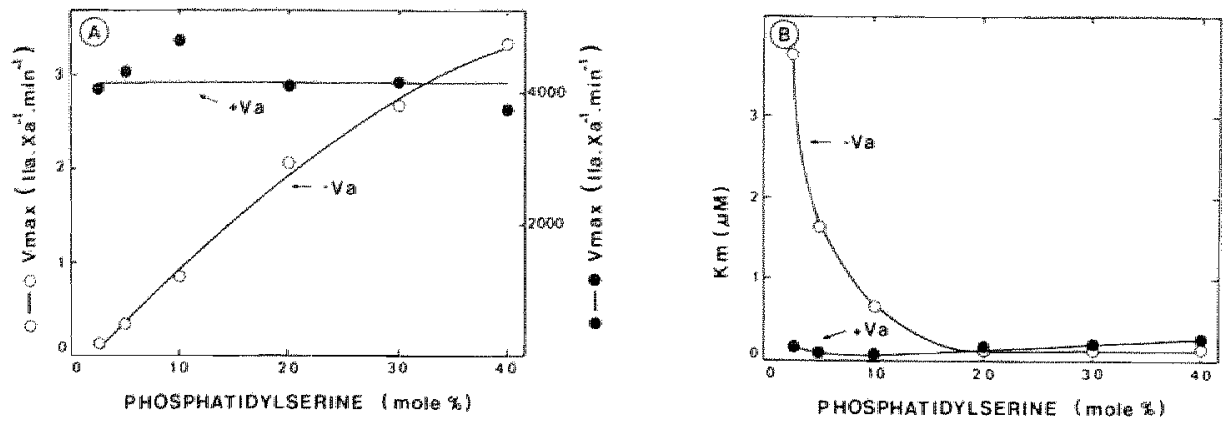

F1g. 2. The effect of the mole percentage PS $\mathbb{A n}$ PS-PC vesicles on the kinetic parameters of prothrombin activation. The experimental conditions are described In the legend of flgure $\mathbb{1}$. (A) represents the effect of mole percentage $P S$ on the Vmax and (B) the effect of mole percentage $P S$ on the $\mathrm{Km}(\mathrm{O}-\mathrm{O}$ no factor Va present; - $5 \mathrm{nM}$ factor Va present).

when the mole percentage $P G$ in the vestcles is increased. In the presence of factor Va, the Vmax is much less dependent on the PG content of the vesicles. At more than 40 mole\% PG a maximal value is observed, which suggests that factor Va is able to promote the binding of all added factor Xa to the phosphollpid vesicles.

The $\mathrm{Km}$ values obtained for weslcles with different mole percentages PG are presented In Figure 1B. Without factor Va, the Km increases when the mole percentage PG is lowered. The increase of the Km for prothrombin runs parallel with the increase of the dissociation constant of the prothrombin-phospholipid complex. Two striking differences are observed, however, when factor Va 1 s

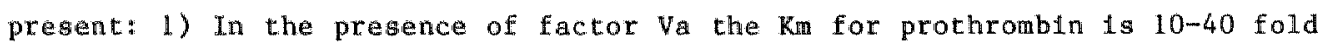
lower than in 1 ts absence and 2) In the presence of factor Va the km is independent of the binding affinity of prothrombin for the phospholipid vestcles between 20 and 100 mole\% $\mathbb{P G .}$

Essentilily the same effects on the kinetic parameters are found when PS 1 s utflized as acidic phospholipld. Unfortunately the mole percentage PS is 1 imfted to $40 \%$ since at higher percentages the vesicles tend to aggregate due to the presence of $\mathrm{CaCl}_{2}$. $\mathrm{FIg} 2 \mathrm{~A}$ shows that in the absence of factor Va there is a continuous increase of the Vmax when the mole percentage PS in the phospholipld vesicles is increased from $2.5 \%$ to $40 \%$ With factor Va the Vmax $1 \mathrm{~s}$ independent of the mole fraction $P S$, which again indicates that under these conditions all factor $X a$ molecules are bound to phospholiptd and particlpate 
Table II. Kinetic paraneters of prethrombin-1 activation. Various amounts of prethrombln-1 were activated in a reaction mixture containing $50 \mathrm{mM} \operatorname{Tr} 1 \mathrm{~s}-\mathrm{HCl}(\mathrm{pH} 7.9), 175 \mathrm{mM} \mathrm{NaCl}, 5 \mathrm{mM} \mathrm{CaCl}, 0.5 \mathrm{mg} / \mathrm{ml}$ human serum albumin, 50 phospholipid, 1 pM factor xa and 5 nM factor Va. Measurement of thrombin formation rates and determination of kinetic parameters were carried out as described in Materials and Methods.

\begin{tabular}{|c|c|c|}
\hline Vesicle phospholipid composition & $\mathrm{Km}(\mu \mathrm{M})$ & $\operatorname{Vmax}\left(1 \mathrm{Ia} \min ^{-1} \mathrm{Xa}^{-1}\right)$ \\
\hline $\begin{array}{lll}\mathrm{PS} / \mathrm{PC} & (25 / 75 ; \mathrm{M} / \mathrm{M}) \\
\mathrm{PA} / \mathrm{PC} & (25 / 75 ; \mathrm{M} / \mathrm{M}) \\
\mathrm{PG} / \mathrm{PC} & (25 / 75 ; \mathrm{M} / \mathrm{M})\end{array}$ & $\begin{array}{r}1.3 \\
12.1 \\
8.1\end{array}$ & $\begin{array}{l}1711 \\
1563 \\
1352\end{array}$ \\
\hline
\end{tabular}

in prothrombin activation. Fig. 2B reveals that in the absence of factor Va the Kin for prothrombin increases when the binding affinity of prothrombin for the vesicles is decreased. Factor Va has minor effects on the Km of prothrombin for vestcles containting between 20 and 40 mole\% PS. At amounts of ps bellow 20 mole\% factor va seems to compensate for the reduced affinity of prothrombln for phospholipid; much lower $\mathrm{Km}$ values are observed in the presence of factor Va than in its absence.

It is even questionable whether in the presence of factor va prothrombinphospholipld interactions sti11 contribute to the formation of the enzytiesubstrate complex. Since the phospholipld binding capacity of prothrombin resides in its fragment-1 reglon, it is linteresting to compare prothrombin and prethrombin-1 (which lacks fragment-1) as substrates for prothrombinase.

Table II gives the kinetic parameters for prethrombin-l activation, determined In the presence of factor $\mathrm{Va}$ and vesicles containing either PS, PA or PG as acidic phospholipld. For all vestcles the $\mathrm{Km}$ values for prethrombin-1 are 100-200 fold higher than for prothrombin (cf. Table I). These experiments actually exclude a variant of the free substrate model in which prothrombinphospholipid interactions do not contribute to the formation of the enzymesubstrate complex. In such a model the Kun for prothrombin would only depend an 1 ts affinities for factor $x a$ and factor Va. The large difference between the Km for prothrombin and prethrombin-1 strongly suggests that prothrombin-phospholipid interactions are essential for the binding of prothrombin to the prothromblnase complex. He have as yet no explanation for the fact that the Vmax of prethrombin-1 activation is 2-3 fold lower than the Vmax for prothrombin activation. The important information contained in the experiments reported in this section is that the kinetic parameters of prothrombin activation $\mathbb{1 n}$ the presence of factor Va and phospholipid have no relation to the prothrombin density at the phospholipid membrane. 
The effect of the phospholipld concentration on the kn for prothrombin.

previous kinetic studies of prothrombin activation carried out in our laboratory revealed that the $\mathrm{km}$ for prothrombin has to be regarded as an apparent Km (Km ${ }^{\text {alPP) }}$ since it increases at increasing phosphollpid concentrations (2). For both the free substrate and the bound substrate model an equation can be derived, that relates the observed $\mathrm{kn}$ with the phospholipid concentration and the binding parameters of prothromin for the phospholipid vesicles present in the kinetic experiment. The total prothrombin concentration required to attaln the observed $\mathrm{Km}$ equals the sum of the concentrations of free and phosphollpid-bound prothrombin (eq 1).

$$
\mathrm{Km}^{\mathrm{apP}}=\left[\mathrm{PT}_{\text {free }}\right]+\left[\mathrm{PT}_{\text {bound }}\right]
$$

Since the concentration of factor $\mathrm{Xa}$ present in our experiments is far below the concentration of binding sites ( $\left.S_{\text {total }}\right)$ for vitamin K-dependent coagulation factors provided by the phospholipid vesicles

$$
K d=\frac{\left[\mathrm{PT}_{\text {free }}\right] \cdot\left(\left[\mathrm{S}_{\text {tota } 1}\right]-\left[\mathrm{PT}_{\text {bound }}\right]\right)}{\left[\mathrm{PT}_{\text {bound }}\right]}
$$

where Kd is the dissoclation constant of the prothrombin-phospholipld complex. Defining $q$ as the maximal amount of prothrombin, that can bind to phospholipid (Mole/Mole) gives

$$
\left[s_{\text {totali }}\right]=q \cdot[\text { phospholipld }]
$$

Substitution of eq 3 into eq 2, followed by rearrangement of eq 2 yields

$$
\left[\mathrm{PT}_{\text {bound }}\right]=\frac{\mathrm{q} \cdot[\text { phospholiptd }]}{\mathrm{Kd} \cdot\left[\mathrm{PT}_{\mathrm{free}}\right]^{-1}+1}
$$

Substituting eq 4 Into eq 1 gives the relation between $\mathrm{Km}$ and the phospholipld concentration (eq 5 ).

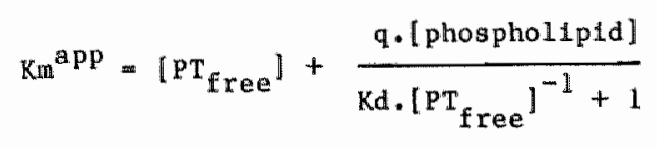

This equation 1 s applicable both to the free and the bound substrate model. In the free substrate model the free prothrombin concentration ( $\left[\mathrm{PT}_{\text {free }}\right]$ ) at the observed $\mathrm{Km}$ apP $1 \mathrm{~s}$ constant and Independent of the amount of phosphollpid present. Since also Kd and $q$ are constants for a particular $k 1$ ind of phospho- 
lipld the $\mathrm{Km}^{\mathrm{aPP}}$ will be linearly dependent on the phosphollpid concentration. In the bound substrate model the $\mathrm{Km}^{\mathrm{app}}$ is attained at a particular prothronbin density at the phospholipld surface. The latter model is defined in such a way that this prothrombin density is independent of the phospholipid concentration and composition. Since the required prothrombin density for certaln kind of phospholipid is always reached at the same free prothrombin concentration, $\left[\mathrm{PT}_{\text {free }}\right]$ at $\mathrm{Km}{ }^{\mathrm{aPP}}$ is constant and a plat of $\mathrm{Km}$ app versus the concentration phospholipid is also a stralght 1 ine in the bound substrate model. Differences exist between the intercept at the ordinate and the slope of the line when leq 5 is applied to the free or the bound substrate model. The intercept at the ordinate is actually the $\mathrm{Km}$ that would be measured at infinitely low phosphoIipid concentration. We will call this value the Intrinsic Kon of the prothrombinase complex. In the free substrate model the intrinsic km is the real km for prothrombin since no excess of phospholipid 1 s present outside the enzymatic domain that can bind prothrombin and lower the free prothrombin concentration that interacts with the enzymatic complex. In the bound substrate model, [PT $\mathrm{free}_{\text {, that }}$ is the intrinsic Ka, is the free prothrombin concentration required to obtain the prothrombin density at the phospholipid surface at which hall of the phospholipid-bound factor Xa is lnwolved in prothrombin activation. In thls model the intrinsic $\mathrm{Km}$ directly relates to the binding parameters of prothrombin for the kind of phospholipld vestcles used in the kinetic experiment. Membranes with less favourable binding parameters for prothrombin w11 have higher intrinsic $\mathrm{Km}$ values, since more free prothrombtin has to be present to obtain the required prothrombin density at the phosphollpid surface.

The slopes of the $\mathrm{Km}^{\text {app }}$ versus [phospholipid] plots contain Important information.

The slope, $\quad \frac{\mathrm{q}}{\mathrm{Kd} \cdot\left[\mathrm{PT}_{\text {free }}\right]^{-1}+1}$ equals $\left[\mathrm{PT}_{\text {bound }}\right] /[$ phospholip1d] (eq 4$)$,

which is actually the prothrombin density at the phospholipld surface required at $\mathrm{Km}^{\mathrm{app}}$. In the bound substrate model this prothrombin density is defined to be a constant, which is independent of the phospholipid concentration and composition. When this model is applicable to prothrombin activation plots of $\mathrm{Km}^{\mathrm{aPP}}$ versus [phospholipid] will yleld a set of parallel lines for phospho1ipid vesicles with different binding parameters for prothrombin. In the free substrate model there are no restraints on the prothrombin density at the membrane surface at $\mathrm{Km}^{\mathrm{apP}}$. The slope of the $\mathrm{Km}^{\text {app }}$ versus [phosphollpid] plots 

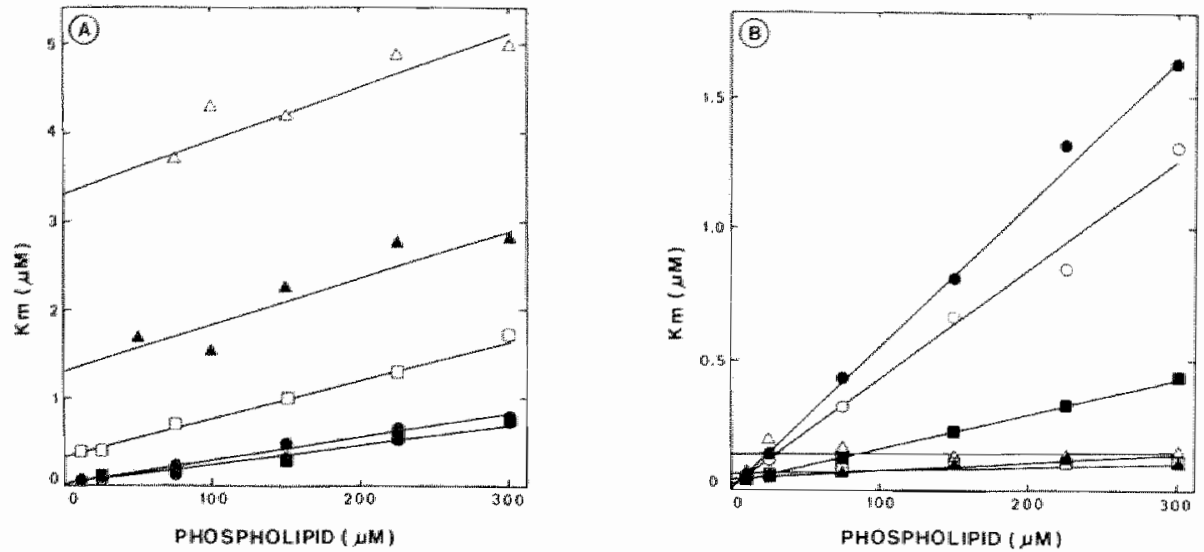

Fig. 3. The effect of the phospholipld concentration on the $\mathrm{Km}$ of prothrombin for phospholipld vesicles containing various mole percentages PS. Various anounts of prothrombin were activated in a reaction mixture containing $50 \mathrm{mM} \operatorname{Tr} 1 \mathrm{~s}-\mathrm{HCl}$ ( $\mathrm{pH} 7.9), 175 \mathrm{mM} \mathrm{NaCl}, 5 \mathrm{mM} \mathrm{CaCl}, 0.5 \mathrm{mg} / \mathrm{ml}$ human serum albumin, amounts of phospholipid indicated in the figure and $1 \mathrm{nM}$ factor Xa and no factor Va (A) or $1 \mathrm{pM}$ factor $\mathrm{Xa}$ and $5 \mathrm{nM}$ factor Va (B). The mole percentage PS present in the vesicles was: $2.5 \%(\Delta-\Delta), 5 \%(\Delta-\Delta), 10 \%(\square-\square), 20 \%(\boldsymbol{\Delta}-\boldsymbol{D})$, $30 \%(0-0)$ or $40 \%(-0)$. Thrombin formation rates and the kinetic parameters were determined as described in the Materials and Methods.

Is therefore in this model function of the blading parameters of prothrombin and the intrinslc $\mathrm{Km}$ ([PT $\mathrm{free}]$ ). Phospholipid vesicles with favourable binding parameters for prothrombln (high $q$ and low $\mathrm{Kd}$ ) will produce steep 1 ines in the Km versus [phospholipid] plot.

Figure 3 shows the effect of increasing phospholipid concentrations on the Km for prothrombin measured in the absence and presence of factor Va. In this experiment phospholipld vesicles contalning different mole percentages PS were used. The plots obtalned in the absence and presence of factor Va are distinctly different. The slopes of the lines vary in the absence of factor va 2-3 fold and $1 \mathrm{n}$ the presence of factor Va 70-fold for vesicles with mole percentages PS between 2.5 and $40 \%$. Table III summarizes the Intrinsic Km values and the slopes calculated from the data presented in figure 3 . In order to determine accurate intrinsic Krn values for 20,30 and 40 mole\% PS a separate experiment was carried out at phosphollpid concentrations between 1 and $25 \mu \mathrm{M}$ (data not shown). In the absence of factor Va the Intrinsic Km shows a wide wariation for vesicles that contain different amounts of PS. At 2.5 mole\% PS the Intrinsic $\mathrm{Kn}$ is $3.35 \mu \mathrm{M}$, while at $40 \mathrm{~mole} \% \mathrm{PS}$ a value below $0.01 \mu \mathrm{M}$ is calculated (the intrinsic $\mathrm{Km}$ was actually too low to be accurately measured). 
Table III. The effect of the mole percentage ps on the intrinsic km for prothrombin and the slope of plots of kn app versus [phosphollpld]. Intrinsic $\mathrm{Km}$ values and the slope of plots of $\mathrm{Km}$ ap versus [phospho11pid for vesicles containing different mole percentages $P S$ were calculated from the data presented in Figure 3. The intrinstc Km for vesicles contaiming, 20,30 and 40 mole\% PS was calculated from Km versus [phospholipid] plots using a phospholipid concentration between 1 and 25 $\mu M$ (date not shown).

\begin{tabular}{|c|c|c|c|c|}
\hline \multirow{3}{*}{$\begin{array}{l}\text { PS } \\
\text { (Mole\%) }\end{array}$} & \multicolumn{2}{|c|}{-factor Va } & \multicolumn{2}{|c|}{ +factor Va } \\
\hline & slope & Intrinslo $\mathrm{Km}$ & slope & Intrinstc Ka \\
\hline & $(M / M)$ & $(\mu M)$ & $(M / M)$ & $(\mu M)$ \\
\hline 2.5 & $7.32 \times 10^{-3}$ & 3.35 & $-a^{a}$ & 0.145 \\
\hline 5 & $5.50 \times 10^{-3}$ & 1.30 & $0.07 \times 10^{-3}$ & 0.072 \\
\hline 10 & $4.55 \times 10^{-3}$ & 0.325 & $0.25 \times 10^{-3}$ & 0.055 \\
\hline 20 & $2.47 \times 10^{-3}$ & 0.023 & $1.35 \times 10^{-3}$ & 0.034 \\
\hline 30 & $2.46 \times 10^{-3}$ & $<0.01^{b}$ & $4.18 \times 10^{-3}$ & 0.027 \\
\hline 40 & $2.67 \times 10^{-3}$ & $<0.01^{b}$ & $5.28 \times 10^{-3}$ & 0.030 \\
\hline
\end{tabular}

a It was not possible to determine an accurate value for the slope. To determine accurate values for the intrinsic $\mathrm{km}$, phospholipid concentrations below $1 \mu M$ were necessary, which gave prothrombin activation rates that were too low to be measured.

When factor Va is present there 1 s much 1 ess variation of the intrinsic Kin. For vesicles with amounts of PS between 10 and 40 mole\% the intrinsic Krm $1 \mathrm{~s}$ almost constant $(0.055-0.030 \mu \mathrm{M})$. From the different effects of PS on the slope of the $\mathrm{Km}^{\mathrm{a}}{ }^{\mathrm{pp}}$ versus phospholipid plot and on the Intrinstc Km it is obvious that the mode of action of phospholipids on prothrombin activation in the absence and presence of factor Va cannot be described in one unilue model. The wide variation of slopes of $\mathrm{Km}^{\text {app }}$ versus [phosphollpid] plots determlned In the presence of factor Va (ftg. 3B) Indicates that only the free substrate model can adequately describe the observed phenomena. In that case the slopes of the lines should correlate with known prothrombin binding parameters for the phospholipid membranes used in this experiment. Paxameter fitting of the Iines according to eq 5 indeed ylelds values for Kd and prothrombin binding sites per phospholipid (M/M), that fulfill the requirements of slope and incercept and which are in close agreement with prothrombin binding parameters for these membranes reported by Nelsestuen and Brodertus (20). Table IV summarizes the binding parameters for prothrombin obtalned by parameter fitting and those reported in the 11 terature. The variation of the Intrinsic Kn (real 
Table IV. Prochrombin binding parameters derived from plots of the Km versus the phospholipld concentration for prothrombin activation in the presence of factor Va.

\begin{tabular}{|c|c|c|c|c|}
\hline $\begin{array}{c}\mathrm{PS}^{\mathrm{a}} \\
\left(\text { Mole } \mathrm{e}^{\mathrm{y}}\right)\end{array}$ & $\begin{array}{l}\mathrm{Kd} \\
(N M)\end{array}$ & $\begin{array}{c}\text { sites/ } \\
\text { phospholipld } \\
(\mathrm{H} / \mathrm{M})\end{array}$ & $\begin{array}{l}\mathrm{Kad}^{\mathrm{b}} \\
(\mu \mathrm{H})\end{array}$ & $\begin{array}{c}\text { sites/ } \\
\text { phospholipid } \\
(M / M)\end{array}$ \\
\hline $\begin{array}{r}5 \\
10\end{array}$ & $\begin{array}{l}5.1 \\
1.5\end{array}$ & $\begin{array}{l}0.005 \\
0.007\end{array}$ & $\begin{array}{l}5.5 \\
1.6\end{array}$ & $\begin{array}{l}0.004 \\
0.007\end{array}$ \\
\hline $\begin{array}{l}20 \\
30 \\
40\end{array}$ & $\begin{array}{l}0.3 \\
0.1 \\
0.05\end{array}$ & $\begin{array}{l}0.012 \\
0.013 \\
0.013\end{array}$ & $\begin{array}{l}0.3 \\
0.1 \\
0.1\end{array}$ & $\begin{array}{l}0.011 \\
0.012 \\
0.013\end{array}$ \\
\hline
\end{tabular}

a) 2.5 Mole\% PS is omitted since no direct binding data were available.

b) from Nelsestuen and Brodertus (1977)

Ku far prothrombinase) with the mole percentage PS observed in the presence of factor Va is also adequately explained in the free substrate model, since there is no correlation between the intrinsic $\mathrm{Km}$ and the binding parameters of prothrombin for vesicles with varylng mole percentage PS. In the free substrate model the Intrinalc Kai is not only determined by the free energy of prothrombin-phosphollpld interaction but also by the free energies of prothrombin-factor $\mathrm{Va}$ and prothrombin-factor Xa interactions. Since Information about the quantitative contribution of each of these interactions is lacking no prediction of the actual value of the intrinsic Kn can be made.

The data obtained in the absence of factor Va are qualltatively better explatned in the bound substrate model. The Intrinsic $\mathrm{Km}$ varies parallel with the dissociation constants reported for the prothrombin-phospholipid complex (20) and the slopes of the plots of $\mathrm{Km}^{\text {app }}$ versus [phospholipid] (although they should be parallel in the bound substrate mode1) vary conslderably less (2-3 fold) In the absence of factor Va than in 1 ts presence. It is impossible, however, to obtaln by parameter fitting binding constants for prothrombin that are comparable to those determined in direct binding studies and at the same time neet the requirements of slope and intercept of the experimentally obaerved $\mathrm{Km}^{\text {app }}$ versus [phospholthid] plot. This is caused by the low value of the intrinsic $\mathrm{Km}$, determined at the higher mole percentages PS. Intrinsic $\mathrm{Km} \mathrm{m}^{\mathrm{s}}$ below 0.01 MM (Table III) cannot be reconciled with etther of the two madels and known parameters of prothrombin binding to phospholiptd.

The effect of the phosphollpid concentration on the Vmax of prothrombln act1vation. In both the free substrate and the bound substrate model prothrombin activation is catalyzed by phospholipid-bound factor Xa. Figure 4A shows that without factor Va, the Wax is dependent on both the phospholipid concentra- 

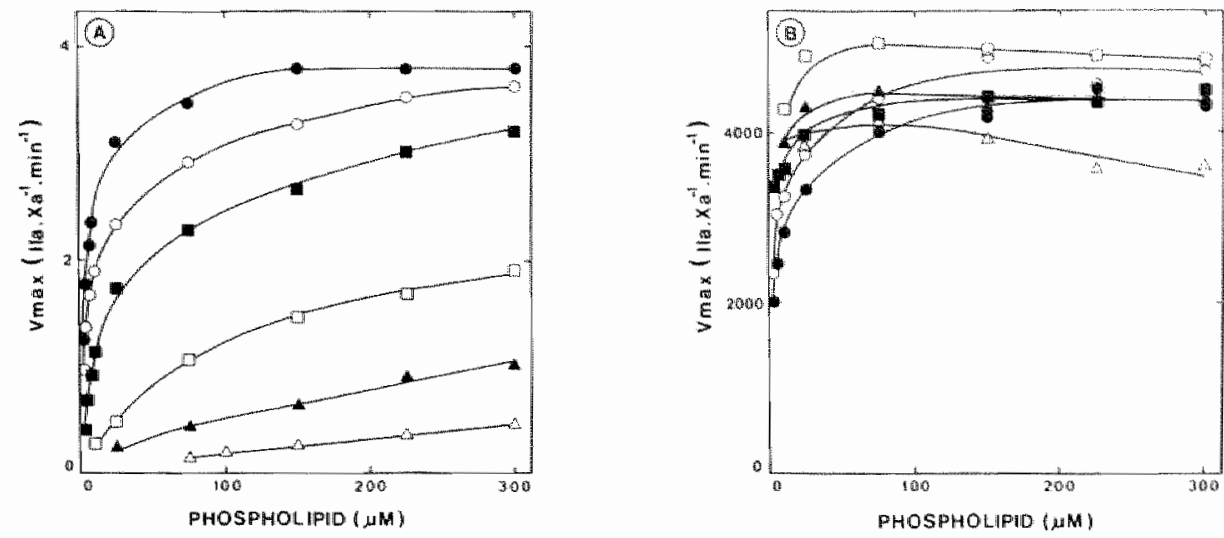

Fig. 4. The effect of the phospholipid concentration on the Vmax of prothrombin activation for phospholipid vesicles containing vartous mole percentages PS. The experimental conditions are described in the legend of figure 3 . (A) no factor $\mathrm{Va}$ present and (B) plus $5 \mathrm{nM}$ factor Va. The mole percentage PS present in the vesicles was: $2.5 \%(\Delta-\Delta), 5 \%(\Delta-\Delta), 10 \%(\square-\square)$, $20 \%(\mathbf{a}-\mathbf{a}), 30 \%(0-0)$, or $40 \%(\boldsymbol{0}-\boldsymbol{0})$.

tion and the amount of PS present in the membranes. Increasting the phospholipid concentration or the mole percentage PS results in an increase of the Vmax of prothrombin activation. This is explained by the fact that more factor $\mathrm{Xa}$ is bound to the phospholipid vesicles and hence more factor Xa partictpates in prothrombin activation. Double rectprocal plots of $1 /$ Vmax versus 1/[phospholipid] are straight lines (figure 5), which upon extrapolation to Infinite phosphollpid concentration yield Vmax values between 2-4 thrombin formed/mia/factor $\mathrm{Xa}$ independent of the amount of PS in the membranes. This shows that the catalytic activity of phosphollpld-bound factor Xa 1. hardly affected by the phospholipid composition of the vesicles. In view of the fact that all added factor Xa participates in prothrombin activation, the Wrax at Infinite phosphollpid concentration is actually the $k_{\text {cat }}$ of prothrombin activation. Figure $4 \mathrm{~B}$ shows that there 15 no correlation between the Vmax and the affinity of factor Xa for phospholipid when factor Va is present. Only minor changes of Vmax are observed for membranes contalining between 2.5 and 40 mole\% PS In a phospholipid concentration range of 10 to $300 \mu \mathrm{M}$. Apparentiy factor Va promotes the affindty of factor Xa for phosphollpld to such an extent that almost all factor Xa molecules are bound to phospholipid and participate in prothrombin activation. Factor va increases the $k_{c a t}$ of prothrombin activation three orders of magnitude. In the absence of factor va the $k_{c a t}$ of prothrombln 


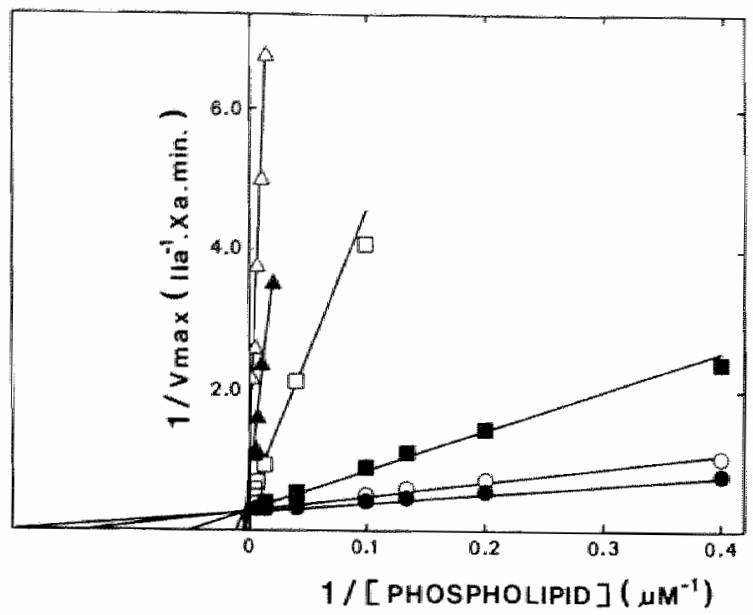

Fig. 5. Double reclprocal plots of 1/Vmax agalinst 1/[phospholipid] for vesicles contalning vartious mole percentages PS. The experimental conditions for prothrombin activation in the absence of factor Va are described in the legend of figure 3. The mole percentage PS present in the vesicles was: $2.5 \%(\Delta-\Delta)$, $5 \%(\Delta-\Delta), 10 \%(\square-\square), 20 \%(\mathbf{D}-\mathbf{\Delta}), 30 \%(0-0)$ or $40 \%(-0)$.

activation 1s $2-4 \mathrm{~min}^{-1}$ while $\mathrm{ln}$ the presence of factor Va values of 4500 min ${ }^{-1}$ are observed.

\section{CONCLUDING REMARKS}

In this paper we presented an extensive study of the effects of different phosphollpids on the kinetic parameters of prothrombin activation in order to discriminate between the two models (1.e. the bound substrate model and the free substrate nodel) that have been proposed to explain the mode of action of phospholipids in prothrombin activation.

The effects of phospholipids on the Km for prothrombin determined in the absence of factor Va cannot be satisfactortly explained in efther of the two proposed models. The $\mathrm{Km}$ for prothrombin measured in the absence of factor $\mathrm{Va}$ warles parallel with the binding affinity of prothrombin for phospholipid (menbranes with a low affinity have a high $\mathrm{Km}$, whlle for membranes with a high affinity a low $\mathrm{Km}$ is measured). Nelther in the bound nor in the free substrate model it 1 possible, however, to correlate the observed $\mathrm{Km}$ on a quantltative basis with known binding parameters of prothrombin for phospholipid.

The mode of action of phospholipid in prothrombin activation in the pre- 
sence of factor Va can be adequately explained in the free substrate model for the following reasons:

1) Factor Va causes a considerable decrease of the kn for prothrombin when phospholipid vesicles with a low affinity for prothrombin are part of prothrombinase.

2) There is no relation between the observed $\mathrm{Km}$ and the prothrombin density at the membrane surface when prothrombin is activated in the presence of factor Va and phospholipid vesicles with a low affinity for prothrombin.

3) The slopes of $\mathrm{Km}^{\mathrm{app}}$ versus [phospholipid] plats vary considerably for membranes with different affinfties for prothrombin, which is one of the predictions of the free substrate model

4) The experimentally obtained km app versus [phosphollpid] plots can be theoretically fitted with binding parameters for prothrombin reported in the literature.

Our experimental data for prothrombin activation in the presence of factor Va support the proposal of Nelsestuen (5) that prothrombinase is a dissociable three component enzyme (factor Xa-factor Va-phosphollpld) that converts soluble prothrombin; the observed increase of affinity for prothrombin, measured as a decrease of the $\mathrm{Km}$, is the result of prothrambin-factor Va and prothrombin-phospholipid Interactions that occur near the active site of prothrombinase. From its effect on the KII it is obvious that factor Va promotes the binding of prothrombin to the prothrombinase complex. This can be accomplished by 1) a direct interaction of prothrombin with factor Va, which provides additional free energy for the binding of prothrombin to the enzymatic complex and/or 2) a factor $V a$ induced rearrangement of phospholipid molecules in the enzymatic domain that results in the creation of a better phosphollpld surface for prothrombin binding. The first possibility 18 gupported by direct binding studies (21) in which it was shown that factor va promotes the binding of prothrombin to negatively charged phospholipids. The formation of a prothrombin-factor Va complex with a $\mathbb{1}: 1$ stolchiometry 1 indicative for direct prothrombin-factor Va interaction. Insufficlent quantitative data prevent, however, direct correlation of the effect of factor Va on prothrombin binding to phospholipids with its effect on $\mathrm{Km}^{\mathrm{apP}}$. With respect to the second possibl11ty Mayer and Nelsestuen (22) reported that factor Va 1 s able to cause lateral phase separation (clustering) of acidic phospholipids in membranes and suggested that this lateral phase separation may be an important process $1 \mathrm{n}$ the formation of the prothromblnase complex. Whether this clustering of actalc phosphollpid molecules by factor Va also promotes prothrombin blinding to the 
membrane is, however, unknown. At present, we cannot draw conclusions with regard to the two possibilltes mentioned above.

It $1 \mathrm{~s}$ to be expected that the intrinsic kn should continuously decrease when the mole percentage acldic phospholipid in membranes is increased since this would result in an lncreased free energy of prothrombin-phospholipid interaction. However, at mole percentages PS exceeding $5 \%$ the intrinsic Kin is vitually constant (Table III), although direct binding experiments (20) revealed that the affinty of the nembranes for prothrombtn still increases. The intrinsic $\mathrm{Km}$ for prothrombinase in the presence of factor Va and membranes containing a high mole percentage PS is even higher than the intrinsic $\mathrm{km}$ measured in the absence of factor Va, which seems to contradict the proposal that factor Va promotes the affinity of the prothrombinase complex for prothrombin. These phenomena can be explained when the rate constants of prothrombinase are considered. From the 1 ntrinsic $\mathrm{Km}$ and the $\mathrm{k}_{\mathrm{cat}} \mathrm{a} \mathrm{k}_{\mathrm{cat}} / \mathrm{km}$ of $2.5 \times 10^{9} \mathrm{M}^{-1} \mathrm{~s}^{-1}$ is calculated for a prothrombinase complex consigting of factors $X a$ and $V a$ and phosphollplds that contain 5 or more mole\% PS. This indicates that prothrombinase under these conditions is a diffusion controlled process in which a further increase of the binding affinity of phospholiplds does not further change the kinetic parameters because of diffusion limitation. Hence the fntrinsic $\mathrm{Km}$ will become constant for veslcles that contaln 5 or nore mole\% PS. When factor Va is absent $\mathrm{k}_{\mathrm{cat}} / \mathrm{Km}$ is three orders of magnitude lower, which $\mathbb{1 n d i c a t e s}$ that prothrombin activation under these conditions is not diffusion limited. This can explain why the intrinsic $\mathrm{Km}$ values decrease below those observed in the presence of factor Va. The rate constant of prothrombinase of $2.5 \times 10^{9} \mathrm{M}^{-1} \mathrm{~S}^{-1}$ exceeds the rate constant for association of prothrombin with a single binding site on a PS containlng membrane $\left(k_{1}=3 \times 10^{7} M^{-1} \mathrm{~s}^{-1}\right)$ reported by wel et 1 . (23). This rate constant, which was deternined in the absence of factor $\mathrm{Va}$, $1 \mathrm{~s}$ not compatible with the rate constant of prothrombinase with factor Va. To account for the rate constant of prothrombin activation factor Va has to increase the assoctation rate constant of prothrombin binding. to the complex.

In conclusion factor Va has three important effects in prothrombinase: 1) it accelerates prothrombin activation by increasing the $k_{c a t}$ more than $1000-$ fold, 2) tt promotes the binding of factor Xa to phospholipids and therefore increases the amount of factor Xa that participates in prothrombin activation 3) it promotes the affinity of prothromblnase for its substrate prothrombin on membranes which have a low binding affinity for prothrombin. The latter effects presumably have physlological importance. It has been proposed that 
activated blood platelets provide the phospholipld surface at which prothronbin activation takes place. Activated platelets expose relatively sinall amounts of acidic phospholipids (16). On platelet membrane areas wh low PS density factor $\mathrm{Va}$ w11 have an important role in the bunding of prothrombin and factor $\mathrm{Xa}$ and the subsequent formation of the enzyme-substrate complex.

\section{REFERENCES}

1. Suttie, J.W. \& Jackson, C.M. (1977) Phystol.Rev. 57, 1-70.

2. Rosing, J., Tans, G., Govers-Riemslag, J.W.P., Zwaal, R.F.A. \& Henker, H.C. (1980) J.Biol. Chem. 255, 274-283.

3. Nesheim, M.E., Taswell, J.B.\& Mann, K.G. (1979) J.Biol.Chem. 254, $10952-10962$.

4. Nesheim, M.E., Eid, S. \& Mann, K.G. (1981) J.Blol.Chem. 256, 9874-9882.

5. Nelsestuen, G.L. (1978) Fed.Proc. 37, 2621-2625.

6. Pusey, M.L. \& Ne1sestuen, G.L. (1983) B1och.Biophys.Res.Comm. 114, 526-532.

7. Cuatrecasas, P. (1970) J.B1ol. Cherm. 245, 3059-3065.

8. Owen, W.G., Esmon, C.T. \& Jackson, C.H. (1974) J.Blol. Chem. 249, 594-605.

9. Fujlkawa, K., Legaz, M.E. \& Davie, E.W. (1972) Blochemistry 11, 4882-4891.

10. Schiffman, S., Theodor, J. \& Rapaport, S.J. (1969) Blochemistry 8, 1397-1405.

11. Fujikawa, K. " Legaz, M.E. \& Davie, E.W. (1972) Blochemlstry 11, 4892-4899.

12. Lindhout, T., Govers-Riemslag, J.w.P., Van de Haart, P., Hemker, H.C. \& Rosing, J. (19.82) Biochemistry 21, 5494-5502.

13. Chase, T.\& Shaw, E. (1969) Blochemistry 8, 2212-2224.

14. Smith, R.L. (1973) J.Biol.Chem. $248,2418-2423$.

15. Comfurius, P. \&waal, R.F.A. (1977) Blochim.Blophys.Acta 488, 36-42.

16. Bevers, E.M., Comfurius, P., van Rijn, J.L.M.L., Hemker, H.C. \& Zwaal, R.F.A. (1982) Eur. J. Biochem. 122, 429-436.

17. de Kruljff, B., Cul11s, P.R. \& Radda, G.K. (1975) Blochim.Blophys.Acta 406, 6-20.

18. Böttcher, C.J.F., van Gent, C.M. \& Pries, C. (1961) Anal.Chim.Acta 24, 203-207.

19. Elsenthal, R. Cornish-Bowden, A. (1974) Biochen.J, 139, 715-720.

20. Nelsestuen, G.L. \& Brodertus, M. (1977) Blochemistry 16, 4172-4177.

21. van de Waart, P., Hemker, H.C. \& Lindhout, T. (1984) Blochemlstry, in press.

22. Mayer, L.D. \& Nelsestuen, G.L. (1983) B1ochim.Blophys.Acta 734, 48-53.

23. Wei, G.J., Bloomfleld, V.A., Resnick, R.M. \& Nellsestuen, G.L. (1982) Blachendstry $21,1949-1959$. 

Prothrombin activation and intrinsic factor $X$ activation are strongly stimulated by the presence of membranes containing negatively charged phospholipids and by non-enzymatic protein cofactors (factor Va for prothrombin- and factor VIrIa for factor $X$ activation). The primary object of the studies presented in this thesis was to investigate the possibility that, during hemostasis, blood platelets provide the membrane surface required for prothromblnand factor $X$ activation. In chapter $I I$ we demonstrated that platelets are most active in promoting prothrombin activation, when they are stimulated by the combined action of collagen and thrombin. Unstimulated platelets or platelets stimulated with either collagen or thrombin alone were much less active in this respect. The phospholipid composition of the outer platelet surface was studied by treatment of activated and control platelets with phospholipase $\mathrm{A}_{2}$ * Phospholipids from unstrulated platelets and from platelets stimulated by either collagen or thrombin were hardly susceptible to phospholipase $A_{2}$. In contrast, when platelets were actlvated by collagen plus thrombin, up to $20 \%$ of the total amount of platelet phospholipids could be degraded by phospholipase $A_{2}$, without significant cell lysis. The hydrolysis of glycerophospho1lpdes comprises $25 \%$ of the phosphatidylserine-, $25 \%$ of the phosphatidy1choline- and $30 \%$ of the phosphatidylethanolamine content of the platelets stimulated with collagen plus thrombin. Using different probes to determine the phospholipid distribution over the inner- and outer leaflet of the platelet's plasma membrane, other authors reported that phosphatidylserine lis almost exclustvely located in the interior of unstimulated and thrombin stimulated platelets $(1-4)$. Structural changes in the plasma rumbrane of platelets after stimulation with collagen plus thrombin may cause both the Increased susceptibility of phospholiplds to phospholipase $\mathrm{A}_{2}$ and the exposure of phosphatidylserine required for efficlent prothrombin activation.

It was expected that exposure of phosphatidylserine at the surface of platelets triggered with collagen plus thrombin would evoke the platelet procoagulant surface not only for prothrombin activation but also for jntrinsic factor $X$ activation. In chapter III we studied the role of stimulated platelets in prothrombin- and factor $X$ activation with purifled coagulation 
factors and chromogentc subatrates to measure rates of thrombin- and factor Xa formation. Using amounts of enzymes, substrates an protein cofactors that were saturating with respect to rates of substrate activation, the rates of prothrombin and factor $\%$ activation found with platelets stimulated with collagen plus thrombin were increased 10 and 20 fold, respectively, as compared with unstimulated platelets. Stimulation of platelets with either collagen or thrombin alone regulted in a complete aggregation and serotonin release but induced less platelet procoagulant activity in prothrombin- and factor $X$ activation than stimulation with collagen plus thrombin. The platelet procoagulant activity induced by collagen plus thrombin could be sedimented with the platelets upon centrifugation. Treatment of the stimulated platelets with phospholipase $A_{2}$ almost completely abolished the platelet activity in prothrombin- and factor $X$ activation. This indicates that phospholipids in the outer leaflet of the platelet membrane are essential for the interaction of platelets with the clotting factors of the prothrombin- and factor $X$ activating complexes.

In the assay systems used for prothrombin- and intrinslc factor $X$ activation, the rates of thrombin- and factor Xa formation were dependent on the presence of phosphatidylserine in artifictal phospholipld membranes. When low concentrations of enzymes and protein cofactors were employed for prothrombin- and factor $X$ activation, the rates of thrombin- and factor Xa formation increased upon increasing the amount of phosphatidylserine in phospholipid vesicles. In contrast, the prothrombin- and factor $X$ activation determined at saturating concentrations of enzymes and protein cofactors, were optimal with vesicles contalning relatively low amounts of phosphatidylserine. This made the assay systems for prothrombin- and factor $X$ activation suitable probes for the detection of varlous mole percentages phosphatidylserine in phospholipid bilayers. When the generation of a procoagulant surface on platelets stimulated with collagen plus thrombin was probed with the assay systems for prothrombin- and factor $X$ activation using sub-saturating concentrations of enzymes and protein cofactors, half maximal platelet procoagulant activity was found within $2 \frac{1}{2}$ minutes after the onset of platelet stimulation. Whth saturating concentrations factor $X a$ and factor Va for the activation of prothrombin, higher rates of thrombin formation were observed in a later stage of platelet activation; half-maximal procoagulant activity was found 9 minutes after the addition of collagen plus thrombin to the platelets. We propose that the phosphatidylserine exposed at the surface of platelets triggered with collagen plus thrombin is not randomly distributed in the outer monolayer of the plate- 
let membrane. Domains with a high phosphatidylserine density are generated. shortly after platelet stimulation and are detected with the systems for prothrombin- and factor $X$ activation using saturating and sub-saturating concentrations of clotting factors. Domains with a low phosphatidylserine density, which are formed later after triggering are probed exclusively wth systems containing saturating amounts of clotting factors.

In chapter IV it was shown that with platelets, which were stimulated by the calcium lonophore A23187, 50-60 fold higher rates of prothrombin- and factor $X$ activation were found than with non-stimulated platelets. The concentration of ionophore required for the induction of platelet procaagulant activity was similar to the concentrations required for platelet aggregation and release of ATP and factor $V$. The procaagulant activity, which was not due to platelet lysis, could be sedimented with the platelets by centrifugation and was completely abolished by treatment of the stimulated platelets with phosphollpase $A_{2}$. Incubation of A23187 stimulated platelets with phospholipase $A_{2}$ has been shown to degrade at least half of the amount of phosphatidylserine present in platelets $(3,5)$. We suggest that phosphatidylserine at the surface of platelets stimulated by $\mathbf{A} 23187 \mathrm{is}$ essential for the platelet procoagulant activity in prothrombin- and factor $X$ activation.

In chapter and VI studies are presented which describe the role of phospholipid bilayers and protein cofactors in the enzymatic complexes for prothrombin- and factor $X$ activation. In previous studies $(6,7)$ it was demonserated that in prothrombin- and factor $X$ activation phospholipids decrease the $\mathrm{Km}$ for the respective substrates, whereas the Vmax of the reactlons $1 \mathrm{~s}$ increased by the presence of their protein cofactors. As shown in chapters $V$ and VI, the protein cofactors increase the Vmax of prothrombin- and factor $X$ activation not only by an Increase of the $k_{c a t}$ of the reactions but also by pramoting the incorporation of enzymes in the enzyme-protein cofactor-phospho11pid complexes. In chapter $V$, the binding parameters of factor IXa for art1ficlal bilayers consisting of phosphollpids found in platelets were inferred from kinetic measurements of factor $X$ activation in the absence and presence of factor VIIIa. Rates of factor $X$ activation were measured at varying concentrations of factor IXa 1 n reaction mixtures containing $\mathrm{Ca}^{2+}$, factor $X$ and phosphollpid vesicles. Double reclprocal plots of rates vs. factor IXa concentrations were straight 1ines. Maximal rates of factor $x$ activation inferred from these plots were proportional to the phospholipld concentration, indicating that phospholipids provide kinetically functional binding sites for factor IXa. The factor IXa concentration required for half-maximal rates of 
factor Xa formation was consldered to be the factor IXa concentration required for the accupation of half the total amount of functional binding sites. The apparent disociation constant so obtalned varled between $0.4-1.1$ p which was not far from the reported dissociation constant obtained by direct binding studles for the binding of factor IXa to phospholipid. (8). Also when factor VIIIa present in the factor $X$ activating reaction mixture the rates of factor $X a$ formation could be saturated with factor IXa. Double reclprocal plotting of rates and factor $\mathrm{LXa}$ concentrations revealed straight lines, indicating that single functlonal binding sites for factor IXa were lnvolved. Maximal rates of factor Xa formation were proportional to the factor VIIIa concentrations and independent of the phospholipid concentration present. These flndings suggest that all factor VIILa was bound to phospholipid, phospholipid-bound factor VIII being the kinetically fuctional binding site for factor IXa. The apparent dissoctation constant determined for factor IXa binding to factor VIITa-phospholipid complexes is 50-100 fold lower than found for the apparent dissoctation constant of factor IXa in the absence of factor VIII. We conclude that factor VIIIa bound at (platelet) phospholipid surfaces functions as a high affinity receptor for factor IXa. Factor VIIIa Increases the Vmax of factor $X$ activation by enhancing the $k_{c a t}$ of the reaction and by increasing the amount of phospholipid-bound factor tXa that particlpates in factor $X$ activation.

Studies on the effect of factor $\mathrm{Va}$ and phospholiplds on the formation of the enzyme-substrate complex for prothrombin activation are presented in chapter WI. Kinetic parameters of prothrombin activation were determined as a function of phospholipid composition and concentration. In the absence of factor va and at 1 imlted anounts of phospholipid vesicles the Vmax correlates with the bindIng affinity of factor $X a$ for the different membranes. Membranes with a high affintty for factor $X a$ have high Vmax values, whereas for membranes with a low affintty a low Vmax is found. The kcat, which is defined as the Vmax at saturating phospholipid concentration, that is when all factor Xa is bound and enzymatically active, was $2-4 \mathrm{~m}^{-1}$ Independent of the phospholipld composition. In the presence of factor Va the $k_{c a t}$ was independent of the type and anount of acidic phospholipid in the vestcles; the value observed was 4500 min $^{-1}$. To achleve a Vmax value of $\frac{1}{2} \mathrm{k}_{\text {cat' }}$ considerably less phosphollpid was required in the presence of factor Va than in its absence. Apparenty, in the presence of factor $\mathrm{Va}$ more factor $\mathrm{Xa}$ particlpates in prothrombin activation than In its absence, which is attributed to the property of factor Va to promote the binding of factor Xa to phospholipld bllayers, a phenomenon also 
reported by other authors $(9.10)$.

In the absence and presence of factor Va, the Kn for prothrombln increases proportional with the phospholipid concentration. In the absence of factor Va the $\mathrm{Km}$ correlates with the affinity of prothrombin for the varlous phospholipid vesicles. Phospholipid nembranes with a high affinity for prothrombin yield low Km values compared to membranes with low affint ty for prothrombin, a correlation that does not exist when factor Va is present. Vesicles containing low amounts of acidic phospholipids have considerably lower kn values for prothrombin in the presence of factor Va than in its absence. The effects of factor $\mathrm{Va}$ on the $\mathrm{Km}$ for prothrombin can be explained by a model in which soluble prothrombin is the substrate for the enzymatic unt of prothrombinase that consists of a three component complex (factor Xa - factor Va - phospholipid) and in which factor va promotes the enzyme-substrate complex formation.

\section{REFERENCES}

1. Schick, P.K., Kurica, K.B. and Chacko, G.K. (1976) J. Clin.Invest. 57, $1221-1226$.

2. Chap, H.J., Zwaal, R.F.A. and van Deenen, L.L.M. (1977) Biach1m.B1ophys. Acta $467,146-164$.

3. Bevers, E.M., Comfurius, P. and Zwaal, R.F.A. (1983) Biochim. Biophys.Act $736,57-66$.

4. Perret, B., Chap, H.J., Douste-Blazy, L. (1979) Bioch1m.Blophys.Acta 556, 434-446.

5. Bevers, E.M., Comfurlus, P., and Zwaal, R.F.A. (1979). Thromb.Haemostas. 42,211 .

6. Rosing, J., Tans, G. Govers-Rlemslag, J.W.P., Zwaal, R.F.A. and Heraker, H.C. (1980). J.B1o1. Chem. 255, 274-283.

7. van Dieijen, G., Tans, G., Rosing, J. and Hemker, H.C. (1981) J.Blol.Chem. $256,3433-3442$.

8. Nelsestuen, G.L., Kiesel, W. and DiSclpio, R.G. (1978) Biochemlstry 17, 2134-2138.

9. Neshe1m, M.H., Taswell, J.B. and Mann, K.G. (1979) J.B101.Chem. 254, 10952-10962.

10. Lindhout, T., Govers-Riemslag, J.W.P., van de Waart, P., Herker, H.C. and Rosing, J. (1982) Blochemistry 21, 5494-5502. 

De prothrombine- en intrinsieke factor $x$ - activeringsreacties worden sterk versneld door de aanwezigheld van membranen met negatief geladen fosfoliplden en door niet-enzymatische eiwit cofactoren (factor Va voos prothrombine- en factor VIIIa voor factor $X$ activering). De studies die in dit proefschrift zijn weergegeven, hadden tot doel de mogelijkheld te onderzoeken dat tijdens de hemostase, bloedplaatjes de membraan-oppervlakken verschaffen die nodig $21 \mathrm{jn}$ voor prothrombine- en factor $X$ activering.

In hoofdstuk II toonden we aan dat plaatjes de prothromblne activering het best bevorderen, als zij gestimuleerd worden door de gecombineerde werking van collageen en thrombine. Niet- gestimuleerde plaatjes of plaatjes die waren gestimuleerd met alleen collageen of thrombine waren hierin veel ninder actlef. De fosfolipide samenstelling van het plaatjes bulten-opperviak werd geanalyseerd door geactiveerde- en controle plaatjes te behandelen met fosfo11pase $A_{2}$. Fosfolipiden van niet-gestimuleerde plaatjes en van plaatjes gestimuleerd door alleen collageen of thrombine waren nawwelijks gevoelig voor fosfollpase $A_{2}$. Als daarentegen, plaatjes werden geactiveerd door collageen plus thrombine, kon $20 \%$ van de totale hoeveelheld plaatjesfosfollpiden worden afgebroken door fosfollpase $A_{2}$, zonder signiflcante cell lyse. De hydrolyse van glycerofosfoliplden omvat $25 \%$ van het fosfatidylserlne-, $25 \%$ van het fosfatidylcholine- en $30 \%$ van het fosfatidylethanolamine gehalte van de met collageen plus thrombine gestimuleerde plaatjes. Andere auteurs (1-4) vonden, met behulp van verschillende methoden ter bepaling van de fosfolipide verdellng over de binnen- en buiten-monolaag van het plasma-membram, dat fosfatidylser lne bijna aitsluitend aanwezig is in het inwendige wan het niet-gestimuleerde en chrombine-gestimuleerde plaatje. Structurele veranderingen in het plasma-membraan wan plaatjes na stimulering met collageen plus thrombine zouden zowel de verhoogde gevoeligheld van fosfollpiden voor fosfollpase $A_{2}$ als het beschikbaar komen van fosfatidylserine, nodig voor een efficiënte prothromblne activering, kunnen veroorzaken.

Verwacht werd, dat door het beschikbaar komen van fosfatldylgerine in het oppervlak van met collageen plus thromblne gestimuleerde plaatjes, cen procoagulant oppervlak zou ontstaan dat niet alleen geschikt is voor prothrombine activering maar ook voor intrinsieke factor $X$ activering. In hoofdstuk 
III bestudeerden wil de rol van gestumleerde platjes in de prothromine en factor $X$ activering met behulp van gezuiverde stolfactoren en chromogene aubitraten voor het meten van de snelheden van thrombine- en factor Xa vorming. Met hoeveelheden enzymen, substraten en eiwit cofactoren die verzadigend waren met betrekklng tot de snelheld van substraat activering, waren de snelTheden wan prothrombine- en factor $X$ activering $1 n$ aanwezigheld wan collageen plus thrombine gestimuleerde plaatjes 10 - resp. 20 maal hoger dan werd gevonden thet nlet-gestlmuleerde platjes. Stimulering wan platjes met alleen collageen of thrombine resulteerde in een volledige aggregatie en release van serotonine maar induceerde minder procoagulante activitelt in prothrombine- en factor $X$ activering dan stimulering met collageen plus thrombime. De procoagulante activiteit van plaatjes geinduceerd door collageen plus thrombine, kon door centrifugering, samen met de plaatjes, worden gesedimenteerd. De activiteft wan plaatjes in de prothrombine- en factor $X$ activering verdween na behandeling van de gestimuleerde plaatjes met fosfolipase $A_{2}$. Dit geeft aan dat fosfollpiden in de buiten-monolagg van het plasma-membraan essentieel zijn. voor de interactie van plaatjes met de stolfactoren van de prothrombine- en factor $X$ activerende complexen.

In de meetsystemen, dle werden gebrulkt voor prothrombine- en factor $X$ activering, waren de snelheden van vorming van thrombine en factor Xa afhankelijk van de aanwezlgheld van fosfatidylserine in artificieel samengestelde fosfo1ipide membranen. Wanneer lage concentraties enzymen en elwit cofactoren werden gebruikt woor de activering van prothrombine en factor $X$, namen de snelheden van thrombine- en factor Xa vorming toe als de hoeveelheld fosfat1dylserlne in fosfollpide vestcles werd verhoogd. Als daarentegen verzadigende concentraties enzymen en cofactoren werden gebrulkt, verliep de activering van prothrombine en factor $X$ optimal met vesicles die relatief lage hoeveelheden fosfatidylaerine bevatten.

D1t makte de meetsystemen voor prothrombine- en factor $X$ activering geschikt voor het detecteren van versch1llende mol-percentages fosfatidylserine in fosfollptde bilagen. Wanneer het genereren van een procoagulant oppervlak op collageen plus thrombine gestımuleerde plaatjes werd gevolgd met meetsystemen voor prothrombine- en factor $X$ act 1 vering met niet-verzadigende concentraties enzymen en eiwit cofactoren, werd half-maximale procoagulante activitelt gevonden binnen 21 minut na stimulering van het plaatje. Met verzadigende concentraties factor $X a$ en factor $V a$ voor de activering van prothrombine werden hogere snelheden van thromblnevorming waagenomen, echter in een later stadium van plaatjes activering; half-maximale procoagulante activiteit werd 
gevonden, 9 minuten na de toevoeging van collageen plus thromblne aan de plaatjes. Een verklaring die hiervoor kan worden gegeven is, dat het fosfatidylserine, dat na stimulering beschlkbaar komt op het oppervlak van plaatjes, ongelijknatig is verdeeld in de buiten-monolaag van het plaatjesmembraan. Gebieden met een hoge fosfatidylserine dichtheld worden gevormd kort na het stimuleren van de platjes en worden gedetecteerd met systemen voor prothrombine- en factor $X$ activering met verzadigende- en niet-verzadigende concentraties stolfactoren. Gebleden met een lage fosfatidylserine dichtheid, die later na de stimulering worden gevormd, kunnen ultsluitend worden aangetoond met systemen die verzadigende hoeveelheden stolfactoren bevatten. In hoofdstuk IV werd aangetoond dat met platjes, die waren gestimuleerd door calciumlonofoor A23187, snelheden werden gevonden voor prothrombine- en factor $X$ activering die 50-60 maal hoger waren dan met niet-gestimuleerde plaatjes. De Ionofoor concentratie die nodig was voor het induceren van plaatjes procoagulante activiteit kwam overeen met de concentratle die nodig was voor plaatjes aggregatie en release van ATP en factor $v$. De procoagulante activitelt, die niet kon worden toegeschreven aan cel 1yse, kon samen met de plaatjes worden gesedimenteerd door centrifugatie en verdween na behandeling van de gestimuleerde plaatjes met fosfolipase $A_{2}$. Eerder was aangetoond dat het Incuberen van A23187-gestimuleerde plaatjes met fosfollpase $A_{2}$ resulteerde in de afbraak van tenminste de helft van de hoeveelheld fosfatidylserine, die in plaatjes aanwezig is $(3,5)$. Wij stellen voor dat fosfatidylserine op het oppervlak van met A23187 gestimuleerde plaatjes, essentieel is voor de plaatjes procoagulante activiteit in de activering van prothrombine en factor $X$.

In hoofdstuk $V$ en VI zijn studles gepresenteerd naar de rol van fosfolipide bilagen en eiwt cofactaren in de enzymatische complexen voor prothrombine- en factor $X$ activering. In eerdere experimenten $(6,7)$ werd aangetoond dat, $1 \mathrm{n}$ de prothrombine- en factor $X$ activering, de $\mathrm{Kr}$ voor de respectievelifke substraten wordt verlaagd door fosfollpiden, terwijl de Vmax van de reacties wordt verhoogd door de aanwezigheid van hun eiwit cofactoren. In de hoofdstukken $V$ en VI wordt aangetoond dat de eiwtt cofactoren de Vmax van prothromblineen factor $X$ activering ntet alleen verhogen door een verhoging van de $k_{c a t}$ van de reacties, maar tevens door het bevorderen wan de inbouw van enzymen in enzym - eiwit cofactor - fosfolipide complexen. In hoofdstuk $v$ werden de bindingsparameters van factor IXa voor bllagen bestaande uit fosfoliplden die ook in het plaatje aanwezig zijn, afgeleid van kinetische metingen van de activering van factor $X$ in aan- en afwezigheld van factor WIIIa. De snelheden van factor $X_{a}$ vorming werden gemeten bil verschillende concentraties factor 
TXa, In reactle mengelg dLe $\mathrm{Ca}^{2+}$, factor $x$ en fosfolipiden bevatten. Rechte lijnen werden gevonden wanner de reciproke snelheden werden ultgezet tegen de reciproke factor IXa concentraties. De maximale snelheden wan factor $X$ act werlng die met behulp van deze plots werden bepald, waren evenredig met de fosfollplde concentratle, hetgeen erop wijt dat fosfollpiden de kinetisch functionele bindingsplaatsen leveren voor factor IXa. De concentratie factor IXa die nodig 15 on half-maximale snelheden van factor Xa vorming te verkrijgen, werd beschouw als de factor IXa concentratie die nodig was voor de bezetting van de helft van alle functonele bindingsplaatsen. De zo verkregen, kinetimeh afgeleide, dissociatie constante varieerde tussen $0.4-1.1$. $\mathbb{M}$ en was vergelijkbaar thet de in de literatur gerapporteerde dissociatie constante, die werd gevonden met directe bindingsstudies ( $B)$.

ook als factor VIIIa aanwezig was in het reactie mengsel voor factor $X$ activering, was het mogelijk de snelheden van factor Xa vorming te verzadigen met factor IXa. Het dubbel reclprook uitzetten van snelheden en factor IXa concentratles leverde rechte lijnen op, hetgeen wijst op de betrokkenheid van eén soort functionele bindingsplaats voor factor IXa. De maximale snelheden van factor Xa worming waren evenredig met de factor VIrIa concentraties en onafhankelijk van de fosfoliplde concentratie.

Deze warnemingen suggereren dat alle factor VIIIa gebonden was aan fosfoliplden en dat de fosfollpide-gebonden factor VIIIa de kinetisch functionele bindingsplats is voor factor IXa. De kinetisch bepalde dissociatie constante, die werd gevonden voor de binding van factor IXa aan factor VIIIa-fosfoliplde complexen, is 50-100 maal lager dan die werd gevonden voor factor IXa in afwezigheld van factor VIIIa. Wij concluderen dat factor VIIIa, dat gebonden is aan (platijes) fosfolipide opperwlakken, functioneert als een receptor met hoge affintelt voor factor IXa. Factor VIILa verhoogt de Vmax van factor X activer $\mathbb{n g}$ door het verhogen van de $k_{\text {cat }}$ van de reactie en door het vergroten van de hoeveelheld factor IXa dat aan fosfolipiden gebonden is en dat deelneemt aan de activering van factor $X$.

Studies naar het effect van factor Va en fosfollplden op de worming van het enzym-substrat complex voor de activerlng van prothrombine zijn gepresenteerd in hoofdstuk VI. De kinetische parameters van prothrombine activering werden bepald als functle wan de fosfollpide concentratie en fosfollpide samenstelling. In afwezlgheld van factor $V a$ en bij beperkte hoeveelheid fosfolipide vesicles, correleert de Vmax met de bindings affiniteit van factor Xa voor de verschillende membranen. Membranen met een hoge affiniteit voor factor Xa geven hoge Vmax waarden, terwlj voor membranen met een lage afflniteit een 
lage Vmax wordt gevonden. De $k_{c a t}$, die is gedefinieerd als de Vmax bly verw zadigende fosfolipide concentratie, waarbij alle factor Xa gebonden is en enzymatisch actief, was $2-4 \mathrm{~min}^{-1}$ onafhankelijk van de fosfoliplde samenstel1ing. In aanwezigheid van factor $V_{a}$ was de $k_{c a t}$ onathankelijk van het soort en de hoeveelheid zure fosfollpiden in de vesicles; de gevonden waarde was 4500 min ${ }^{-1}$. Om een Vmax waarde te vinden gelljk aan $k_{c a t}$, was aanzlenliflk minder fosfolipide nodig in aanwezigheid van factor Va dan in afwezigheld hiervan, hetgeen wordt toegeschreven aan de elgenschap van factor Va om de binding van factor Xa aan fosfollplde bilagen te bevorderen; een elgenschap die oak is gerapporteerd door andere auteurs $(9,10)$.

Zowel in aanwezigheld als in afwezigheld van factor Va, stijgt de km voor prothrombine proportioneel met de fosfolipide concentratie. In afwezigheid van factor Va correleert de km met de affinitelt van prothrombine voor de verschillende fosfolipide vesicles. Fosfolipide membranen met een hoge affinitellt voor prothrombine geven lage $\mathrm{Km}$ waraen vergeleken met membranen met een lage affiniteit voor prothrombine, een correlatie die niet bestaat als factor va aanwezig is. Vesicles met lage percentages zure fosfollpiden hebben aanzienlijk lagere Km waarden voor prothrombine in aanwezigheld van factor Va dan in afwezigheid hiervan.

De effecten van factor $\mathrm{Va}$ op de $\mathrm{Km}$ voor prothrombine kunnen worden verklaard met een model waarin prothrombine in de oplossing het substraat is voor de enzymatische unit van prothrombinase, die bestaat uit drie componenten (factor $X a$ - factor Va - fosfolipide) en warin factor Va de enzyn-substraat complexvorming bevordert.

\section{REFERENTIES}

1. Schick, P.K., Kurica, K.B. and Chacko, G.K. (1976) J.Clin.Invest. 57, $1221-1226$

2. Chap, H.J., Zwaal, R.F.A. and yan Deenen, L.L.M. (1977) Bloch1m.Biophys. Acta $467,146-164$.

3. Bevers, E.M., Comfurlus, P. and Zwad1, R.F.A. (1983) Blochim.Blophyi..Acta

4. Perret, B., Chap, H.J., Douste-Blazy, L. (1979) Bloch1m.Blophys.Acta 556,

5. Bevers, E.M., Comfurlus, P. and Zwaal, R.F.A. (1979) Thromb.Haemostas. 42, 211.

6. Rosing, J., Tans, G., Govers-Riemslag, J.W.P., Zwaa1, R.F.A. and Hemker, H.C. (1980) J.BLal. Chem. 255, 274-283.

7. van Dieijen, G., Tans, G., Rosing, J. and Hemker, H.C. (1981) J.Blol. Chem. $256,3433-3442$. 
B. Weloestuen, G.L., KLesel, W. and DiSclpto, R.G. (1978) Biocheristry 17, $2134-2138$.

9. Wesheim, M.H., Taswell, J.B. and Mann, K.G. (1979) J.Blol.Chem. 254, $10952-10962$.

10. Lf ndhout, T., Govers-Rlems lag, J.h.P., van de Wart, P., Hemker, H.C. and Rosing, J. (1982) BLochemistry $21,5494-5502$. 
De auteur van dit proefschrift werd geboren te Haarlem op 9 december 1952. Hij behalde het diploma HBS-B in 1970 an het Triniteits Lyceum te Haarlem. Vanaf 1970 studeerde h1 scheikunde an de Untversiteit van Amsterdam. In april 1974 werd het kandidaatsexamen afgelegd, gevolgd door het doctoraal examen in november 1978. Zijn hoofdvak, bifvak en spectalle richting waren respectievelijk blochemle, klinische chemie en kristallografie.

Van mei 1979 tot oktober 1984 is hij als wetenschappelijk assistent in dienst van de Nederlandse Organisatie voor Zulver Wetenschappelljk Onderzoek ( $Z$.W. O./FUNGO) en werkzaam bilj de capaciteitsgraep Biochemie van de Rijksuniversiteit Limburg te Maastricht. Gedurende deze perlode werd onder leiding van Prof.Dr. R.F.A. Zwall en Dr. J. Rosing het onderzoek verricht dat heeft geleid tot deze dissertatle. 